Florida International University FIU Digital Commons

$11-12-2015$

\title{
Monitoring Physiological Reactions of Construction Workers in Virtual Environment: A Feasibility Study Using Affective Sensing Technology
}

Hazal Ergun

Florida International University, hergu001@fiu.edu

DOI: 10.25148 /etd.FIDC000199

Follow this and additional works at: https:// digitalcommons.fiu.edu/etd

Part of the Construction Engineering and Management Commons

\section{Recommended Citation}

Ergun, Hazal, "Monitoring Physiological Reactions of Construction Workers in Virtual Environment: A Feasibility Study Using Affective Sensing Technology" (2015). FIU Electronic Theses and Dissertations. 2302.

https://digitalcommons.fiu.edu/etd/2302 


\section{FLORIDA INTERNATIONAL UNIVERSITY}

Miami, Florida

MONITORING PHYSIOLOGICAL REACTIONS OF CONSTRUCTION WORKERS IN VIRTUAL ENVIRONMENT: A FEASIBILITY STUDY USING AFFECTIVE SENSING TECHNOLOGY

A thesis submitted in partial fulfillment of the

requirements for the degree of

MASTER OF SCIENCE

in

CONSTRUCTION MANAGEMENT

by

Hazal Ergun

2015 
To: Interim Dean Ranu Jung

College of Engineering and Computing

This thesis, written by Hazal Ergun, and entitled Monitoring Physiological Reactions of Construction Workers in Virtual Environment: A Feasibility Study Using Affective Sensing Technology, having been approved in respect to style and intellectual content, is referred to you for judgment.

We have read this thesis and recommend that it be approved.

$\begin{array}{r}\hline \text { Armando Barreto } \\ \hline \text { Irtishad Ahmad } \\ \hline \text { Nipesh Pradhananga, Major Professor }\end{array}$

Date of Defense: November 12, 2015

The thesis of Hazal Ergun is approved.

Interim Dean Ranu Jung

College of Engineering and Computing

Dean Lakshmi N. Reddi

University Graduate School

Florida International University, 2015 
(C) Copyright 2015 by Hazal Ergun

All rights reserved. 


\section{DEDICATION}

I dedicate this thesis to my parents and my sister for their endless love and care from such a long distance and their support for every single moment. Whatever makes me successful belongs to them and I dedicate my thesis to my Chinese sister, my biggest chance in this new country, she is the one who makes me strong and cheerful all the time with her huge smile and feel like I have a family here. 


\section{ACKNOWLEDGMENTS}

I would like to express my gratitude to my major professor, Dr. Nipesh Pradhananga, for his guidance and support through all my graduate studies. His way to understand and help always enlightened my way to solve problems and learn with an eager.

I also wish to thank the members of my committee Dr. Armando Barreto and Dr. Irtishad Ahmad for their support and guidance through this rigorous journey and their understanding to arrange a time for my dissertation in their tight schedule.

My sincere gratitude is extended to my all colleagues for their friendship and support throughout all my master study and researches. 


\begin{abstract}
OF THE THESIS
MONITORING PHYSIOLOGICAL REACTIONS OF CONSTRUCTION WORKERS

IN VIRTUAL ENVIRONMENT: A FEASIBILITY STUDY USING AFFECTIVE

SENSING TECHNOLOGY
\end{abstract}

by

Hazal Ergun

Florida International University, 2015

Miami, Florida

Professor Nipesh Pradhananga, Major Professor

This research aims to monitor workers' physiological reactions in virtual construction scenario. With the objective of leveraging affective sensing technology in construction scenario, experiments with Galvanic Skin Response (GSR) was conducted in a 3D simulation developed based on a real construction site. The GSR results obtained from sensor were analyzed in order (i) to assess the feasibility of using virtual environment to generate real emotions, (ii) to examine the relation between questionnaires used to ask people about their experience and their physiological responses and (iii) to identify the factors that affect people's emotional reactions in virtual environment. Subjects of the experimental group exhibited incoherent responses, as expected in experiments with human subjects. Based on the various reasons for this incoherence obtained from questionnaire part of the experiment, the potential in research for developing training methods with respect to workers' physiological response capability was identified. 
CHAPTER PAGE

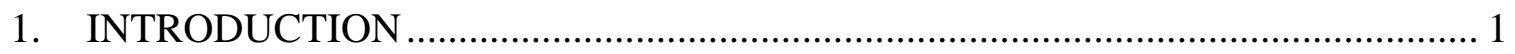

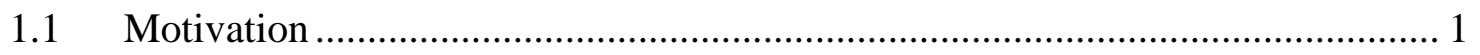

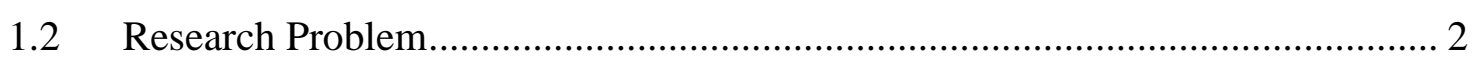

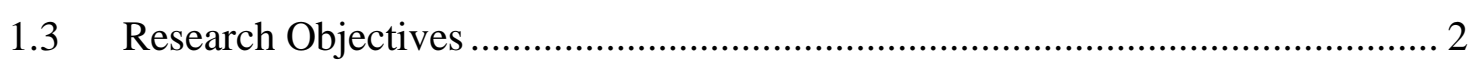

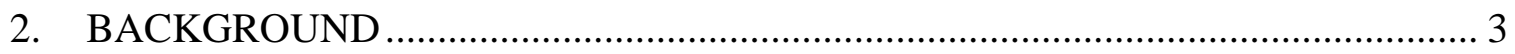

2.1 Safety Statistics in Construction Industry ........................................................ 3

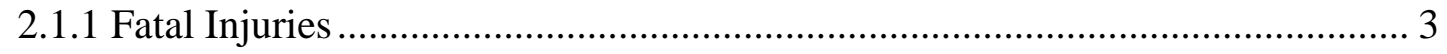

2.1.2 Non-Fatal Injuries ..................................................................................... 4

2.2 Major Construction Accidents …………….............................................. 5

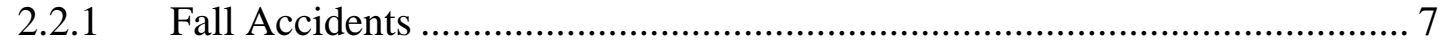

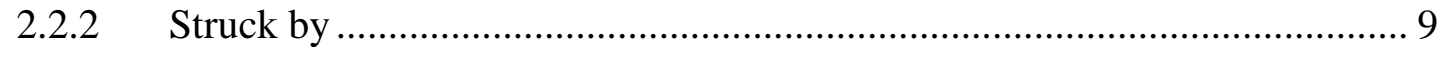

2.2.3 Electrocution ................................................................................ 9

2.2.4 Caught in/between .................................................................................. 10

2.3 Lagging and Leading Safety Indicators ............................................................. 11

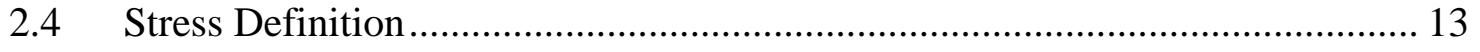

2.5 Stress Response Process ............................................................................... 14

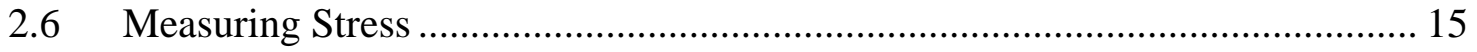

2.7 Activity of Human Brain.............................................................................. 15

2.8 Decision Making Under Stress..................................................................... 16

2.9 Non-Intrusive Stress Monitoring................................................................ 17

2.9.1 Physiological Characteristics ............................................................. 18

2.9.1.1 Galvanic Skin Response (GSR)............................................................ 19

2.9.1.2 Heart Rate Variability (HRV)............................................................... 20

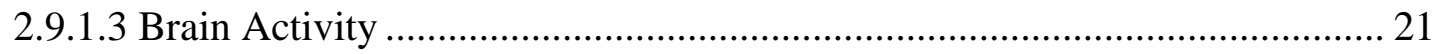

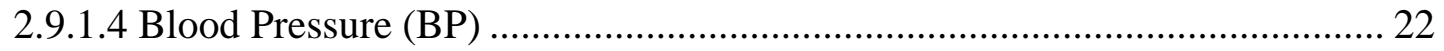

2.9.1.5 Blood Volume Pulse (BVP) .................................................................. 22

2.9.1.6 Skin Temperature (ST) .................................................................... 22

2.9.2 Physical Characteristics ………..................................................... 22

2.9.2.1 Behavior and Gesture …………………….......................................... 22

2.9.2.2 Facial Expression.................................................................................. 22 


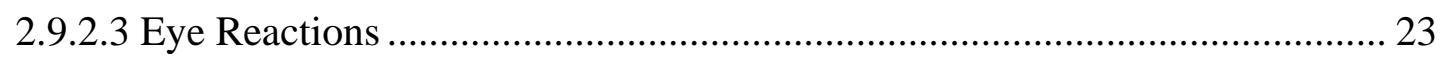

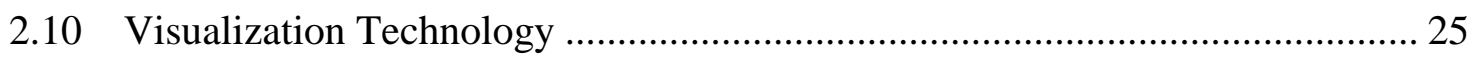

2.10.1 Benefits of using Virtual Reality ............................................................. 27

2.10.2 Virtual Reality in Different Fields ............................................................ 27

2.10.3 Virtual Reality in Construction Industry.................................................... 29

2.11 Case Studies - Stress Detection with Affective Sensing ………......................... 30

2.11.1 Detecting Stress during Real-world Driving.............................................. 30

2.11.2 Stress Recognition in Typical Virtual Environment.................................... 31

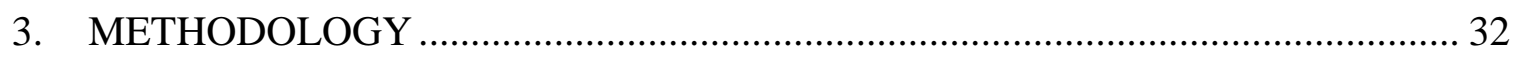

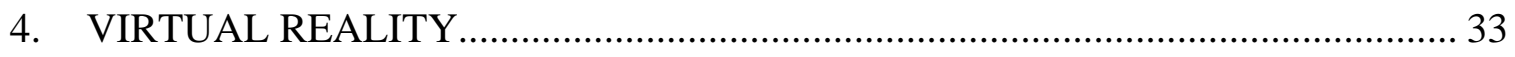

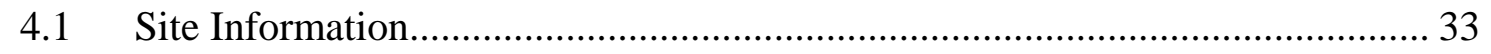

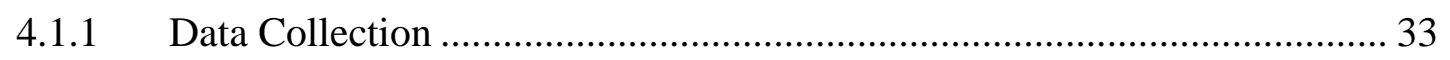

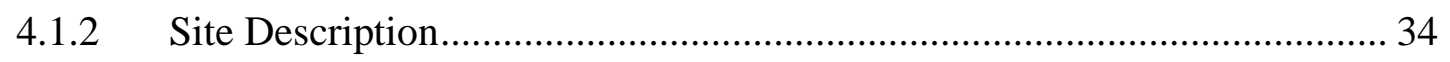

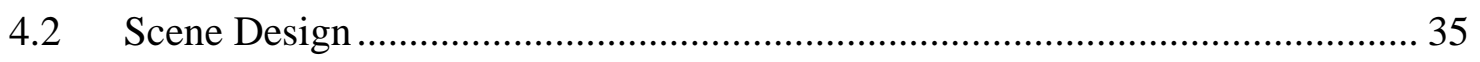

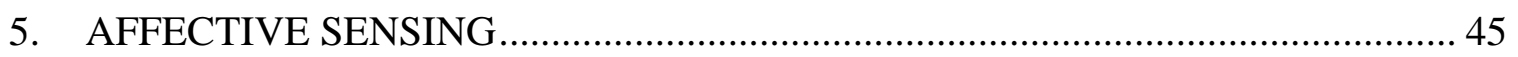

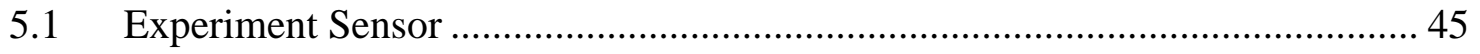

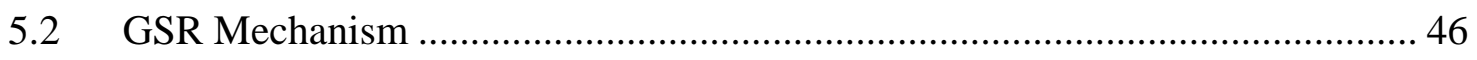

5.2.1 Choosing Sensor Device for Experiment................................................... 46

5.2.2 Testing GSR Sensor............................................................................... 47

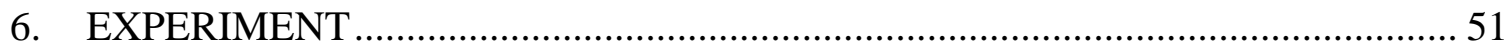

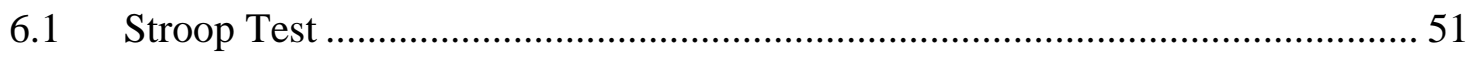

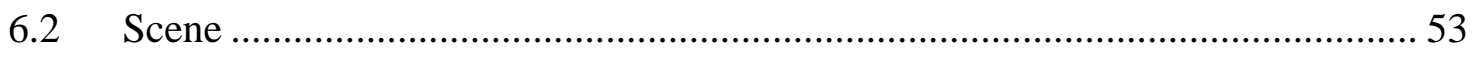

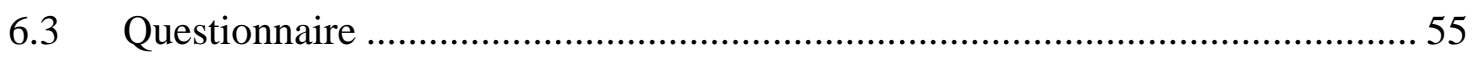

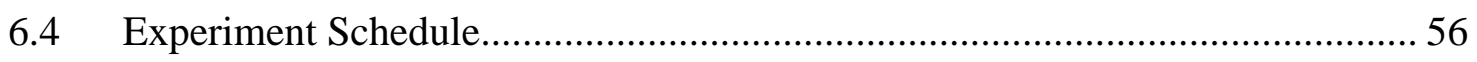

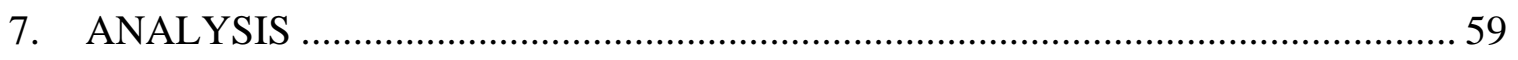

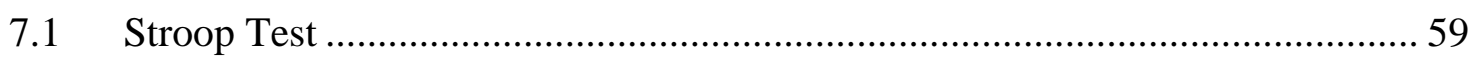

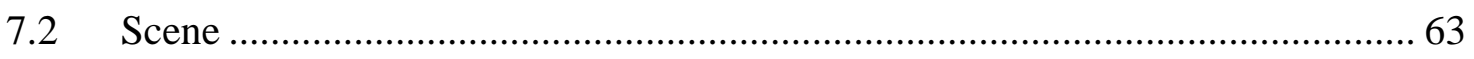

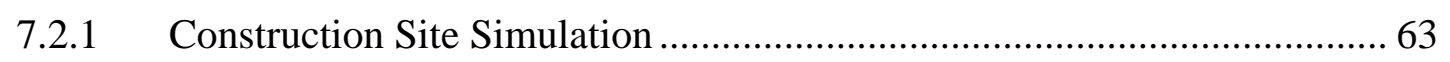

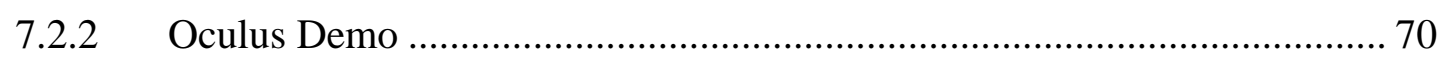

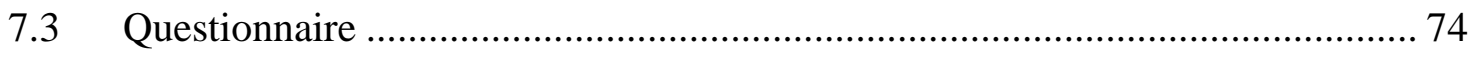

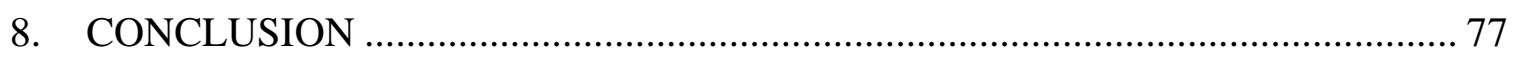

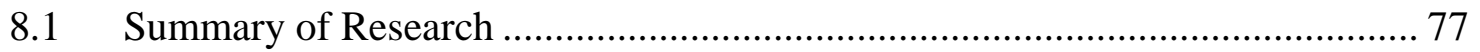




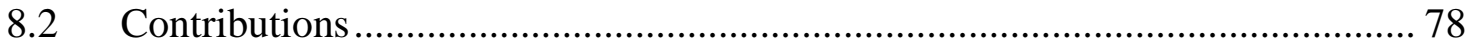

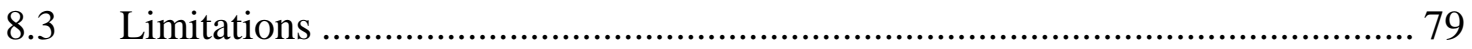

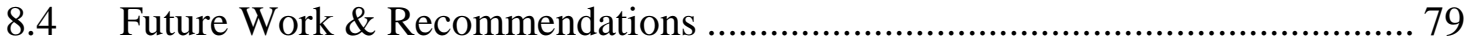

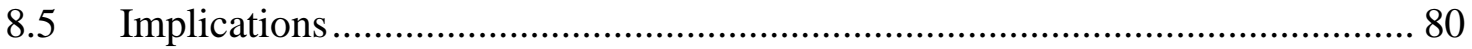




\section{LIST OF TABLES}

TABLE

PAGE

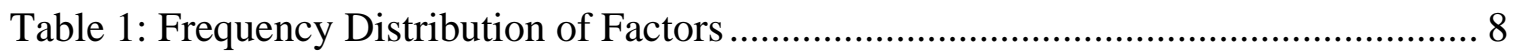

Table 2: EEG Frequency Band Categories ............................................................ 21

Table 3: Empirical Ranking for Stress Measuring Methods......................................... 24

Table 4: Scene design for the first half of the simulation ............................................. 40

Table 5: Scene design for the second half of the simulation ...................................... 40

Table 6: Different Physiological Measurement Changes ............................................. 46

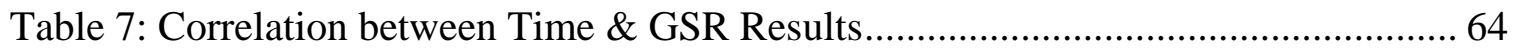




\section{LIST OF FIGURES}

FIGURE

PAGE

Figure 1: Occupational Fatalities in 2013 by Industry................................................. 3

Figure 2: Occupational Fatalities by Year ................................................................ 4

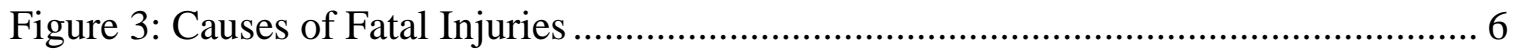

Figure 4: Distribution of Caught in/between Accidents ............................................ 10

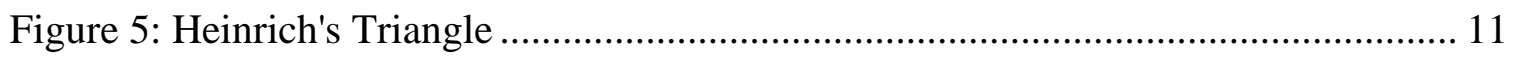

Figure 6: Common Physical and Physiological Measures.......................................... 18

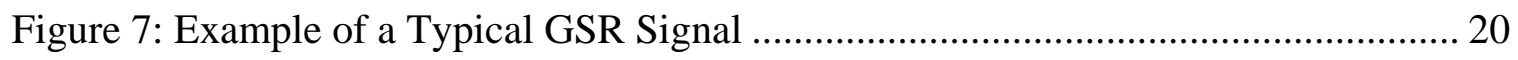

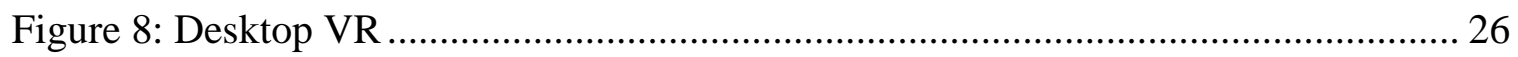

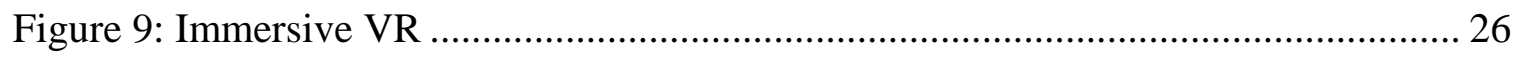

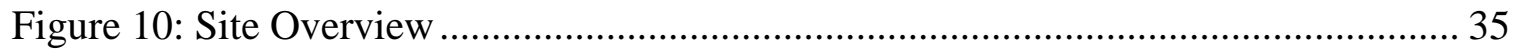

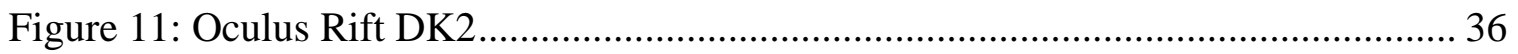

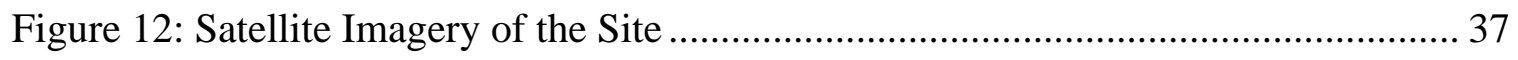

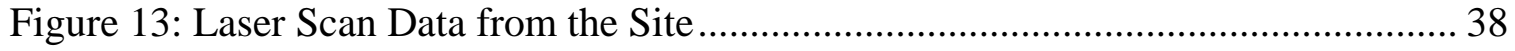

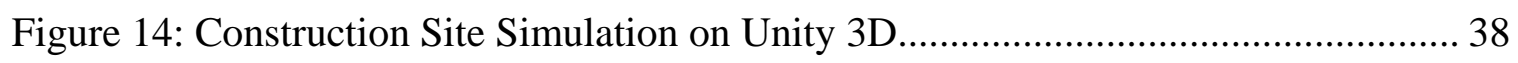

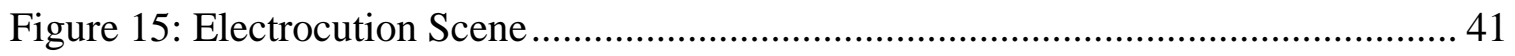

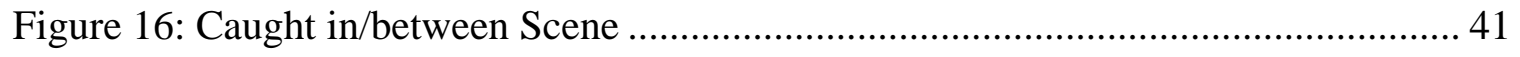

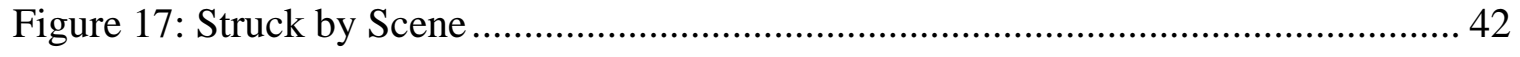

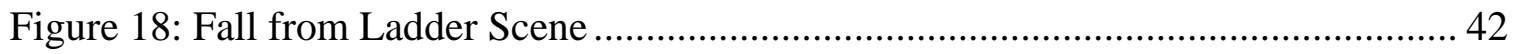

Figure 19: Movement of the Yellow Worker ......................................................... 43

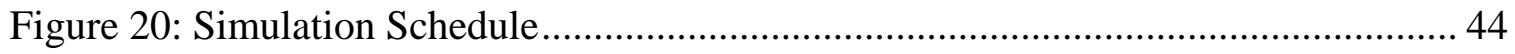

Figure 21: Neulog Galvanic Skin Response Sensor ............................................. 47 
Figure 22: Experiment for Sensor Test...................................................................... 48

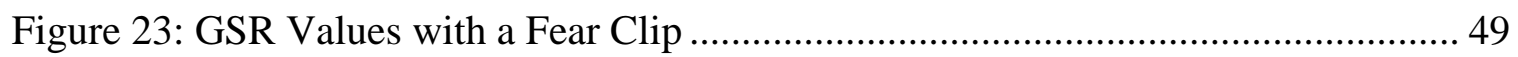

Figure 24: GSR Values with a Relaxing Music............................................................... 50

Figure 25: GSR Values with a Funny Clip ………………........................................... 50

Figure 26: Congruent Stroop Test............................................................................ 52

Figure 27: Incongruent Stroop Test .......................................................................... 52

Figure 28: When trial was not replied........................................................................ 52

Figure 29: Picture from the Experiment …………………....................................... 54

Figure 30: Oculus Tuscany Demo Scene..................................................................... 54

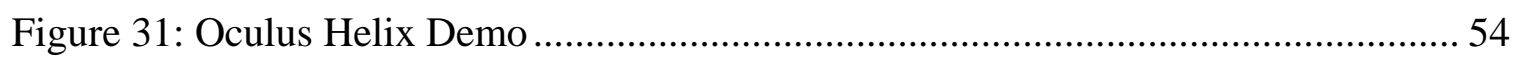

Figure 32: Overall Experiment Schedule with Approximate Durations............................. 58

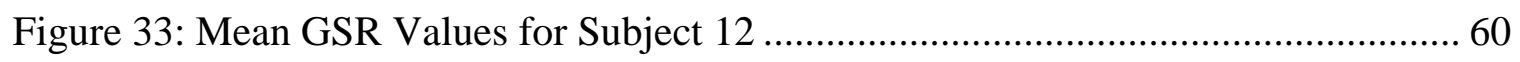

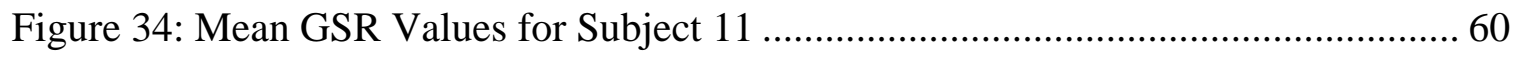

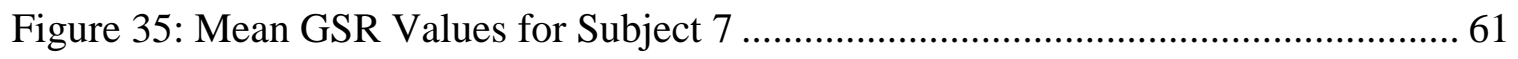

Figure 36: Mean GSR Values for Subject 3 ............................................................... 62

Figure 37: Mean GSR Values for Subject 5 ................................................................ 62

Figure 38: Mean GSR Values for Stroop Test.............................................................. 63

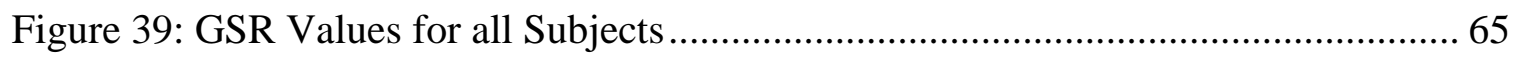

Figure 40: Detailed GSR Graph between Time 15.00 - 45.00 sec.................................... 66

Figure 41: Detailed GSR Graph between Time 270.00-310.00 sec .................................. 67

Figure 42: Subject 10 Material Fall Reaction .................................................................. 68

Figure 43: Subject 10 Fall from Ladder Reaction ......................................................... 68

Figure 44: Subject 3 Material Fall Reaction ................................................................... 69 


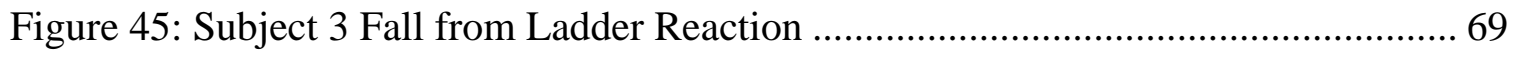

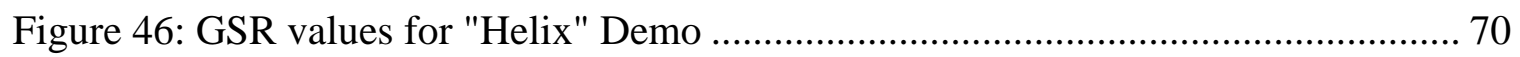

Figure 47: GSR Values for "Tuscany" Demo ......................................................... 71

Figure 48: Subject 5 Construction Simulation GSR Results .................................... 72

Figure 49: Subject 5 Rollercoaster Demo GSR Results ........................................... 73

Figure 50: Subject 6 Construction Simulation GSR Results ..................................... 73

Figure 51: Subject 6 Rollercoaster Demo GSR Results .......................................... 74 


\section{INTRODUCTION}

\subsection{Motivation}

The high number of accidents occur in construction field and destructive results like fatalities and serious injuries bring about a focus on safety aspects for last decades. To demonstrate this importance with numbers Bureau of Labor Statistics release in 2012 can be used that shows 780 fatalities correlated with construction works and 4,000 accidents reported in US. According to the recorded results construction industry can be listed as the $3^{\text {rd }}$ most unsafe industry which means that technological development should be used to create solutions for safety issues. Additionally, OSHA 2012 results show that fatality rate in construction site is three times higher than the national average that explains how the construction workers are vulnerable to the accidents. These amount of high rates caused by insufficient skills for hazard recognition and low respond efficiency under stressful conditions. In other words qualified safety programs are not enough without proper hazard awareness and recognition. (Chen et. al., 2013)

What makes the results impactful is the reaction difference between under normal working and site situations and under hazardous conditions. The literature researches show that stress or emotional changes resulted by danger or unexpected changes come up in degrade of perceptual-motor performance, amount of focus on peripheral information and tasks decreases, additionally judgment and decision making becomes more rigid without examining the variety of reaction options. (Staal, 2004) 


\subsection{Research Problem}

Although most of the studies focus on the causes of the accidents and injuries on construction site, statistics show the results for the number of people affected by hazardous situations, detailed analysis for safety aspects and furthermore; researchers did not concentrate on the changes in human body under stress or emotional changes and their effect on decision process. In order to have a better analysis for safety conflicts on construction site, the conditions make construction workers stressed or tensed and their reflections should be analyzed. Accordingly, proper safety precaution methods and training systems can be developed.

The main goal for this research is investigating physical changes under changeable environment by examining effects for different hazard scenarios. The results obtained from virtual reality simulation is going to be analyzed under the effect of different scenarios which occur with the highest frequency on real construction sites. With respect to the results, correlation between personality and reactions under tense can be analyzed for developing possible future training methods or safety management techniques.

\subsection{Research Objectives}

- Test the feasibility of using virtual environment instead of real environment to generate same emotions as in a construction site

- Test if “questionnaires used to ask people about their experience” and "what their physiological state says about them” match with each other

- Identify the factors that people show emotional reactions in virtual environment 


\section{BACKGROUND}

\subsection{Safety Statistics in Construction Industry}

\subsubsection{Fatal Injuries}

Construction industry has a serious safety concerns can be related with numbers according to which more than 26,000 U.S. construction workers have died in the last two decades and this is approximately equal to five death every working day. (Zhang et al., 2012) According to the Figure 1, provided by the Bureau of Labor Statistics and Health (2013), construction industry has the highest number of fatal work injuries within all the human-involved industries.

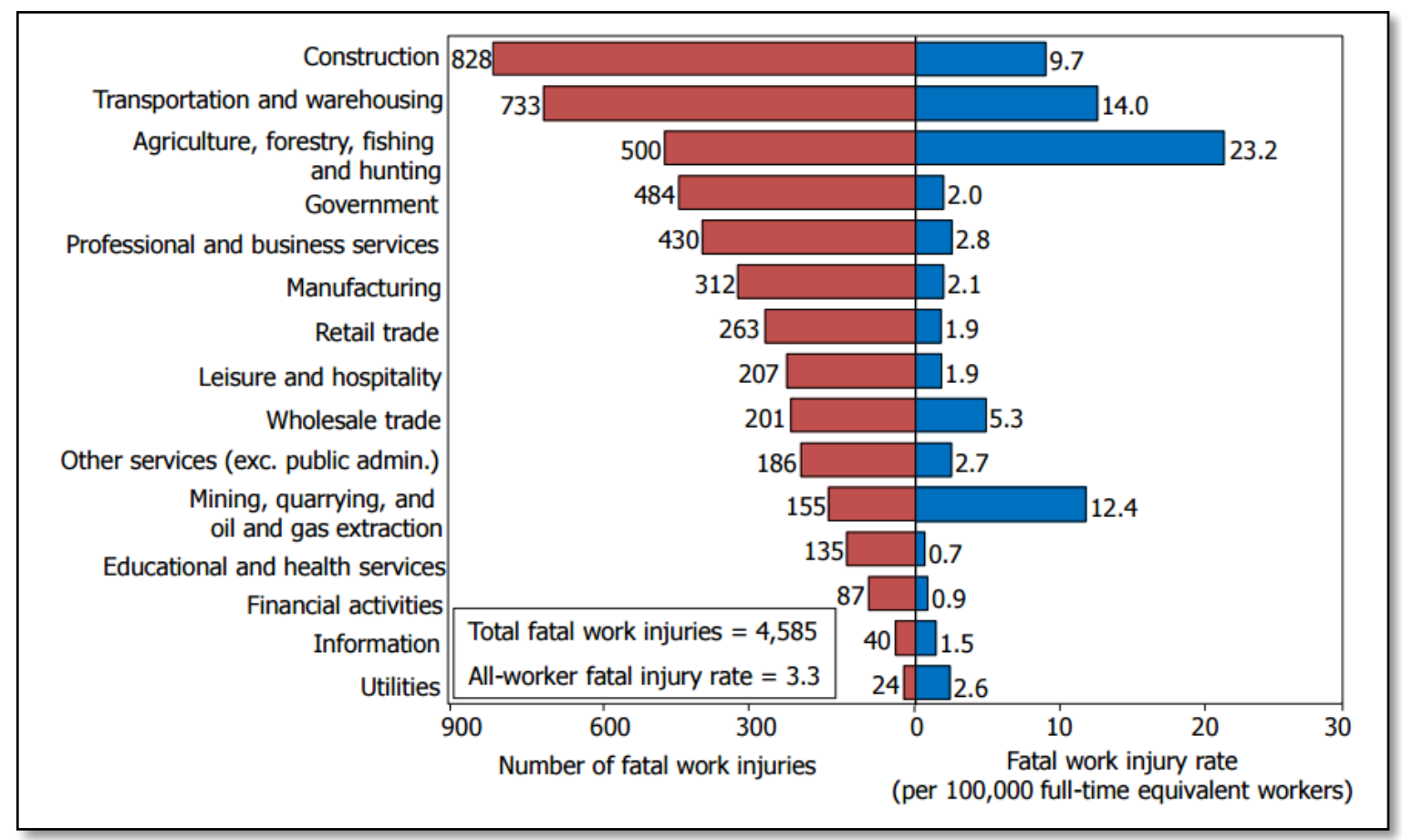

Figure 1: Occupational Fatalities in 2013 by Industry 
With respect to the numerical values provided by the Census of Fatal Injuries (CFOI), difference between average and construction industry fatal injury numbers can be shown as per Figure 2.

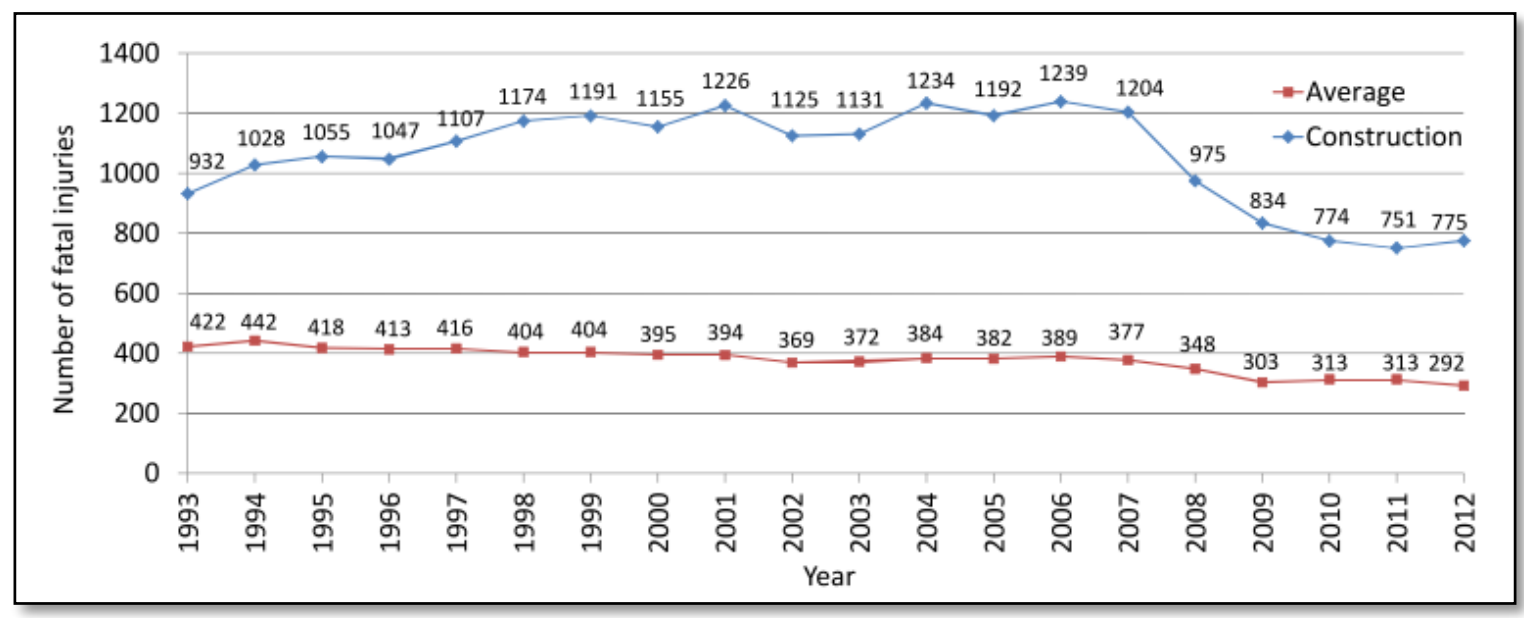

Figure 2: Occupational Fatalities by Year

\subsubsection{Non-Fatal Injuries}

Besides the huge number of death cases, construction industry has the first place with injury rates. Bureau of Labor Statistics show that the total number of non-fatal injuries occurred in construction industry is 3,153,701 between the years 1992-2010. While this number is 184,700 for 2011 ; it decreases to 179,100 in 2012 . These numbers reflect the cases for which workers are absent from work because of the injuries based on Occupational Safety and Health Administration (OSHA).

These injuries have impacts like personal suffering, construction delays, productivity decrease and compensation costs. (Abudayyeh et al., 2006) The National Safety Council reports demonstrates that compensations costs are over \$10 million for both fatal and non-fatal injuries in construction industry in 2008. 
The key point to deal with safety issues is understanding the root causes result in huge amount of budget inadequacy, injuries and threatening to human life. Zhang et al. (2012) mentions that lack of expertise or engineers' carelessness during planning, executing and safety training phases bring about failures in hazard identification. Insufficiency in them may increase risk exposure for workers in construction field. To have a proper safety plan, potential hazards should be identified, root causes for accidents should be determined and accordingly an active communication or information sharing system should be developed. The barriers of traditional safety planning methods are highly inefficient and time consuming manual observations (Chantawit et al., 2005), existing insufficient safety rule and regulations and also design choices bring about hazardous situations. However, technological improvements like Building Information Modeling (BIM), Virtual Design and Construction Technology (VDC) etc. have lots of contributions to Architecture, Engineering and Construction (AEC) industry for hazard recognition and safety planning concepts by detecting conflicts for constructions with the help of 4D visualization models.

\subsection{Major Construction Accidents}

The Occupational Safety and Health Administration (OSHA) examines construction injury causes under five basic categories named as; falls (from elevation), shock (electrical), caught in/between, struck-by and other factors. Regarding the accident data collected through five years 1985-1989, OSHA issued a report at 1990 showing that the majority of accidents is falls with $33 \%$, it is followed by $22 \%$ struck by accidents, 18\% caught-in/between, 17\% electrical shock and 10\% other causes. (Hinze et al., 2005) 


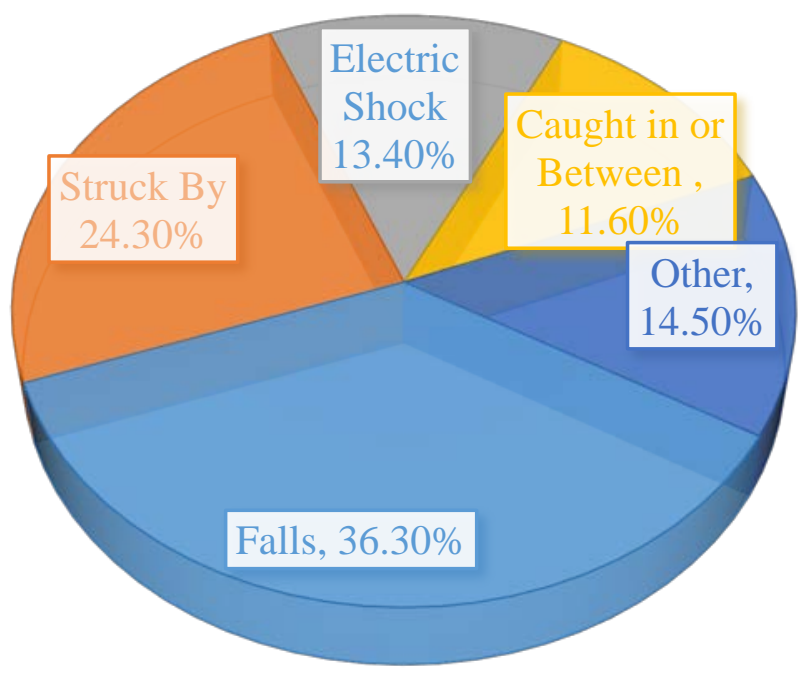

Figure 3: Causes of Fatal Injuries based on Huang \& Hinze 2003

Figure 3 demonstrates the change in four major accidents regarding the time period from January 1990 through October 2001 including 7,543 OSHA-investigated accidents. (Huang \& Hinze, 2003)

To provide the information for each injury/fatality, OSHA established the IMIS database that records accident data. With the help of this database, researchers can access the previous incidents in order to develop new methods for injury prevention and have detailed analysis on the current information. Each recorded accidents should have a specific case number with the information of date of accident, name and address of the employer and OSHA citations reported to the employer. Addition to these information, victim data is recorded with victim's name, age, gender, occupation, part of the body injured, type of injury and whether it was fatal or not. The event causes injury is also recorded with a code for event type, hazardous substance involved and information related with the source of injury (material or equipment). Besides, OSHA compliance officers prepare an abstract which is generally a single paragraph describes the situation 
at the accident time by physical investigation and witness interview. Abstract is the key point to have detailed and specific information about accident. (Hinze et al., 2005)

\subsubsection{Fall Accidents}

With respect to the study held by Drury \& Brill (1983), causes for work-related fatal falls can be categorized into four as follows; individual, the task, tolls and equipment used, and managerial and environmental factors. Bodily actions like climbing, walking or leaning against, distraction, insufficient capacities, and incorrect usage of personal protective equipment (PPE) can be investigated under individual category. Task factors can be covered by overexertion and unusual control, poor work practices and lack of protection measures. While mechanical failure, unsafe ladder and tolls are considered as a tools and equipment factor, unguarded openings, lack of complying scaffolds, unauthorized access to hazard areas and contact with falling object form management and environment part of the causes. $80.5 \%$ of all kind of fall injuries and deaths occur in group of worker with less than one year experience, which shows the importance of training for construction safety issues (Chi et al., 2005).

Accordingly the US Department of Labor (2003), fatal injuries can be categorized under 11 different events that can be listed as follows,

(1) Falls from stairs or steps,

(2) Falls through existing floor openings,

(3) Falls from ladders,

(4) Falls through roof surfaces,

(5) Falls from roof edges, 
(6) Falls from scaffolds or staging,

(7) Falls from building girders or other structural steel,

(8) Falls while jumping to a lower level,

(9) Falls through existing roof openings,

(10) Falls from floors, docks or ground level

(11) Other

The gradation according to the frequency of event can be seen at following table,

Table 1: Frequency Distribution of Factors (Chi et al., 2005)

\begin{tabular}{|l|c|c|}
\hline Accident Event & Frequency & \% \\
\hline Fall from scaffold, staging & 189 & 30.4 \\
\hline Fall through existing floor opening & 128 & 20.6 \\
\hline Fall from building girders or other structural steel & 70 & 11.3 \\
\hline Fall from roof edge & 65 & 10.5 \\
\hline Fall from floor, dock, or ground level & 51 & 8.2 \\
\hline Fall through roof surface & 44 & 7.1 \\
\hline Fall to lower level & 33 & 5.3 \\
\hline Fall from ladder & 26 & 4.2 \\
\hline Fall down stairs or steps & 11 & 1.8 \\
\hline Jump to lower level & 2 & 0.3 \\
\hline Fall through existing roof opening & 2 & 0.3 \\
\hline
\end{tabular}




\subsubsection{Struck by}

Struck by accidents can be analyzed in two major groups as material involved struck-by accidents and equipment involved ones. Hinze et al. (2005) provides the detailed information with respect to the 743 struck-by accidents or cases, The research shows that the materials most frequently involved in accidents are wood, concrete, soil, steel, tree, brick, line or cable, tank and lumber with a descending order. When the cases were analyzed with equipment list became as follows; truck, private vehicle, crane, excavator, loader, forklift, bulldozer, hoisting, roller, saws and scraper. While, truck is the top of the list with $39.4 \%$ scraper has the least percentage as 0.8 .

\subsubsection{Electrocution}

Occupational Safety and Health Administration (OSHA) describes electrocution as a serious workplace hazard that exposes workers to the burns which is a shock-related injury, electrocution (results in fatality), shock when current enters the body and also leaves it, arc flash, fire and explosions.

According to the Bureau of Labor Statistics and Health (2008) data, contacting with electric current was reason for $4 \%$ of the fatal injuries in United States in 2006, it was equal to 250 deaths for which 126 of them belong to construction industry. The highest rates of fatality belongs to electrical power installers and earth drillers.

The major accidents are grouped as electrocution are contacting with electric current, electric current of a machine, tool, appliance, or light fixture, wiring, transformers, or other electrical components, overhead power lines, underground, buried power lines and being stuck by lighting. 


\subsubsection{Caught in/between}

Occupational Safety and Health Administration (OSHA) describes caught in/between and struck by together to have a better understanding. Accordingly, "when the impact alone creates the injury, the event should be recorded as struck. When the injury is created more as a result of crushing injuries between objects, the event should be recorded as caught.” Cave-ins or events like being pulled by machinery can be recorded as a caught in/between accident.

To analyze the causes and effects for caught in/between accidents, Figure 4 is developed with respect to the information provided by Hinze et al. (1998) that gives a general perspective about caught in/between category construction accidents.

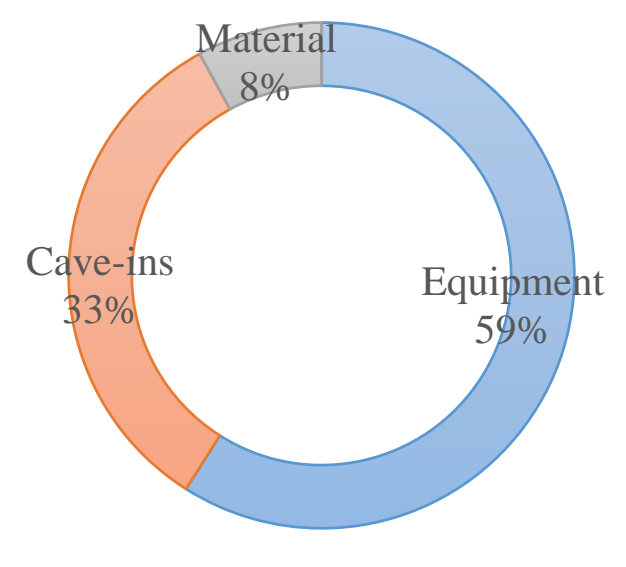

$\square$ Equipment $\square$ Cave-ins $\square$ Material

Figure 4: Distribution of Caught in/between Accidents based on Hinze et al., 2003 


\subsection{Lagging and Leading Indicators of Safety}

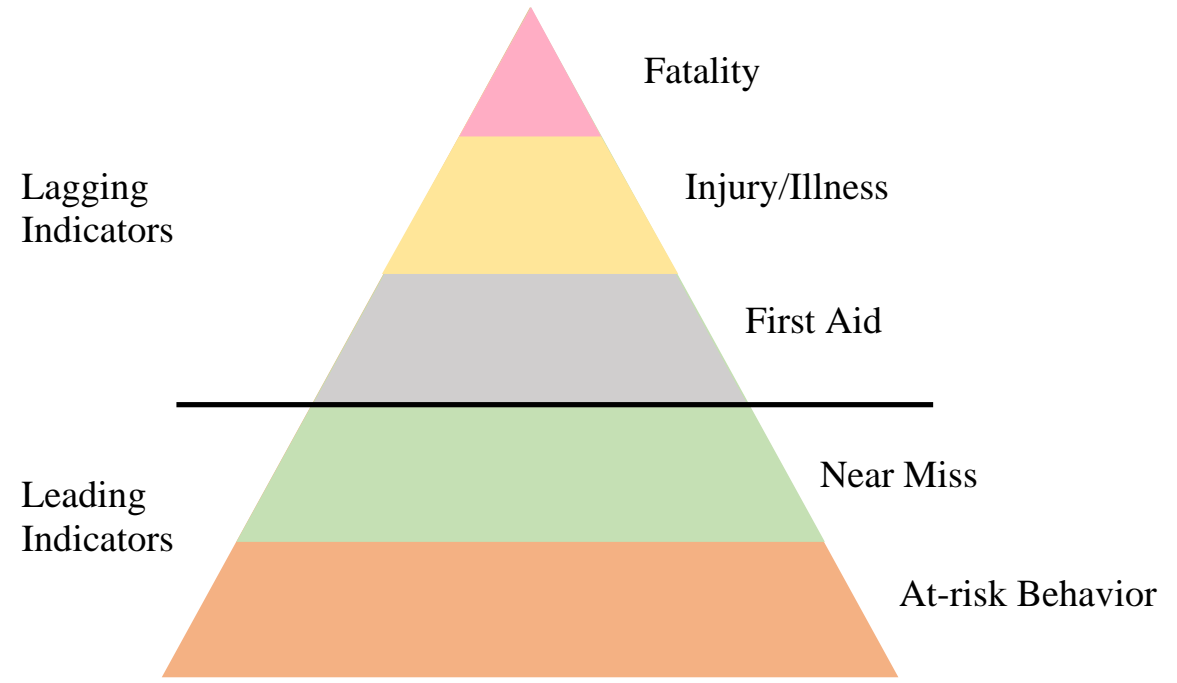

Figure 5: Heinrich's Triangle (Adapted from OSG 2009)

Heinrich's triangle shown in Figure 5 demonstrates that fatality comes after successive non-fatal injuries. Each of the group leads to the upper consequence, in this case analyzing the injury/illness cases will bring about less fatality or incidents generating first aid injuries can be investigated to decrease number of non-fatal results. In this manner, variety of incidents help for taking more detailed precautions.

As per the Heinrich's triangle leading indicators categorized into two as; near miss and at-risk behaviors. Near miss events are the ones had potential to cause injury or other type of damages but did not in reality. (Marks, 2014) At-risk behaviors can be explained as the ones have potential to result in hazardous circumstances for a worker or equipment operator in the field. (Pradhananga, 2014) All of the steps named as leading indicators has some amount of cost and compensation that increases through the top level of the triangle. On the other hand, leading indicators does not have a severity or direct cost because they don't cause any injury or damage and. With the purpose of zero- 
incident construction field all leading indicators can be investigated and related precautions can be implemented. This study focus more on the first step of the safety issues in construction industry, at-risk behaviors.

The historical data for injuries and fatalities only help to evaluate results of the accidents but cannot provide possibility of reoccurrence or background of the events. Lagging indicators are under this category which doesn't include pro-active measure for site conditions. (Pradhananga, 2014) These indicators focus on negative data and results that collected only when incident happens. (Hinze \& Godfrey, 2003) On the other hand, leading indicators help predicting hazardous situations and undesired events. (Grabowski et al., 2007) Leading indicators also have the ability to assess whether hazard is under control and detect the causes on an incident. (Lindsay, 1992) Finally, leading indicators might be beneficial for effective plan modifications to decrease severity of the incidents. (Hinze et al., 2013)

Understanding what makes workers or equipment operators stressed, tensed or distracted in the field, what factors bring about less concentration and incorrect decisions, what are the aspects need more attention and all related topics bring about less at-risk behaviors. For the following steps, frequency of the higher levels in triangle can be decreased. This study targets analyzing at-risk behavior level and creating a connection between safety issues and stress topic which may lead further studies for zero-incident construction environment. 


\subsection{Stress Definition}

It is not easy to have a common description for stress, because of that researchers have a plenty of divergent definitions to create an imagery for this concept. First one made by Stokes and Kite (2001) defines stress as “an agent, circumstance, situation, or variable that disturbs the 'normal' functioning of the individual". This definition can be

modelled by two traditional approaches named as stimulus-based and response-based stress. Nevertheless, when the studies are enlarged they came up with a new model called as transactional, which defines stress as "the result of mismatch between individual perceptions of demands of the task or situation and their perceptions of the resources for coping with them". The reason of having different explanations for this concept is majorly resulted by variety of perspective. The another one explained by McGrath (1979) shows stress as interaction difference between three concepts labeled as perceived demand, perceived ability to cope and perception for the importance of meet the demand. Which means that, stress can be described as desire to cope with the demand.

As a basic and general clarification stress can be named as time pressure, because lack of the time to analyze, decide and perform the task creates stress. (Lupien, 2007) According to Hendy et al. (2001) an algorithm between time pressure and stress can be as follows;

Task load $/$ Processing rate $=$ Decision time

Decision time $/$ Time available $=$ Time pressure

Since time exiguity might make some people more careful and agile, it is not accurate to generalize time pressure effect on people. Because of these reasons stress 
phenomenon can't be described in a single way with a distinct explanation, it is still elusive even within a single field.

\subsection{Stress Response Process}

Under the stressful situation hypothalamus and adrenal glands are activated by hormonal and nerve signals. (Sharma, 2014) There are two main stress hormones secreted are the glucocorticoids (cortisol for humans) and the catecholamines (epinephrine and norepinephrine). These two groups of hormones are the primary reflections under stress which gives body rise to protect itself, fight-or-flight response and can be detected by experiencing increment in heart rate or blood pressure. To occasion a stress response three individuals should be provided; the situation or incident ought to be novel or unpredictable and make the feeling that situation can't be controlled. These makes stress responses specific, predictable and measurable. (Lupien, 2007)

Selye (1980) defines stress into two groups as good stress or eustress and bad stress or named as distress. While eustress bring about a positive emotional state like joy, happiness or excitement; distress cause negative emotional, mental or physical state. The aim of this study is focusing negative stress that can be observed under tension, fear, anxiety or anger.

Stressors can be categorized with respect to physical, biological, cognitive, emotional or physiological stimulus. (Sharma, 2014) Stress symptoms may be observed after a period of time stimulus occurred or recover time may take couple of minutes, these durations can be correlated with the type of stressor and physiology of individual. (Healey \& Picard, 2005) 


\subsection{Measuring Stress}

Traditional way to analyze and measure stress is using individually rates stress scales; likewise, Relative Stress Scale (Ulstein et al., 2007) or Fear Survey Schedule (Miller et al., 1995) One of the other convenient way to measure psychological stress is questionnaires concentrates on language, cognition, characteristics and emotions. With help of wide range of questions psychological factors related with stress can be detected and evaluated (Lupien, 2007). As a common result, all of these methods are both subjective and they require manual recognition. Although subjective self-assessment methods have popularity for measuring stress, it totally depends on the way individuals realize and experience stress.

Furthermore to subjective methods, being exposed to stress result in secretion of cortisol and catecholamines in humans that can be easily measured in blood, urine and saliva. Both of them are being measured through blood samples, by the way new studies found out that cortisol can be measured with the help of saliva with no need of skilled person. (Lupien, 2007)

\subsection{Activity of Human Brain}

Understanding how human brain reacts when the situation goes under difficulty and someone needs to deal with more than one task at the same time with the same amount of effort, in other words with the aim of exploring functional architecture of human brain under dual-task interference. The reason why people are not able to deal with two different tasks at the same time can be described by three approaches named as; capacity sharing, bottlenecks (task switching) and cross talk. Capacity sharing is the most 
accepted way for dual-task interference, which describes this subject as sharing mental resources among tasks. For which individual tasks will be performed with less capacity or when one of the tasks becomes more though amount of effort for this special task is being increased. As an example; while carrying out driving and speaking at the same time, driver may give more emphasis to driving under busy traffic. According to the bottleneck (task-switching) model, parallel processing might be impossible, if two tasks need the same mechanism at the same time. This results in delay in task or they might be impaired. Depending on the resource limitations and mental operations, number of bottlenecks may vary. Cross-talk models focus on content of the information, with respect to the sensory inputs, responses being produced and the thoughts in people's mind. In conformity with the principle, it might be easier to perform two concurrent tasks if they have similar inputs. (Pashler, 1994)

Study held by Telford (1931) shows that when people need to respond two following stimuli, decrease in the time between two stimuli result in slower response to the second stimuli. This can be correlated with refractory period of neurons and this effect can be observed in a large variety of different tasks.

\subsection{Decision Making Under Stress}

Decision making a part of everybody's daily life just deciding where to, what to eat as a lunch and a great number of examples like this. The classical decision making analysis like Naturalistic Decision Making (NDM) and Multi Attribute Utility Theory (MAUT) describes the process. (Bayouth et al., 2013) Multi Attribute Utility Theory (MAUT) is the classical model describes decision making process among the alternatives. 
According to this theory, decision maker identifies the alternatives and evaluates the utility for each decision. As a result, decides the alternative with the highest utility. But studies show that this classical method is not good enough to describe rapid decision making under uncertainty. When decision needs to be taken under high stress and time or under critical conditions the Recognition-Primed Decision (RPD) should be used to define this progress for which decision based on experience. For this specific theory, instead of evaluating decision possibilities like traditional theory, decision maker just focus on a single possibility and acts accordingly. This single and strong possibility comes from previous experiences and helps decision maker to save time and follow an acceptable solution (Keren \& Franke, n.d.). Klein (1998) shows that decisions made under time pressure have more risk aversion. When both physical and psychological stress effects on construction field are added, stressors’ mortality may increase. (Keren \& Franke, n.d.)

\subsection{Non-Intrusive Stress Monitoring}

The power of the stress is widely accepted that has effects on immune and cardiovascular systems and if it becomes chronic makes individuals more open to illnesses and infections. (Segerstrom \& Miller, 2004) Accordingly the age, gender, experience and similar effects individual's reaction to the stress may vary. Symptoms of stress can be categorized as hormonal imbalances, physiological and physical changes. Under stress increase in hormones can be detected by invasive methods like blood, saliva or urine samples; on the other hand, heart rate (HR), blood pressure (BP), pupil diameter (PD), galvanic skin response (GSR) can be measures with non-invasive technics to measure the stress effect on human body. (Sharma \& Gedeon, 2012) 
Physical characteristics can be defined as changes can be observed without any kind of equipment or tools, just by observing; while, physiological characteristics are the ones fluctuations can be measured with tools or sensors. The following demonstration labeled as Figure 6 shows physical and physiological measures can be used for stress recognition.

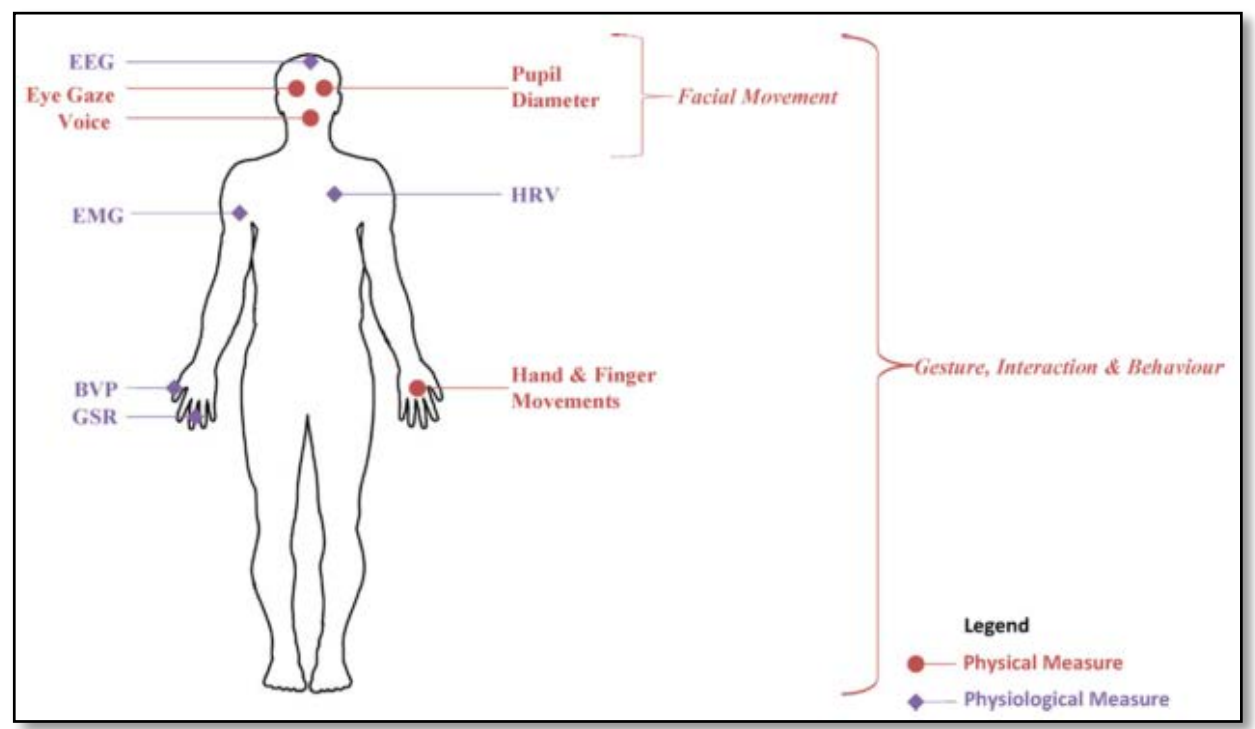

Figure 6: Common Physical and Physiological Measures (Sharma \& Gedeon, 2012)

\subsubsection{Physiological Characteristics}

The Autonomic Nervous System (ANS) contains the Sympathetic and Parasympathetic nervous systems responsible for the activities can't be controlled. ANS system affects the organs like heart or seat glands. (Hudgahl, 2001) Events trigger stress increases Sympathetic Nervous System (SNS) activity rate and decreases Parasympathetic Nervous System (PNS) activities, which means that PNS is more active during resting period. Both of these nervous systems adjust galvanic skin response, heart rate variability, brain waves and blood pressure. When the physiological signals are 
monitored and variations detected it is possible to record stress effects. (Sharma \& Gedeon, 2012)

\subsubsection{Galvanic Skin Response (GSR)}

Galvanic Skin Response (GSR) or named as skin conductance or electrodermal activity response measures the electricity flow through the skin for which stress increases skin conductance because of the moisture increase on surface skin and contrary of the situation can be monitored when stress level decreases. (Liao et al., 2005) GSR variations can be measured with the help of electrodes placed on the first and middle fingers on the hand and studies show that there is a strong correlation between GSR and stressors likewise, cognitive load, work performance or uptight computer games. (Sharma \& Gedeon, 2012)

Galvanic Skin Response is comprised of two main components named as Skin Conductance Level (SCL) and Skin Conductance Response (SCR). While SCL provides measure of arousal, SCR can display the changes, in other words it shows response to stimulus. When emotions are categorized, their reflections on GSR values fluctuates as follows; when the subject feels anger it decreases, under fear increase can be observed and happiness doesn’t bring about change (Tóth, 2015). Figure 7 shows the characteristic increase in the GSR signal; 


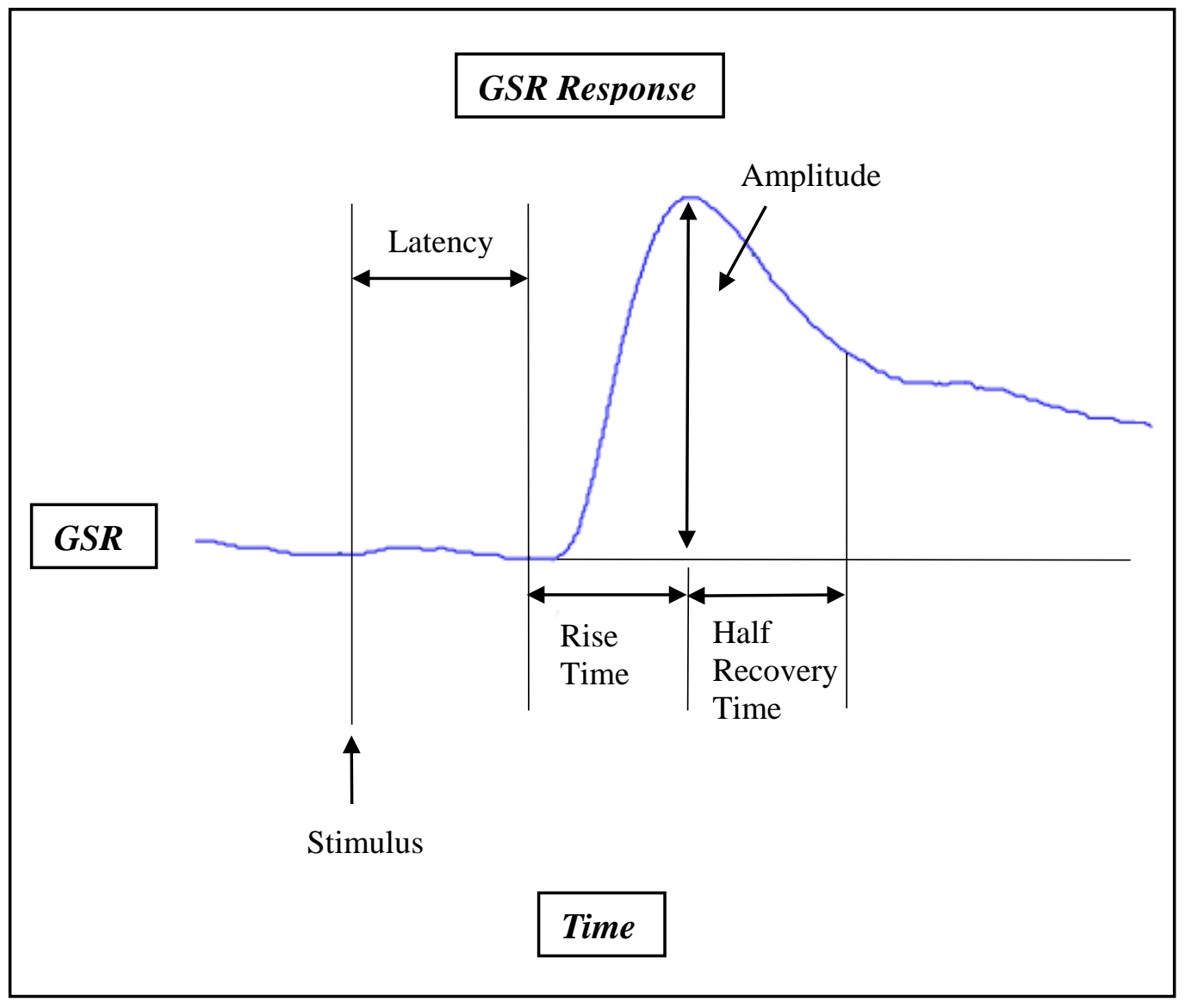

Figure 7: Example of a Typical GSR Signal (Barreto, 2008)

\subsubsection{Heart Rate Variability (HRV)}

Another way to monitor stress effect is measuring heart rate variability that perceives cardiovascular situation and ANS activities, it also shows the capacity of adapting with stress. Electrocardiogram (ECG) or named as electrocardiogram (EKG) is the way to measure HRV by recording electrical activity generated by an impulse of ions flowing through cardiac muscles. In order to deal with intense stress, heart frequency 
increases and this can be observed by decrease in ECG amplitude. (Sharma \& Gedeon, 2012)

\subsubsection{Brain Activity}

In the light of the researches, it can be mentioned that there is a relation between stress and brain activity (Dharmawan, 2007). There is a variety of methods can be used to analyze brain activity, which are functional magnetic resonance imaging (fMRI), positron emission tomography (PET) and electroencephalography (EEG) (Sharma, 2013).

The mostly used method EEG provides information about electrical signals that are caused by neural activity in brain. Frequency, amplitude, shape and sites of the scalp are the features analyzed from EEG waveforms and the following table explains the relation between frequency of EEG waveforms and person's state with respect to the stress (Sharma, 2013).

Table 2: EEG Frequency Band Categories (Sharma, 2013)

\begin{tabular}{|l|l|l|} 
Band & \multicolumn{1}{l|}{ Frequency } & \multicolumn{2}{l|}{ Person's State } \\
Category & Range (Hz) & \multicolumn{2}{l|}{ Alertness or anxiety } \\
\hline Beta & $13-30$ & Relaxation \\
\hline Alpha & $8-13$ & Dream sleep or phase between consciousness and \\
\hline Theta & $4-8$ & drowsiness \\
\hline Delta & $0.5-4$ & Coma or deep sleep \\
\hline
\end{tabular}




\subsubsection{Blood Pressure (BP)}

Blood circulation from minimum to maximum creates pressure on the walls of blood vessel and it can be related with the increase in stress (Pickering et al., 1996).

\subsubsection{Blood Volume Pulse (BVP)}

Blood volume can be described as the amount of blood in a blood tissue during a specified time and also BVP measures the light amount that skin surface reflects. After heart beat blood flows through the blood vessels and this brings about variation of light reflections which can be measured by Photoplethysmography (PPG) from the skin capillary bed of a finger and increasing stress level decreases BVP or just the contrary if the stress level decreases BVP rises (Sharma \& Gedeon, 2012).

\subsubsection{Skin Temperature (ST)}

Skin temperature can be monitored in addition to the other physiological measures and it has a negative correlation with stress level (Sharma \& Gedeon, 2012).

\subsubsection{Physical Characteristics}

\subsubsection{Behavior and Gesture}

If there is a chance to observe body pose or body motion than stress states can be evaluated with the help of body language (Sharma \& Gedeon, 2012).

\subsubsection{Facial Expression}

Facial features are the good indicators for emotional changes including stress level. Studies developed model based on facial expressions show that it can be used to 
determine and assess stress level. As an example, increase in head and mouth movements point to stress level increase (Sharma \& Gedeon, 2012).

\subsubsection{Eye Reactions}

Eye gaze, pupil diameter and blink rates the other features give information about the stress. Eye gaze provides information about people's attention source and also individual's mental states and intentions can be evaluated accordingly (Liao et al., 2005) . Another common indicator for stress is pupil diameter, increase in the diameter can be interpreted as individual is under stress. On the other hand, pupil diameter can be affected by both negative and positive stimuli; likewise, arousing sounds (Partala \& Surakka, 2003). Furthermore, blink rate can be measured to stress determination, but there is a conflict for this issue for which some of the researchers mention that blink rate increase caused by stress and some of them claim just the opposite (Liao et al., 2005). 
Accuracy for methods can be used for stress detection is ranked as follows;

Table 3: Empirical Ranking for Stress Measuring Methods (Sharma \& Gedeon, 2012)

\begin{tabular}{|c|c|}
\hline Rank & Measurement Method \\
\hline $\mathbf{1}$ & Heart Rate Variability (HRV) \\
\hline $\mathbf{2}$ & Galvanic Skin Response (GSR) \\
\hline $\mathbf{3}$ & Electroencephalography (EEG) \\
\hline $\mathbf{4}$ & Pupil Diameter (PD) \\
\hline $\mathbf{5}$ & Voice \\
\hline $\mathbf{6}$ & Eye Glaze \\
\hline $\mathbf{7}$ & Facial Expression \\
\hline $\mathbf{8}$ & Blood Pressure (BP) \\
\hline $\mathbf{9}$ & Skin Temperature (ST) \\
\hline $\mathbf{1 0}$ & Blood Volume Pulse (BVP) \\
\hline $\mathbf{1 1}$ & Eye Blinks \\
\hline $\mathbf{1 2}$ & Respiration \\
\hline
\end{tabular}




\subsection{Visualization Technology}

The main schema for a construction project is information belongs to project, teams performing on site and information delivery between them. In order to have a successful project, communication among stakeholders is the key point. With this purpose and having timelier, more accurate decisions, detailed construction activity information in real time with a visually likeable formats can be used. Consolidating this with real-time data conditions on construction field and related risky decisions can be controlled (Cheng \& Teizer, 2012).

Virtual reality can be described as the visualization of real world objects and scenes as real life images which can be used in practice and education for architectures, engineers and contractor involved in design and construction phases. The importance and effectiveness of virtual reality comes from the sense of presence and scale makes feeling like observing a realistic world (Cheng \& Teizer, 2012). Virtual reality methods can be grouped into two as desktop-VR and immersive-VR. While desktop-VR as shown in Figure 8 provides interaction through a computer monitor, immersive-VR exemplified in Figure 9 provides a direct interaction with the virtual environment (Setareh et al., 2005). 


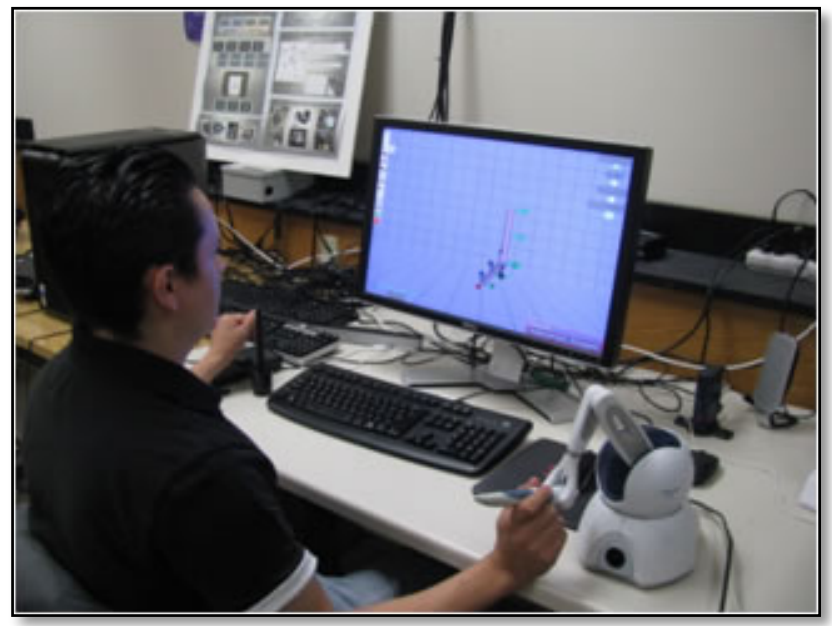

Figure 8: Desktop VR (retrieved from http://www.umbc.edu)

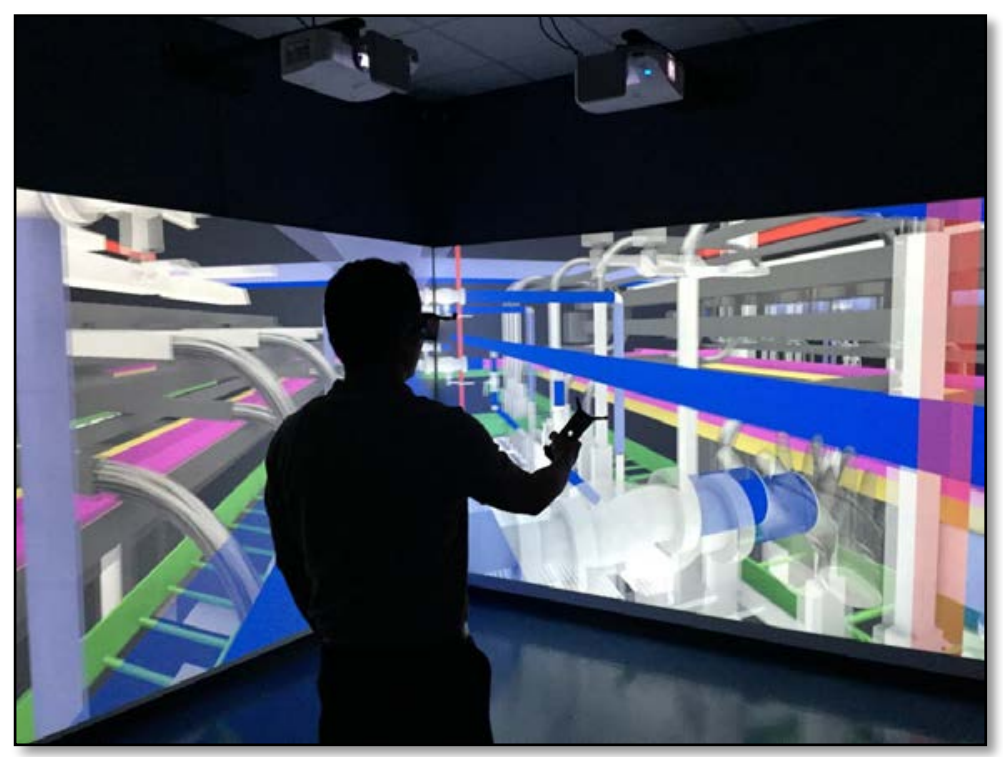

Figure 9: Immersive VR (taken from FIU Built Environment Informatics Laboratory)

Total immersive-VR, Semi-immersive VR and augmented reality are the three different types for immersive-VR, for which total immersive-VR creates and environment that user is totally immersed, semi-immersive VR keeps some parts of the physical world as seen and augmented reality is an extension format for semi-immersive 
method, it keeps the important information from both physical and virtual world (Lu et al., 2001).

\subsubsection{Benefits of using Virtual Reality}

The benefits of VR systems make them widely used as time goes by, with the help of this technology work environment and workers' safety behaviors can be improved by training and educating designers, planners and workers through front-end project phase. If real-time data is being used under potential incidents data visualization can be used to have more effective rescue by engineers and managers. Additionally all of these information can be documented and used for future safety practices and trainings (Cheng \& Teizer, 2012).

Virtual reality provides an active experience rather than a passive one and the person totally immersed in the environment is not distracted by external factors. It ease the process of analyzing and learning of complex subjects or designs. Since it is a virtual world there is no risk to simulate hazardous conditions with different scenarios in a realistic way. Safety training can be experienced in a more pleasing way with higher level of learning. When all of these benefits come together it is possible to save more on time and cost.

\subsubsection{Virtual Reality in Different Fields}

It is easily can be mentioned that virtual reality technology has a wide range of usage in a huge number of different professional fields. Analysis can start with health industry and diverse type of studies conducted with virtual reality. Sen et al. (2015) provides a research related with stroke which is a serious health problem result in severe 
disabilities. With respect to the stroke reports, after treatment $60 \%$ stroke survivors are discharged to home, $15-20 \%$ are to rehabilitation facilities and $20-25 \%$ of them are provided long-term care (Jusoh, 2006). Since the majority of the patients aren't cared for long term, recovery of motor function performance decreases. To prevent this virtual reality tools like; Nintendo Wii, Sony Play Station Move and Microsoft Xbox 360 Kinect gaming products are used to supply them a rehabilitation service at home without direct physiotherapist need (Sen et al., 2015). Another example from health industry can be given as haptics-based virtual reality periodontal training simulator, in which dental and hygiene students are trained in order to increase safety and reduce risk effect caused by human errors (Luciano et al., 2009). Moreover to health related researches, virtual reality can also be used to improve the assessment and treatment of eating disorders and obesity (Maldonado et al., 2015)

Above and beyond, training and sport topics can be combined and improved with virtual reality technology. According to Stinson \& Bowman (2014), virtual reality systems can initiate anxiety and stress by preparing them real-world high pressure conditions which makes athlete experiencing fail to perform what is expected. Apart from anxiety control for athlete, VR technology is used for college sports training. (Pan, 2015). Another utilization area for virtual reality is assembly planning and evaluation, it is used to have a successful product design process by considering time, sequence, ergonomics, operator safety and accessibility factors and aimed to reduce time and cost required for design. (Seth et al., 2010) Besides all of these different practice field for VR technology, it is even used to explore visual flicker preferences in honeybees. (Van de Poll et al., 2015) 


\subsubsection{Virtual Reality in Construction Industry}

The methods have been developed to advance hazard recognition for construction industry can be grouped as predictive and reactive methods. Predictive methods is based on scenario-structure for which workers identifies hazards with respect to different kind of activities by using job hazard analysis, task analysis and safety planning. The reactive method is usually developed based on previous experiences and projects. While predictive methods have limitations as isolation, biased assumption and higher safety knowledge requirement; reactive methods are not enough for future improvement, only contains small group of scenarios and transferring these information to workers is not convenient. The goal of integrating virtual reality technology into construction field is helping workers to forecast, identify and respond to possible hazards in advance they are exposed. (Chen et al., 2013) With this purpose Chen et al. (2013) developed an augmented virtuality (AV) environment to develop and test a new hazard recognition training system. They developed a four phase system in an order of; collecting data from different resources, importing proper BIM model to the Safety for Augmented Virtuality Environment System (SAVES), developing training scenarios and testing its impact on hazard identification skills.

The other safety areas that virtual reality integrated are real-time location and visualization technology for safety and activity monitoring (Cheng \& Teizer, 2013), safety checking of construction model and schedules (Zhang et al., 2012) and managing electrocution hazards by using VR simulation and cloud technology. (Zhao et al., 2012) Cheng \& Teizer (2013), developed a virtual reality scene representing construction site that contains live field data from dynamic resources. That was used to see the potential 
risk for workers nearby heavy equipment and it was aimed to make more enlightened decisions with less time and lower cost.

Moreover to training and safety purposes, virtual reality is used for structural analysis and a virtual structural analysis program is designed by Setareh et al. (2005), in which user can interact with building structures, assign gravity, wind and earthquake loads. Also the user can modify the structure accordingly the loads and structural values assigned for design, it can be tested and altered to get the optimum design results.

All of these examples are just an indicator for how virtual reality and the technologies has origin with a similar logic and range of application can be integrated into construction field related studies to have optimum results for safety, energy consumption, material usage and suchlike subjects.

\subsection{Case Studies - Stress Detection with Affective Sensing}

\subsubsection{Detecting Stress during Real-world Driving}

Healey and Picard (2005) collected data from a real-world driving task in order to analyze driver's relative stress level under normal conditions. For this goal they used physiological sensors like, electrocardiogram, electromyogram, skin conductance and respiration. Data collected from 24 drivers throughout the 50 min driving for which two different analysis are performed. 5-min intervals of data during rest, highway and city driving are used for Analysis I to see the effects of different driving environments on stress level and obtain results for low, medium and high stress levels; and Analysis II is consisted of 1-s intervals during whole driving period to see how stress level varies in detail. Analysis II is also supported by a video record. To get the main idea for research 
in a proper way two different kind of stress is described, that are named as 'eustress' and 'distress'. Eustress is a positive or good stress likewise, enjoy; however, paper focuses on the distress which has negative effects on individuals. Assumption aimed to prove was getting low, medium and high stress levels with the same order of rest, highway and city driving periods. The assumptions were validated with both questionnaire answered by drivers and videotape recorded through driving. Accordingly the results, it can be said that skin conductivity and heart rate measurements give the most reliable results and it can be said that stress levels were identified with an $97.4 \%$ inclusive accuracy.

\subsubsection{Stress Recognition in Typical Virtual Environment}

Sharma and Gedeon (2013) use physiological and physical signals to observe stress level during their research. While the physiological signals used are galvanic skin response (GSR), electrocardiogram (ECG) and blood pressure (BP), physical signals observed are eye gaze and pupil dilation signals. This paper presents a model of stress for subjects watching stressed and non-stressed film clips with the aim of seeing stress response with the different kind of signals being used. Twenty five undergraduate students (15 males and 10 females) with the age from 18 to 30 contributed this experiment. The experiment is practiced at two rooms named as acquisition and inquisition rooms. While the participant was watching film at inquisition room, the experiment instructor was collecting data at acquisition room. All of the signals used are labeled under a single name as primary stress signals and results collected from them had 95\% percent accuracy for stress classification. Also survey answers from participants showed that stressed and non-stressed film labels match with the results from both 
physiological and physical signals, which means that participants also found the same films stressful as they categorized. 
3. METHODOLOGY

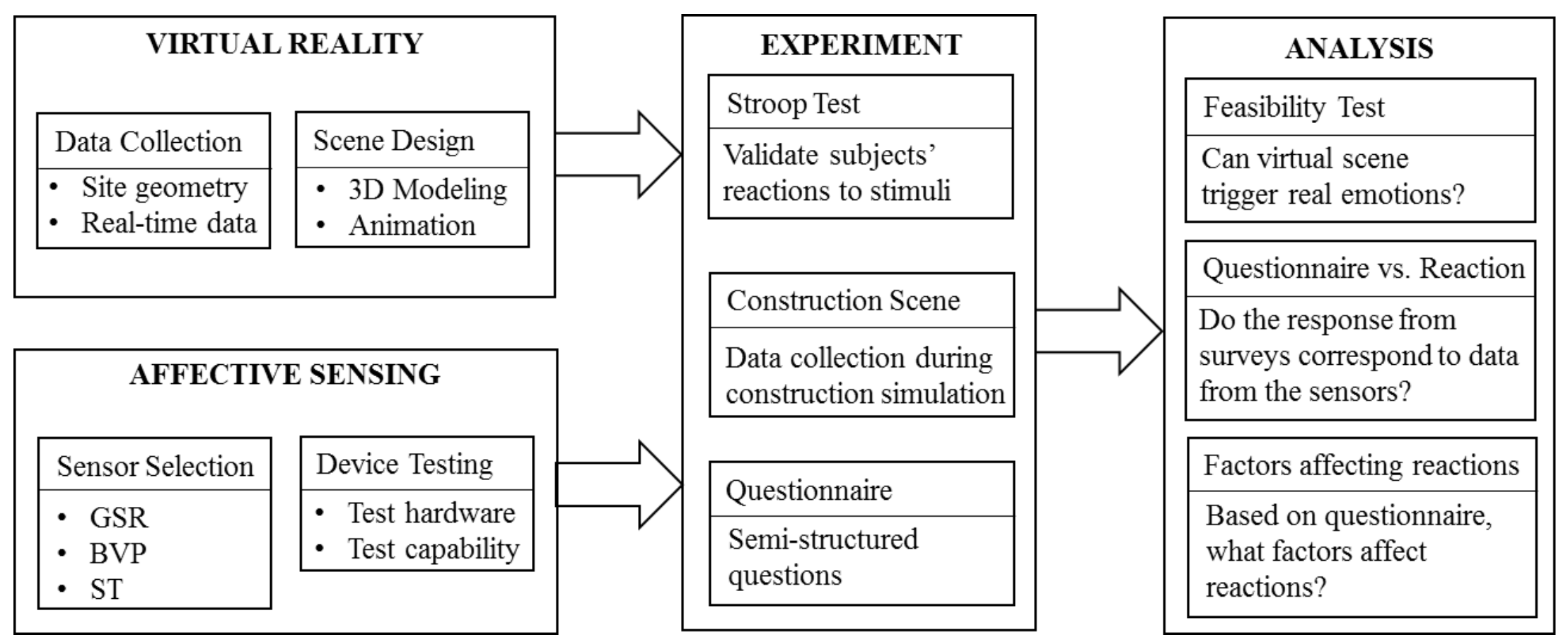




\section{VIRTUAL REALITY}

\subsection{Site Information}

The data used for scene design is provided from research that is dissertated by Pradhananga (2014). All of the information provided under this chapter is obtained from the dissertation titled as "Construction Site Safety Analysis for Human-Equipment Interaction Using Spatio-Temporal Data”.

\subsubsection{Data Collection}

To have a better understanding, first a construction environment can be described; it involves two components as the "site" where construction occurs and the second part is the resources like workers, equipment and material which are a part for overall construction process. Data collection part for the construction site both contains real-time location data and information about geometric conditions of the site. Site geometry can be described as the geometrical configuration of construction site that contains terrain of the ground, built components of the structure, site logistics and site layout plan. Real-time data is the one records dynamical changes; likewise, location of workers, equipment or material. Addition to them, data collection process is supported by pictures/videos and site notes.

For the optimum result technology that is economic, easy to install, not limited for specific task, small in size, with high frequency (one second or less), usable for outdoor, reliable and accurate is decided. Among the Radio Frequency Identification (RFID), Ultra Wideband (UWB), Global Positioning System (GPS) and vision technologies lowcost GPS loggers are chosen to collect spatio-temporal data. 
All the data used can be listed as follows;

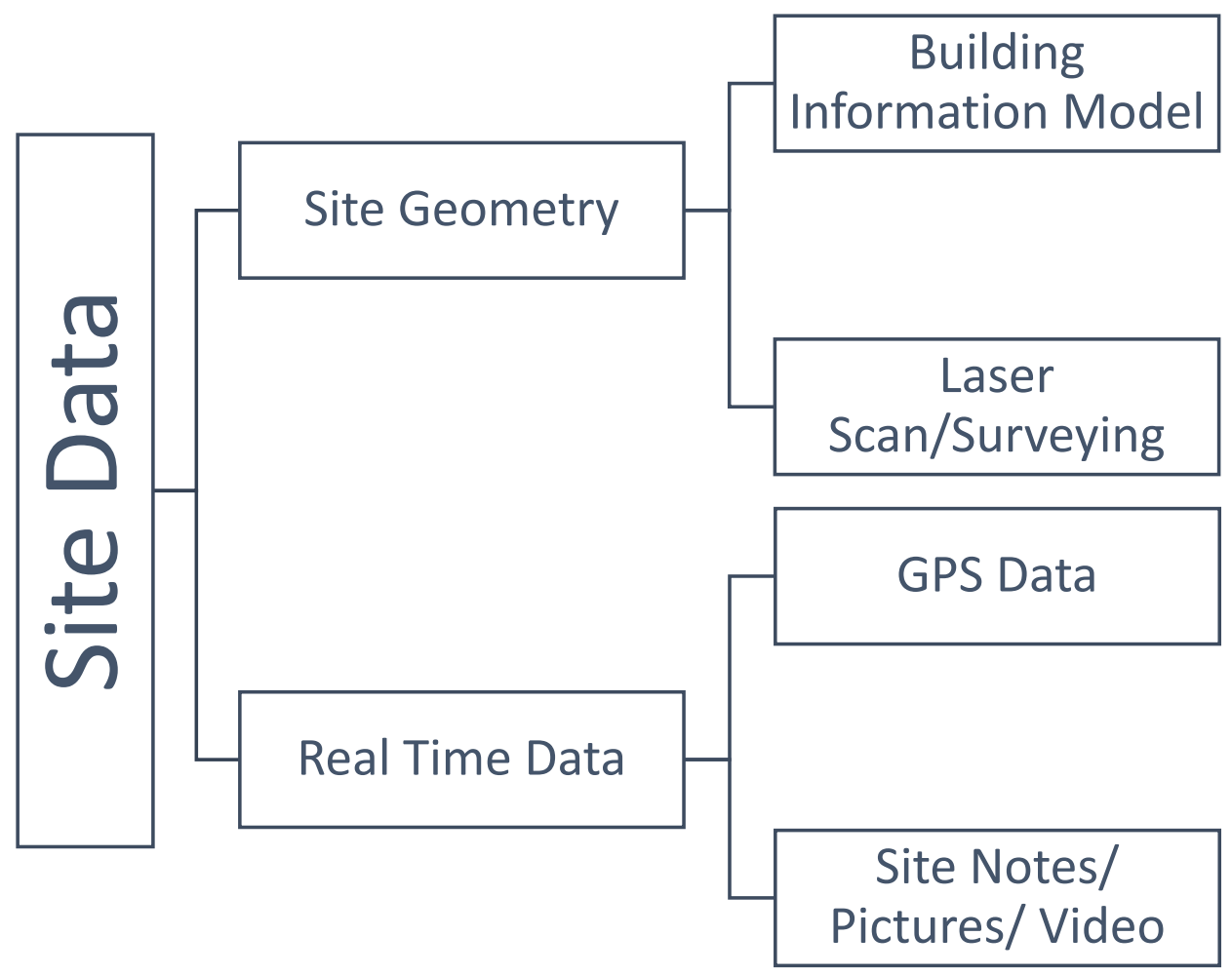

\subsubsection{Site Description}

Construction site belongs to The Engineered Biosystems Building (EBB) on the Georgia Institute of Technology Campus at the 10th Street and State Street intersection. The entire dimensions for site is approximately $120 \mathrm{~m} \times 100 \mathrm{~m}$. The excavation volume is 40,000 cubic yards and the period for excavation starts from November 28, 2012 and ends at February 18, 2013. Figure 10 shows the overall condition throughout the described activity and duration. 


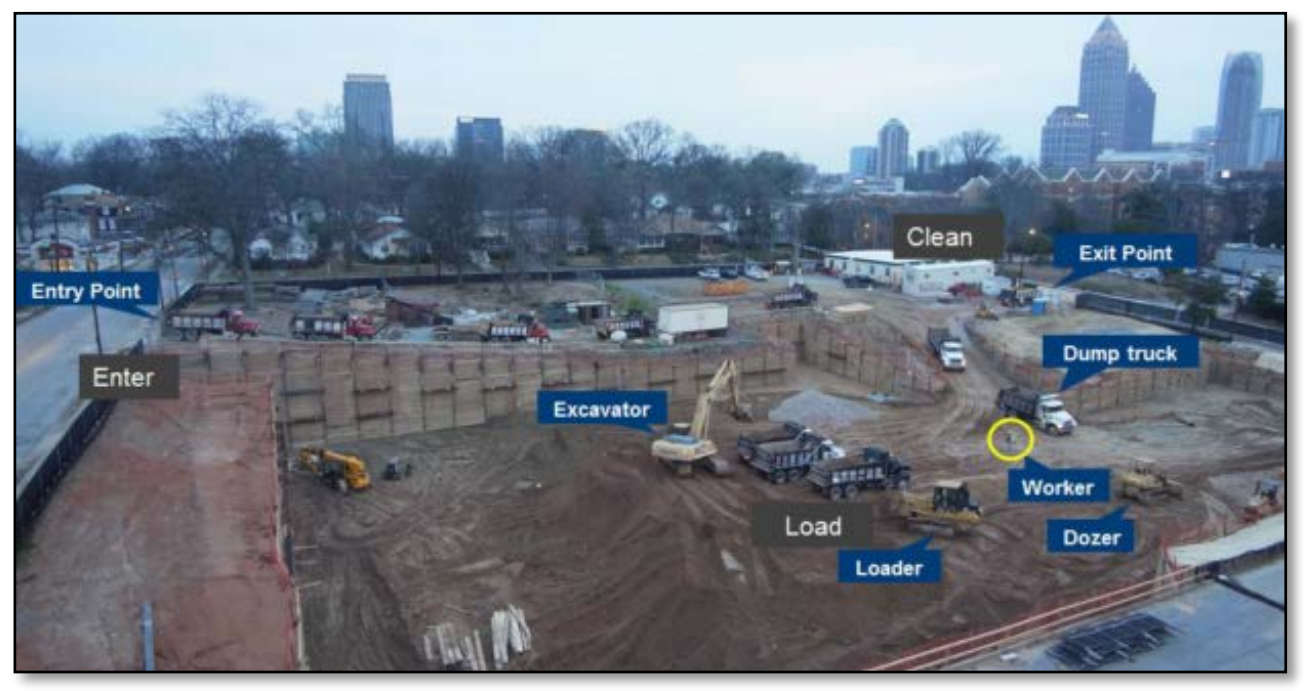

Figure 10: Site Overview (Pradhananga, 2014)

\subsection{Scene Design}

The devices used for this construction site simulation is virtual reality glasses Oculus Rift DK2 that can be seen at the following picture and the software used for designing animation is a game engine named as Unity3D.

The rift is a head-mounted display hardware developed by Oculus VR (Figure 11) which is used for totally immersive virtual scenes to provide the feeling of being in the reality. OLED panel that having a resolution of 1080x1020 are used for each eye and these panels have $90 \mathrm{~Hz}$ refresh rate with low persistence by displaying an image for 2 milliseconds of each frame. Unity is a game engine developed by Unity Technologies and can be used to as a development platform for 3D and 2D games creation. 


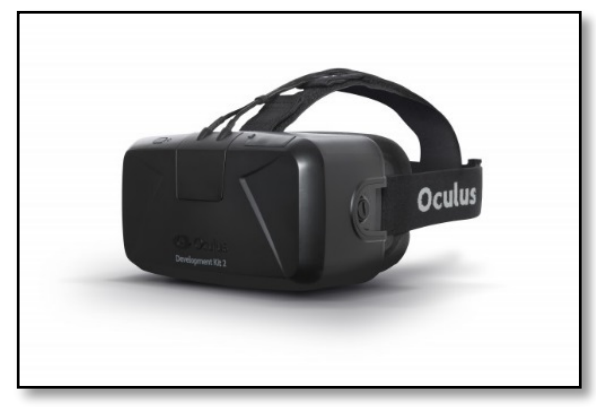

Figure 11: Oculus Rift DK2 retrieved from http://arstechnica.com/

To have a proper design for construction field simulation, the most frequent hazards and the related causes were analyzed. According to the previous information provided under background section four major construction injury causes are designed for simulation; fall, struck by, caught in/between and electrocution. For fall hazard, simulation includes one steel I-beam falls from crane into the middle of the side and one worker loses the balance and falls from the ladder while working besides the wall. Struck by is tried to simulate by using a worker passes by the truck with the aim of giving a feeling like near miss accident without showing a real crash between worker and truck. Caught in/between hazard is simulated with a cave-in scenario for which worker tries to rescue himself from the soil moves through him. Finally electrocution hazard simulated with the help of a group of electric pole that tip over after a sparkles show up from fires.

The real construction site is built in 3ds Max by using laser scanner data for The Engineered Biosystems Building (EBB) on the Georgia Institute of Technology Campus. After having 3D model with all necessary construction equipment and workers, model is imported in Unity3D to animate according to the scene designed. Succeeding pictures describe the way how the construction field is built in virtual reality. An overall picture 
for the site, laser scan data and the one created in 3D are shown in order as follows in Figure 12, Figure 13, Figure 14.

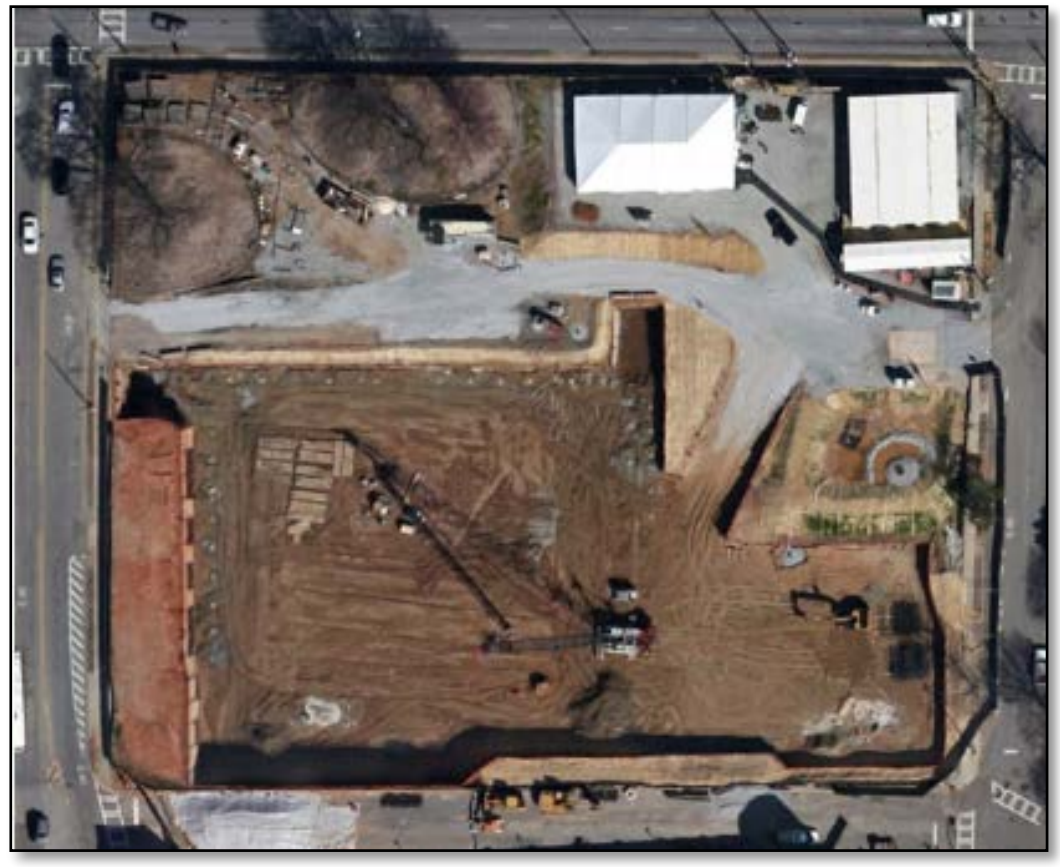

Figure 12: Satellite Imagery of the Site (Pradhananga, 2014) 


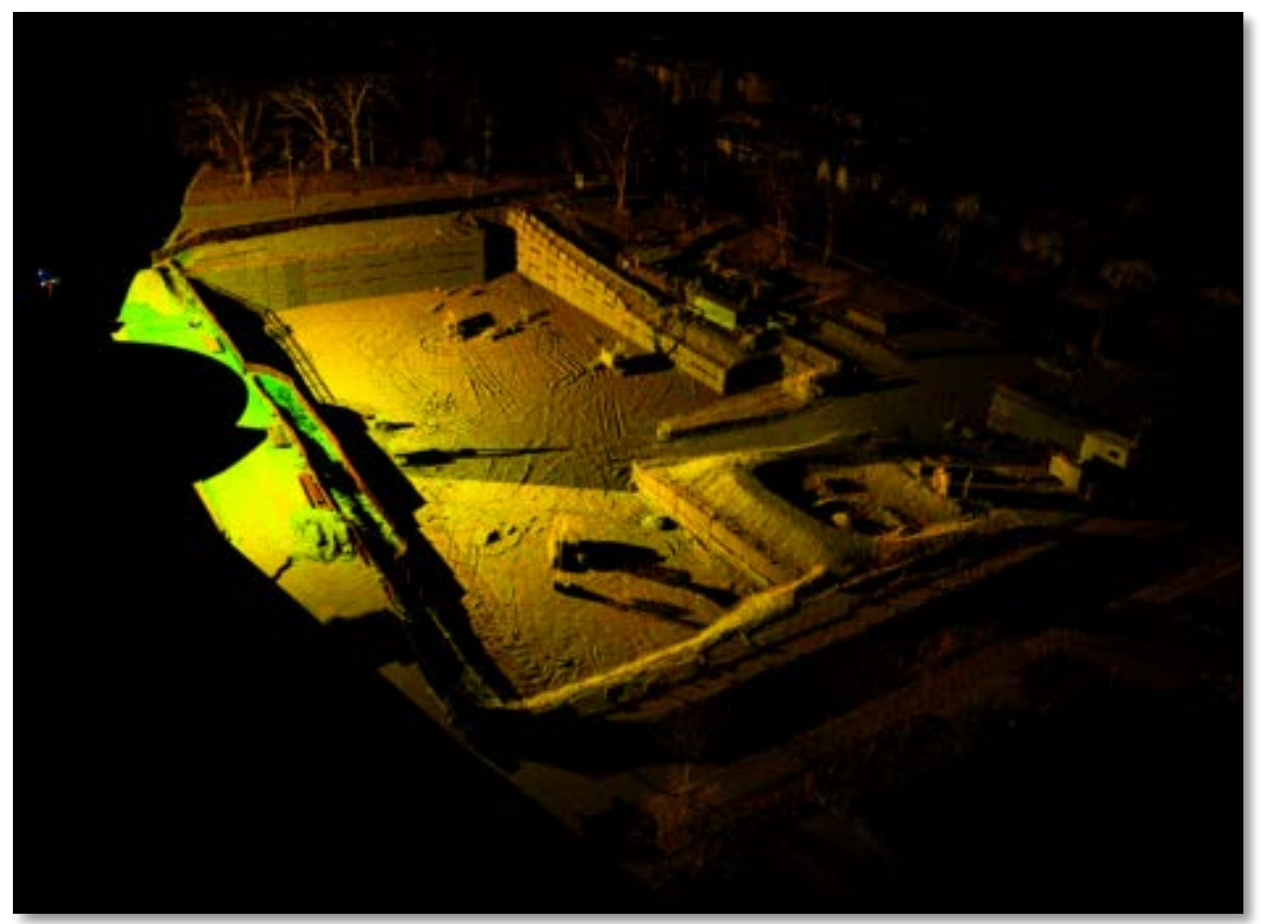

Figure 13: Laser Scan Data from the Site (Pradhananga, 2014)

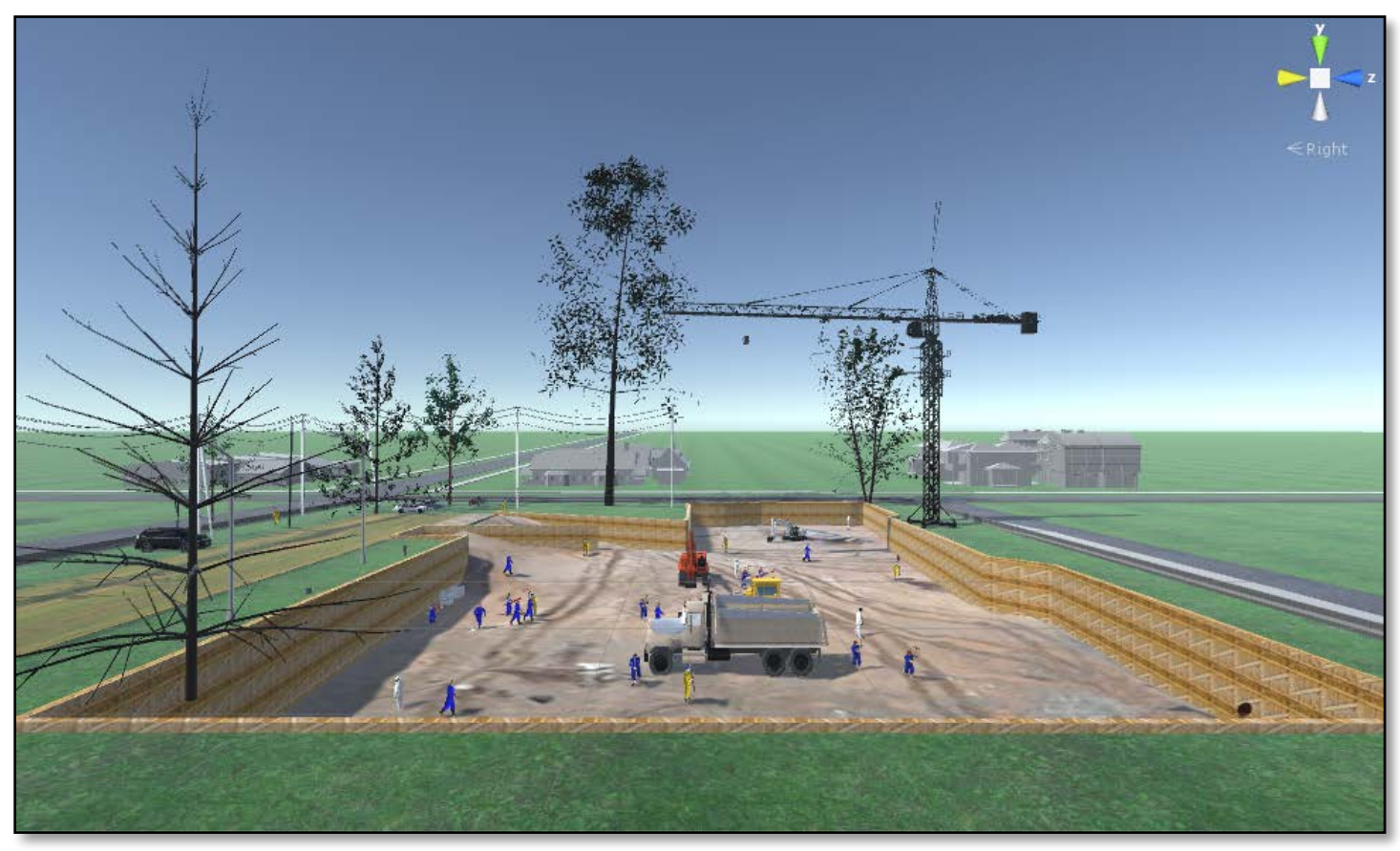

Figure 14: Construction Site Simulation on Unity 3D 
Total duration for the simulation is 370 sec with all major four hazards. During simulation a truck completes the pre-designed route in construction field, at the same time all distractions around the field take place in specific time. With the help of the camera set inside the truck subjects follow the path like an equipment driver. In order to correlate our results with the Stroop Test outcomes, scene is designed into two phase. For the first half continues for $180 \mathrm{sec}$, has less distraction and animation than the second half. With this purpose we expect to observe more stable stress recordings. The second half of the simulation contains more distractions, more hazard scenes and a lot number of workers and equipment to make our subjects more stressed. While watching the simulation subjects are asked to give input with a stopwatch whenever they see a moving worker with yellow clothes and stop sign holding in hand. We asked subjects to give input in order to see the relation between distractions in construction field and their effect on people attention for accident realization. We expect to get results show that subjects are more stressed when they need to perceive different things at the same time and by detailed analyzing we aim to make a comment about dual-task interference.

The first half of the simulation includes two major hazards and two moving yellow clothes worker need to be detected. Time schedule for these activities are; 
Table 4: Scene design for the first half of the simulation

\begin{tabular}{|c|c|}
\hline Activity & Time \\
\hline Yellow Worker 1 & $20-40$ sec \\
\hline Electrocution & $50-70 \mathrm{sec}$ \\
\hline Yellow Worker 2 & $65-80 \mathrm{sec}$ \\
\hline Caught in/between & $120-140 \mathrm{sec}$ \\
\hline
\end{tabular}

Second half of the simulation with more intense activities is as follow:

Table 5: Scene design for the second half of the simulation

\begin{tabular}{|c|c|}
\hline Activity & Time \\
\hline Yellow Worker 3 & $155-180 \mathrm{sec}$ \\
\hline Material fall (Steel I-beam) & $170-180 \mathrm{sec}$ \\
\hline Struck by & $210-220 \mathrm{sec}$ \\
\hline Yellow Worker 4 & $230-250 \mathrm{sec}$ \\
\hline Yellow Worker 5 & 240-270sec \\
\hline Fall from ladder & 285-290sec \\
\hline Yellow Worker 6 & $275-300 \mathrm{sec}$ \\
\hline Yellow Worker 7 & $305-320 \mathrm{sec}$ \\
\hline Yellow Worker 8 & $315-330$ sec \\
\hline
\end{tabular}


The following pictures demonstrate the scene design for mentioned stress stimuli;

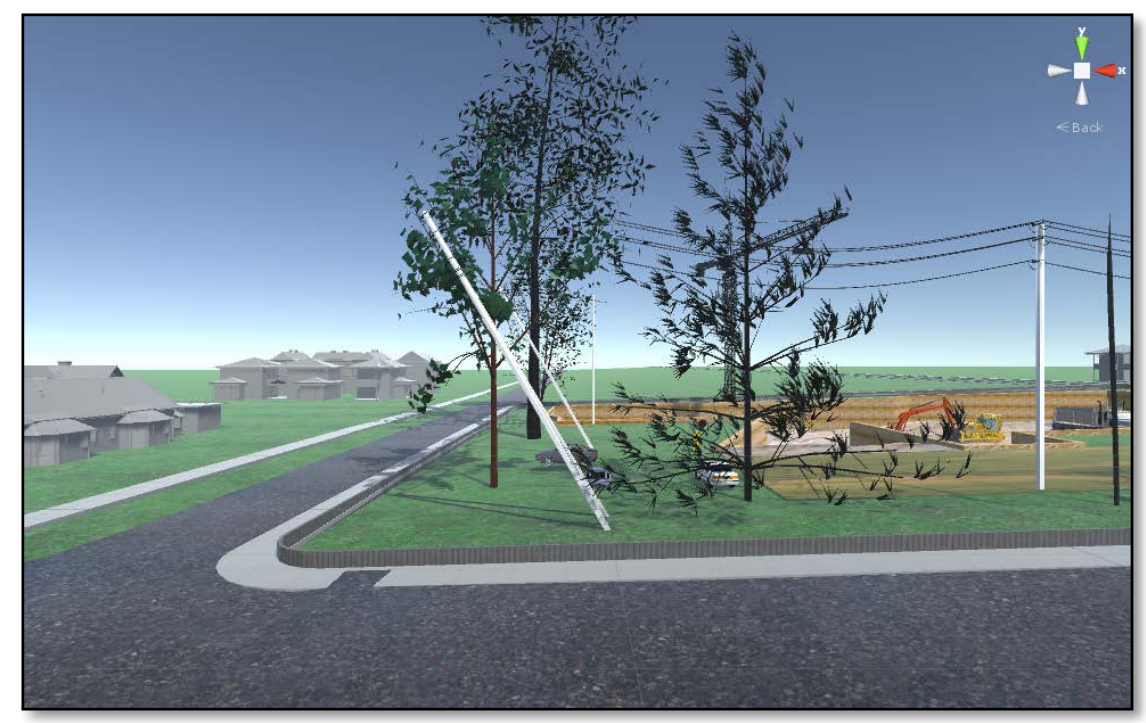

Figure 15: Electrocution Scene

To demonstrate electrocution hazard can be seen in Figure 15, electric poles can be seen on the picture are moved with an increasing angle until they hit the floor.

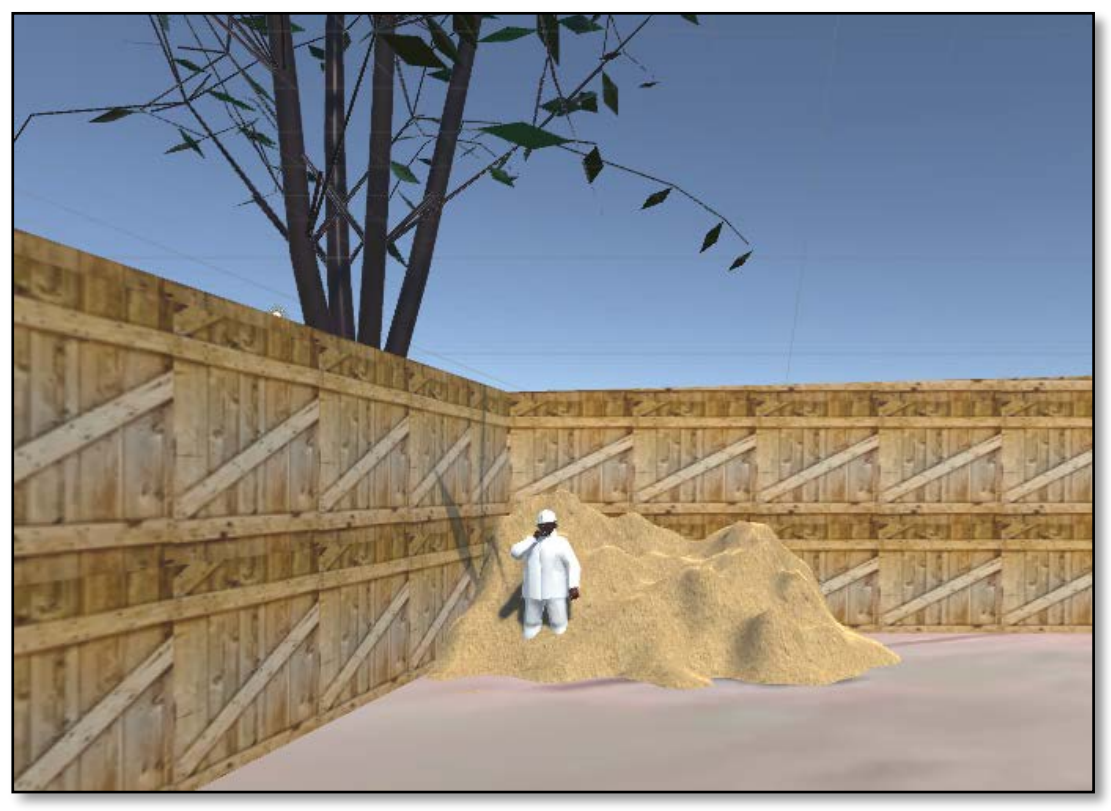

Figure 16: Caught in/between Scene 
As can be seen in Figure 16 caught in/between scene is demonstrated with a worker who is being caught by an amount of soil and tries to escape from the soil.

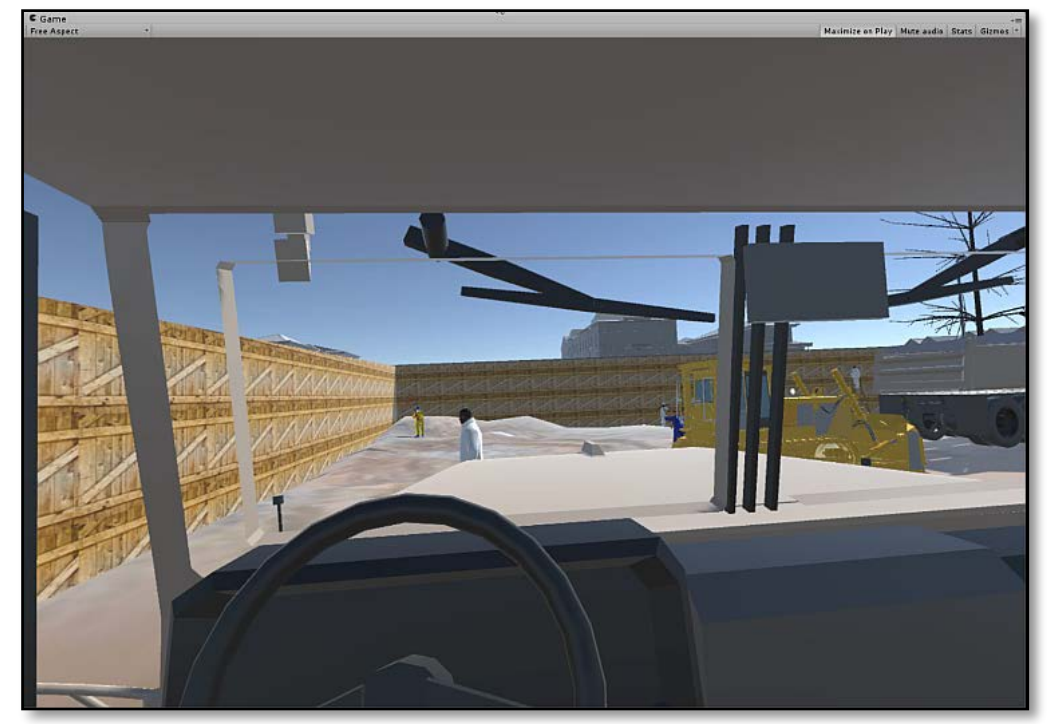

Figure 17: Struck by Scene

As Figure 17 shows, in order to give struck by feeling a white worker is animated accordingly to pass from the frontal part of the truck at last moment without hitting.
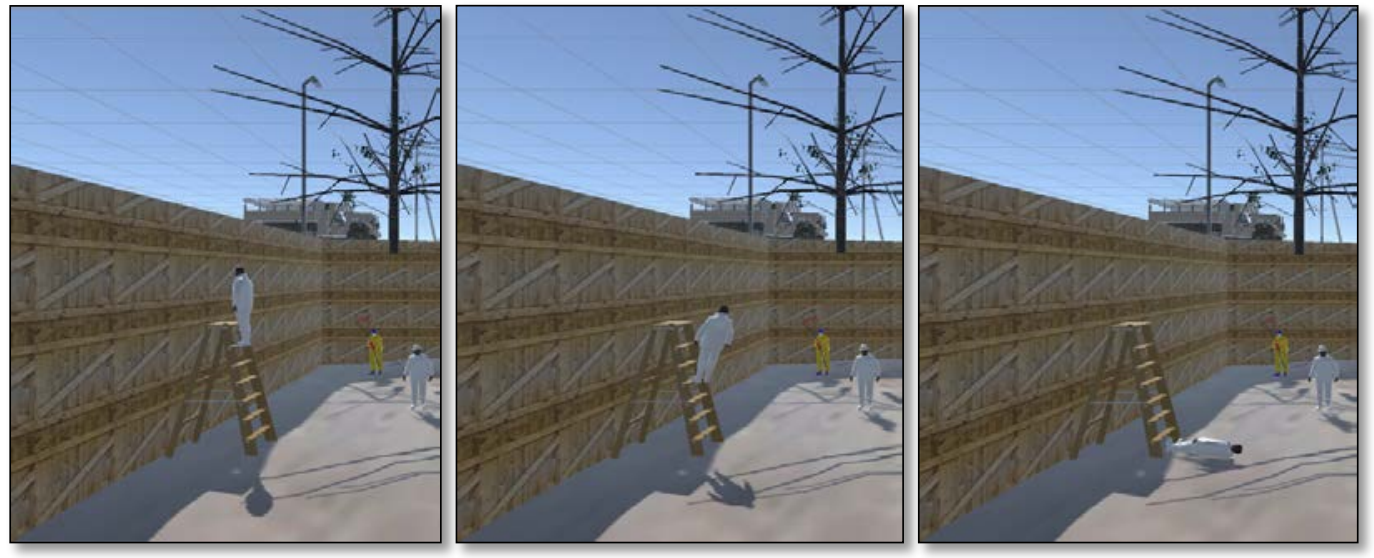

Figure 18: Fall from Ladder Scene 
With the help of Figure 19 movement of the yellow worker can be demonstrated as described previously and as following, Figure 20 shows the overall picture for simulation through 370 sec.
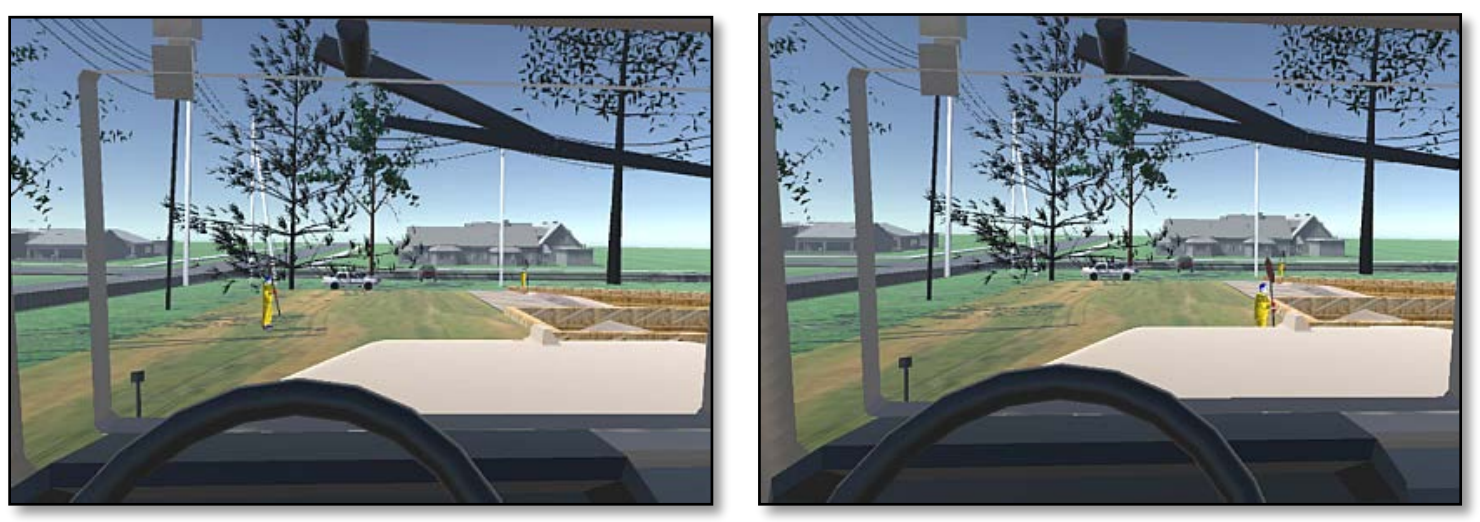

Figure 19: Movement of the Yellow Worker 


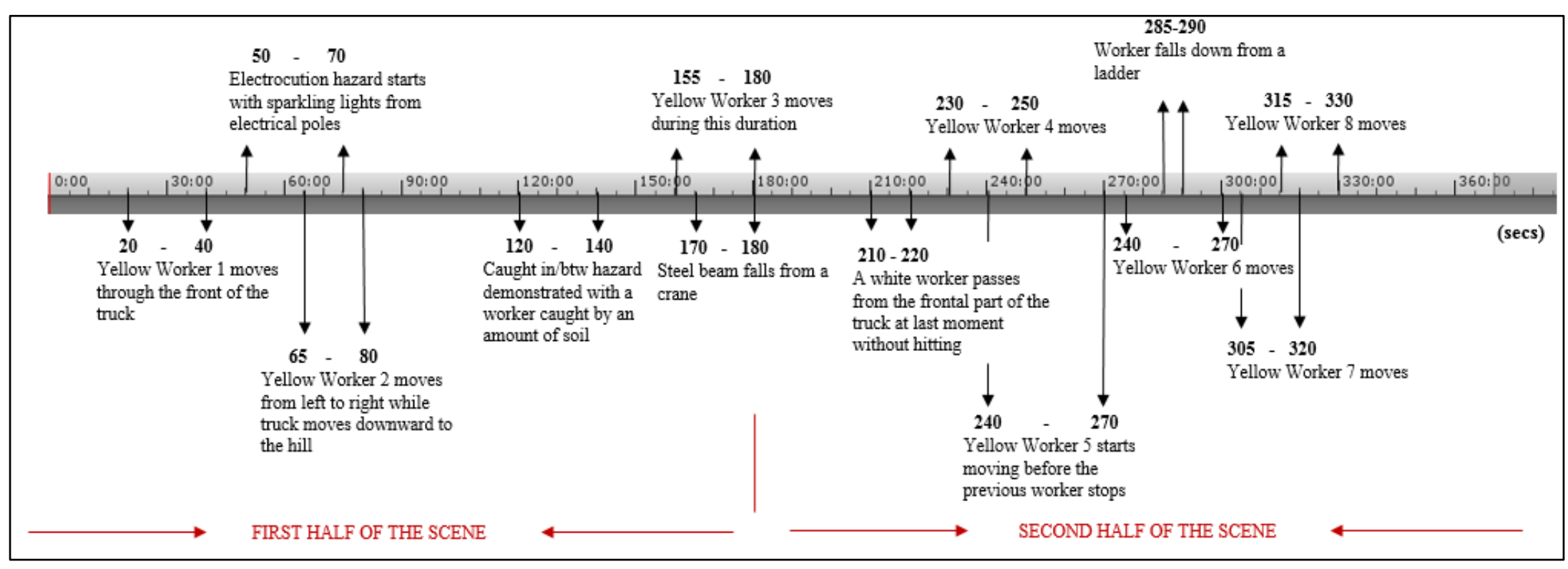

Figure 20: Simulation Schedule 


\section{AFFECTIVE SENSING}

\subsection{Experiment Sensor}

The common sensors used for non-intrusive stress monitoring are galvanic skin response (GSR), electrocardiogram (ECG) to monitor heart rate variability (HRV), electroencephalography (EEG) for brain activity, blood pressure (BP), blood volume pulse (BVP), skin temperature (ST) and respiration. Among these alternatives the best options for our experiment are decided according to the following criteria;

- $\quad$ The technology should be economic.

- The sensor should be easy to install and use.

- The technology should provide reliable and accurate measurements.

- Data collection and synchronization processing should not require an inordinate amount of manual work and time.

- $\quad$ Since the experiment phase of this research requires additional hardware as Oculus Rift DK2 glasses, it should be possible to use sensors with glasses.

- Sensors should correspond the needs for an accurate stress recognition.

With respect to the described needs, sensors need eye contact are eliminated (pupil diameter, eye gaze, facial expression and eye blinks). Sensors requires more time to adjust and install or the ones require more professional background are also eliminated. (HRV, EEG and respiration). As a result we decided to use Galvanic Skin Response (GSR) sensor, which provides accurate and reliable results, as main stress recognition method for this thesis. Besides GSR, for future researches and developments for this topic we decided to collect data with Blood Volume Pulse (BVP) and Skin Temperature 
Sensor (ST). The following table can be taken as reference for the expected stress level and emotional changes.

Table 6: Different Physiological Measurement Changes (Tóth, 2015)

\begin{tabular}{|c|c|c|c|}
\hline Emotions & \multicolumn{1}{|c|}{ GSR } & BVP & Temperature \\
\hline Anger & Decrease & Increase & Increase \\
\hline Fear & Increase & Increase & Decrease \\
\hline Happiness & No change & Normal & No change \\
\hline
\end{tabular}

\subsection{GSR Mechanism}

Changes in electrical conductance on skin result from alteration in one's psychological state. The way to measure is applying a constant voltage to the skin with the help of electrodes which are measuring the current flow. When the surrounding events trigger the sympathetic nervous system, sweat glands are activated and accordingly skin conductance and amount of sweat in hand increases. (Busing, 2014)

\subsubsection{Choosing Sensor Device for Experiment}

Neulog GSR logger sensor NUL-217 in Figure 21 that has two ranges as conductivity in microsiemens and arbitrary numbers is used for the experiment. Measurement units can be described as follows;

Micro Siemens ( $\mu S)$ : Unit for electrical conductance

Arbitrary Analog Units (Arb): Arbitrary unit for waves, frequencies and periods 
Sensor is pre-calibrated during factory process and includes two components as durable rubber-coated wires and two white Velcro finger connectors with a maximum sample rate 100 per second and maximum 31 days duration.

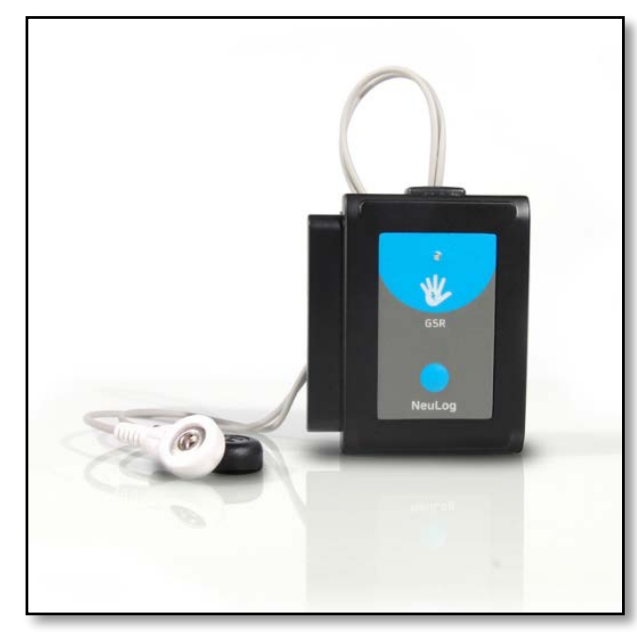

Figure 21: Neulog Galvanic Skin Response Sensor (retrieved from http://www.arborsci.com/)

\subsubsection{Testing GSR Sensor}

To test and understand sensor mechanism a test is executed as following steps and the result graph obtained as in Figure 22;

- Sensor system was set up on the computer and activated.

- $\quad$ The subject was asked to rub his hands and make them warm.

- Areas on subject's finger were moistened by a wet cotton pad and finger electrodes were attached.

- The subject took a position can feel relaxed and closed his eyes. A silent environment was provided during the experiment in order to prevent distraction.

- $\quad$ Range for the measured response value was arranged as arb units. 
- Then the subject tried to be stimulated by touching, air movements and strong aroma smell.

- $\quad$ First the subject's ear was lightly touched, then his shoulder and since the subject was habituated by touching third stimuli was blowing across his face and finally it was followed by a perfume aroma.

- It is possible to observe a time delay between stimulation and response which is approximately 0.8 to 4 seconds.

- The overall graph was as follows, for which three distinct increase were observed after the first three stimuli. However, it can be seen that GSR value keeps increasing after third stimuli which is explained by the subject as expecting another one and trying to figure it out made him tensed.

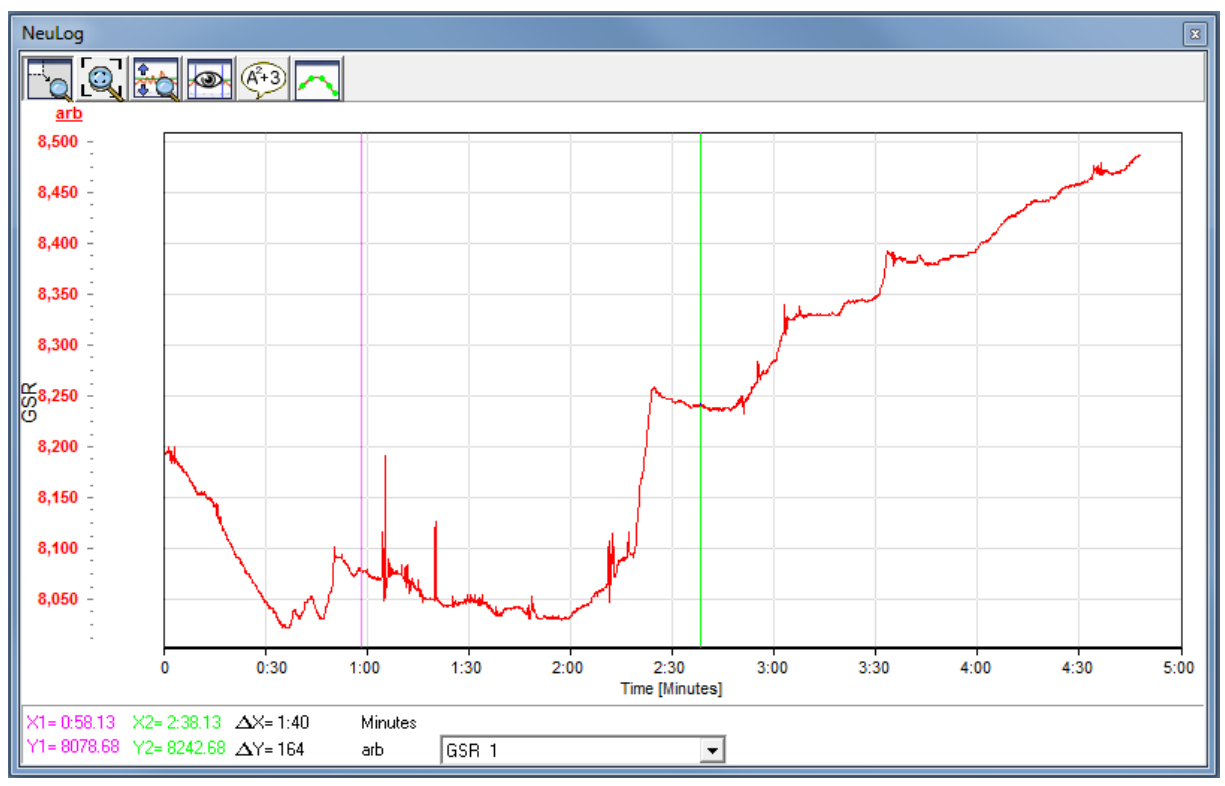

Figure 22: Experiment for Sensor Test 
Besides that in order to test the sensor different kind of clips are watched and the results are monitored. As demonstrated in Figure 23 fear clip results show an continuously increasing GSR values with a variety of peak points, after fear clip a relaxing music is listened by meditating and the values decreased as in Figure 24 without peaks which shows emotional changes. Following one labeled as Figure 25 shows GSR change while watching a funny clip, in which funny stimuli can be observed as peak points in graph. All of these results can be interpreted as GSR sensor going to be used during experiment is successful to detect emotional changes.

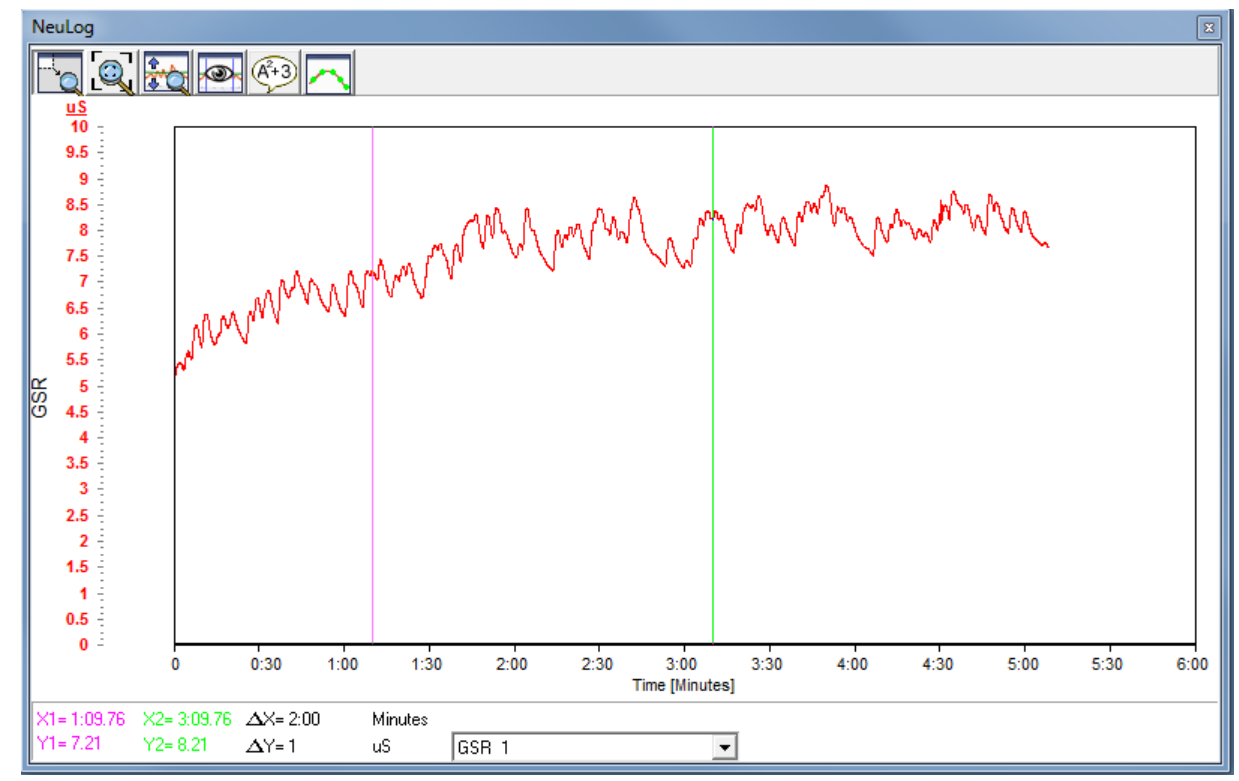

Figure 23: GSR Values with a Fear Clip 


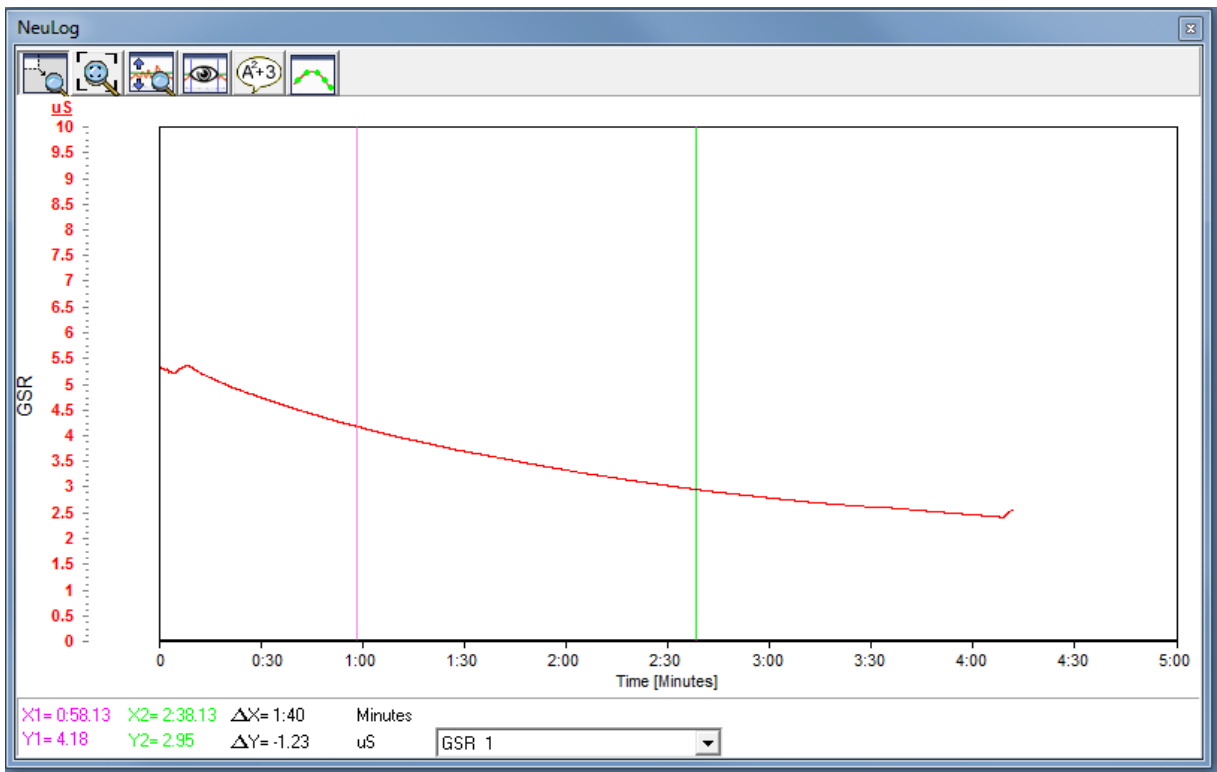

Figure 24: GSR Values with a Relaxing Music

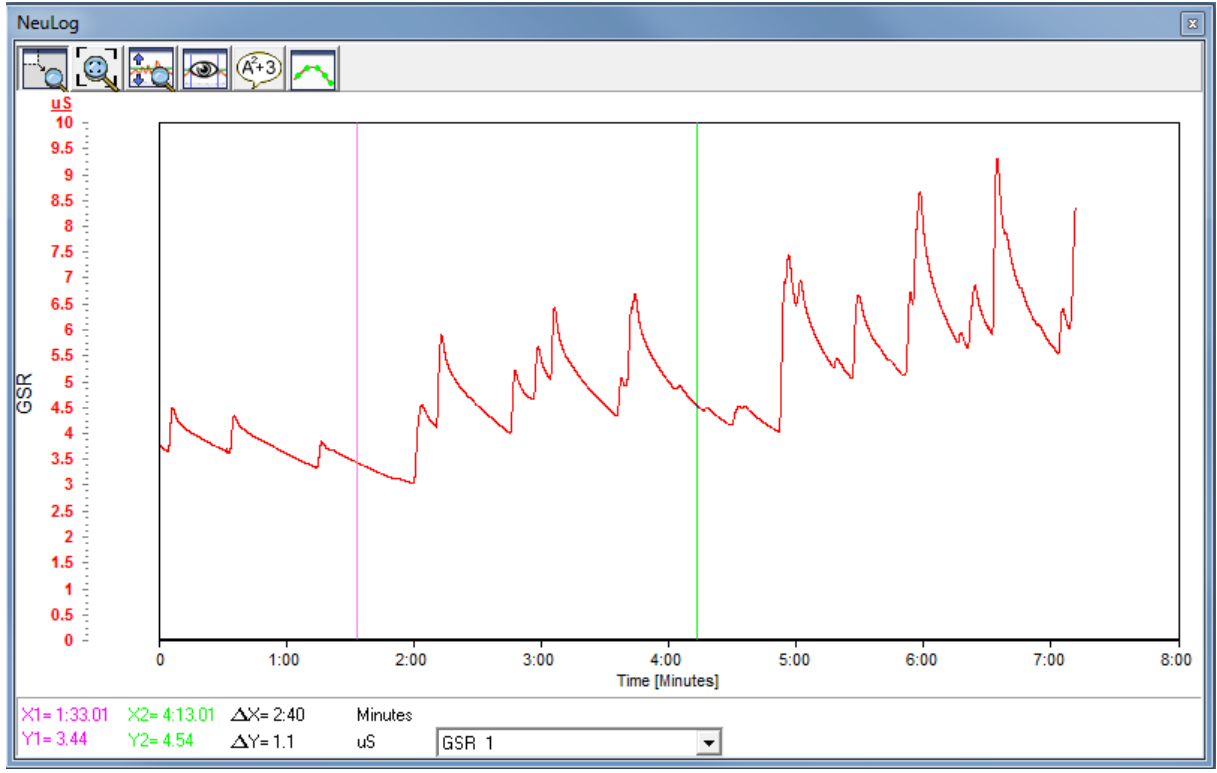

Figure 25: GSR Values with a Funny Clip 


\section{EXPERIMENT}

Experiment group includes 12 subjects in which majority of the group consists of graduate students have education and background in construction field with an age range can be described as above 25 years old.

\subsection{Stroop Test}

The Stroop test is a mechanism usually used for measuring one's mental and cognitive capacity throughout the performances require cognitive processing. (Nguyen et al., 2015)

The original Stroop Test contains four parts, the first step subjects just reads the names of color written in black ink, in second step they need to read the name of the colors written with different colored ink this time, third step includes colorful squares and subjects need to tell these colors and final step subjects need to repeat second step but by saying the color of the ink, not the word written. (Stroop, 1935)

The Victoria version developed in 1984 (Regard, 1984) has there steps which are, first recognizing names of the colors written in black ink, in second step subjects need to tell the name of the colors for colorful squares and at the final step includes name of the colors with different colored ink. Subject should give a quick response in first step and this needs to be followed by saying color of the circles and printed words, respectively.

The Stroop Test developed for this research is a based on the model called as “Paced Stroop Test” designed by Zhai \& Barreto (2006). With this interactive Stroop Test method, subjects are asked to click on one of the five buttons on the screen within a time limitation 3 seconds (Figure 28). If the subject cannot give an answer, the system 
automatically moves to the next trial. The system involves two parts named as “Congruent Segment” (Figure 26) and “Incongruent Segment” (Figure 27), in detail congruent segment has 45 trials in which meaning of the word and the font color matches and incongruent segment has 30 trials with different word and color.

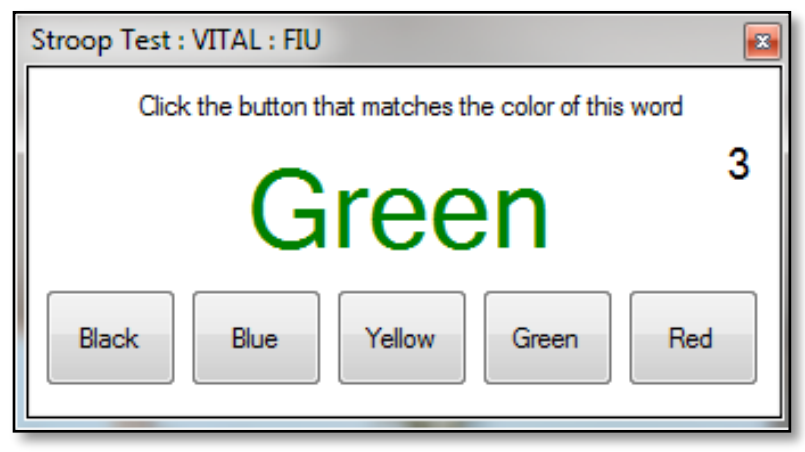

Figure 26: Congruent Stroop Test

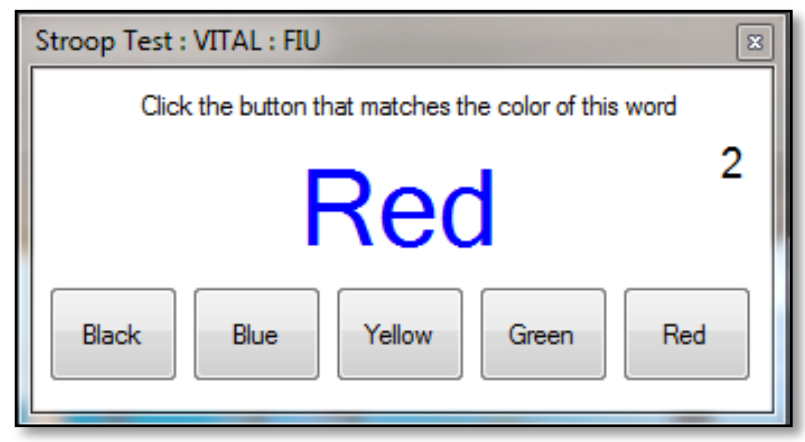

Figure 27: Incongruent Stroop Test

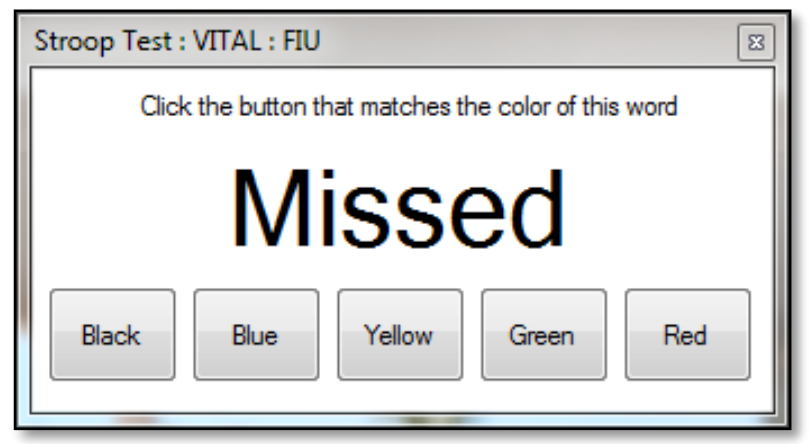

Figure 28: When trial was not replied 
The purpose to design this stroop test part for our experiment is analyzing subjects' reactions under a validated stress recognition process. According to the previous stroop test researches (Zhai \& Barreto, 2006), we expect to see subjects are stressed during incongruent segment. These results can help to analyze subjects' reactions under stress and correlate them with the outcomes obtained from virtual reality experiment.

\subsection{Scene}

Scene part of the experiment includes two parts as the simulation that we developed and the demo scenes comes with the Oculus Rift DK2. The aim to show two different virtual reality scene is analyzing the difference of the sensor values and observing the effect of the scene quality on results. In other words, these can help our feasibility study to come up with a result whether virtual reality make subjects stressed or not.

Firstly construction field simulation which is pictured in Figure 29 is played and sensor results are recorded, this is followed by demo scenes named as Tuscany and Helix which is shown in Figure 30 and Figure 31 with a following order. Tuscany demo includes a two story building with a big yard and gives opportunity to subjects control environment by using keyboard arrows. Helix demo is a rollercoaster ride simulation, subjects do not need to give any input to control the scene. We wanted to give choosing option to our subjects, in case they feel uncomfortable with rollercoaster scene they have opportunity to try other option. 


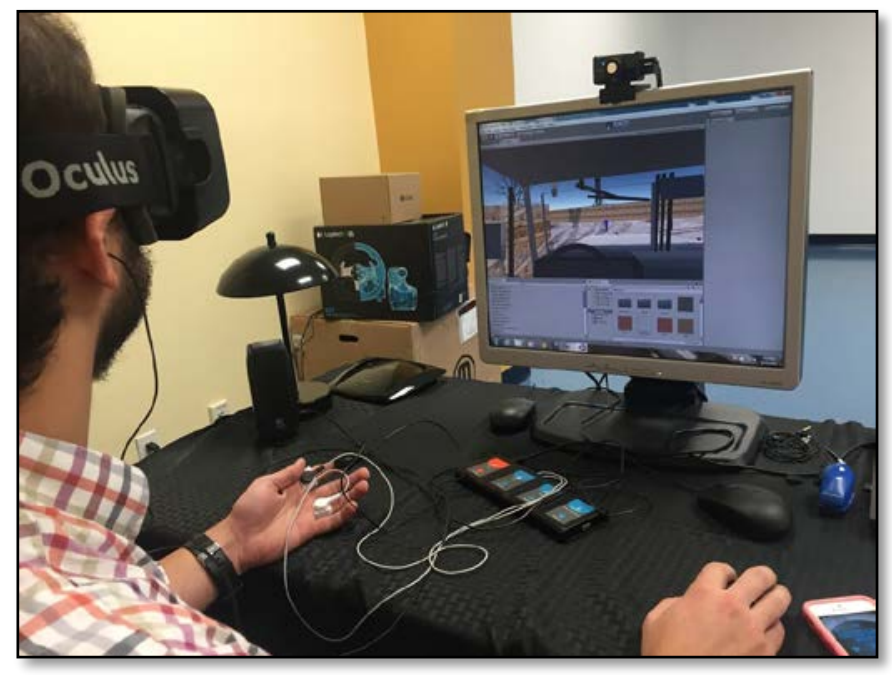

Figure 29: Picture from the Experiment

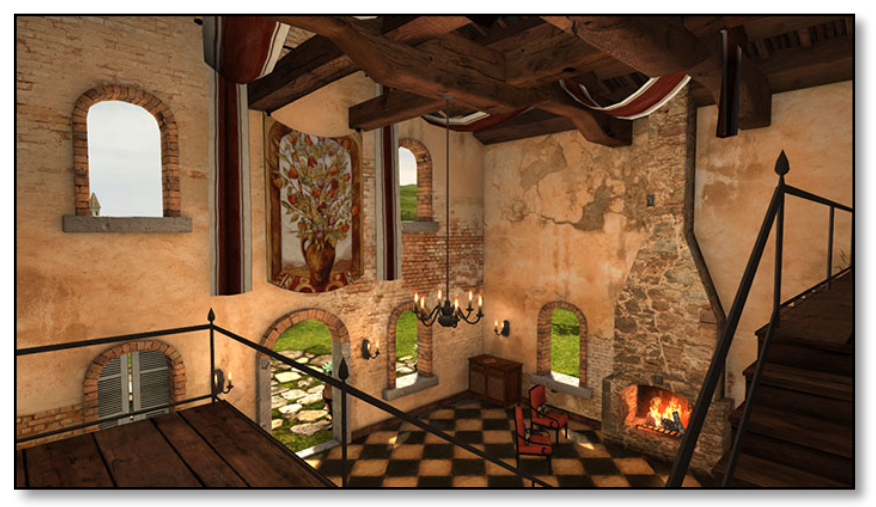

Figure 30: Oculus Tuscany Demo Scene

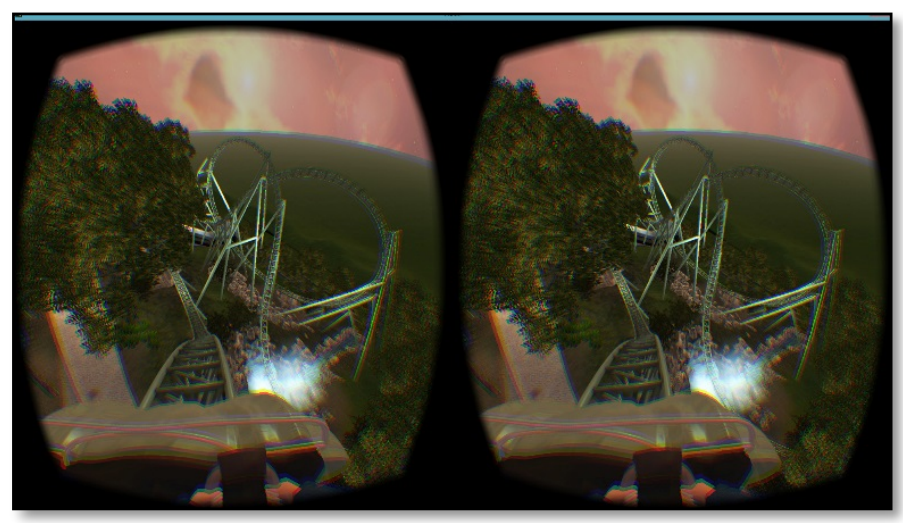

Figure 31: Oculus Helix Demo 


\subsection{Questionnaire}

We prepared a questionnaire with subjective questions to see the perception and reaction of our subjects for experiment. The following questions have different purposes to prepare.

First question aims to analyze subjects' reaction to the scene we developed, understanding whether they find it realistic or not helps to analyze effect of reality.

Answers for second question can correlate the relation between each subject and their results, with respect to their general sense for stress.

Third question is prepared to understand which of the four fatal construction hazards has the biggest impact on the subjects.

Fourth question can help us to see the feasibility of the devices, sensors we use during our experiment; whether numeric results and the feelings can be correlated or not.

Final question can show the effect of expectation, which means that if workers are trained or well educated about the hazards on construction field their anticipation may help them to control their stress or anxiety.

\section{Questions}

1. How was your experience with the virtual scene compared to real world?

Poor, Fair, Good, Very Good, Excellent

2. How do you assess your attitude for extraordinary situations in daily life; stay calm or panic? 
3. Which part(s) of the scene made you feel excited?

4. Do you think the data we gathered (changes in affective parameters) reflects your emotional reaction during the experiment?

5. Do you think your reaction might have changed because you were anticipation matched what you saw in the virtual scene?

\subsection{Experiment Schedule}

At the beginning of the experiment, subjects are informed about the system we are using and their approval for participation received with the help of Institutional Review Board (IRB) form. The most important for the experiment preparation, they are informed about their right to leave experiment whenever they want and additional questions are answered to enlighten them.

After information session, subjects are prepared for the sensors that described in previous chapters. GSR, BVP and ST sensors are placed on their left hand and they are asked to keep left hand in rest position. With their right hand, they are asked to give input with mouse click.

System setup is followed with the first step of the experiment: Stroop Test. During the test their sensor results are recorded separately for congruent and incongruent segments.

Following Stroop Test, subjects are asked to put on Oculus and headphones in order to feel totally immersed virtual reality simulation. During simulation, subjects are asked to give input with their right hand by using a stopwatch whenever they see the workers described under Scene Design chapter. 
After construction site simulation, as described under Scene chapter subjects are asked to choose whether Tuscany or Helix demo scenes and during demo run their stress level is recorded with sensors.

With respect to the results collected subjects reply subjective questions mentioned in Questionnaire section and answers are discussed together by running the 2D simulation video record. To have a better explanation Figure 32 is developed that shows overall experiment schedule with approximate durations. 


\begin{tabular}{|l|l|l|l|l|}
\hline \multicolumn{3}{|c|}{$\mathbf{5 5}$ sec } \\
Incongruent Stroop Test \\
Incongruent Stroop Test is the \\
one subjects tried to reply the \\
answers 30 trials with different \\
word and color
\end{tabular}

Figure 32: Overall Experiment Schedule with Approximate Durations 


\section{ANALYSIS}

\subsection{Stroop Test}

Stroop Test is performed to see our subjects' reaction under stressful conditions, it is aimed to validate sensors used for experiment with the help of this test. As described in previous chapters, it is expected to observe higher Galvanic Skin Response (GSR) values under tension. To observe this change, subjects are asked to relax before the test and their sensor results are recorded during this relaxation period. This step is followed by congruent and incongruent phases, in which a continuous increase in GSR values are aimed to monitor. As a general results, most of the subjects reacted as anticipated; besides a few number of them reacted in different ways which can be analyzed as an indicator for their reaction under tension.

The graphs belong to subjects numbered as 12,11 and 7 are the ones gives the expected increase in GSR mean value results for the relaxation phase and other two steps for Stroop test. Related sensor results can be seen in the figures with a following order as; Figure 33, Figure 34, Figure 35. 


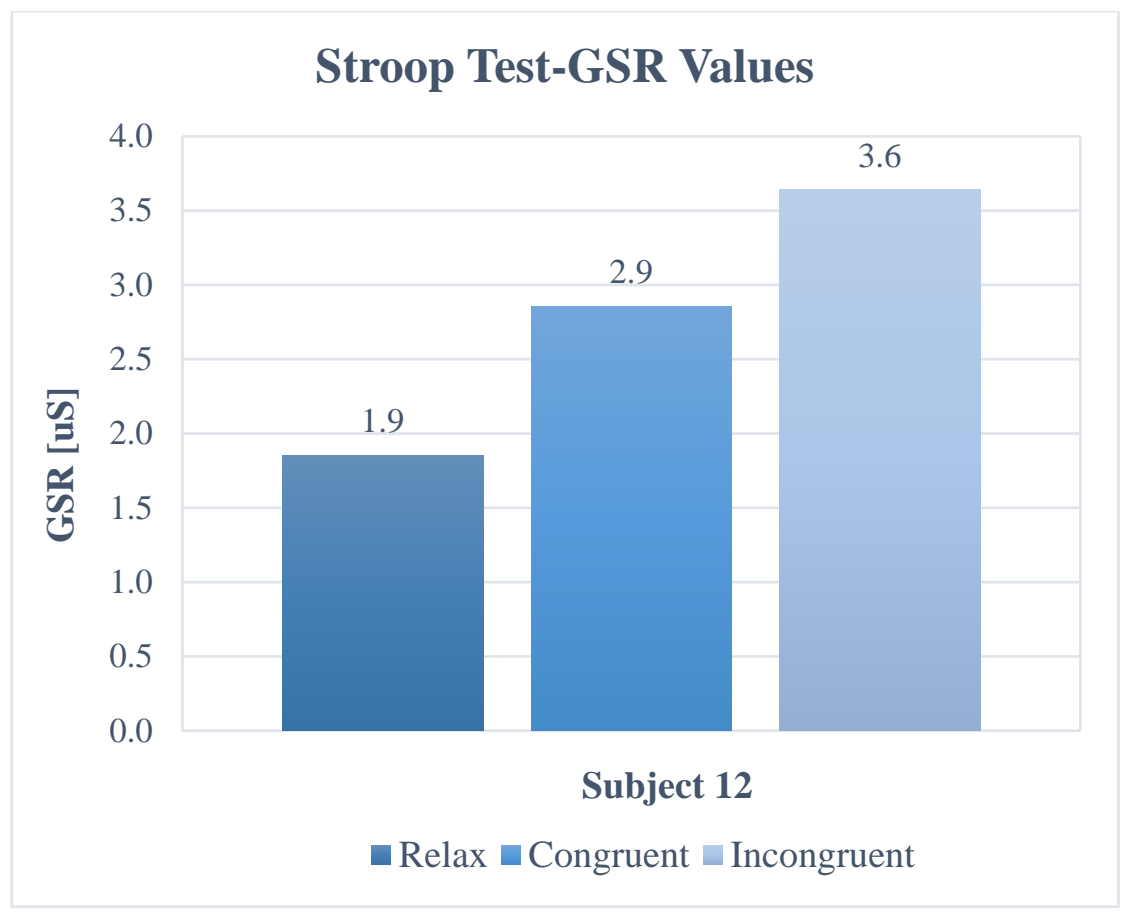

Figure 33: Mean GSR Values for Subject 12

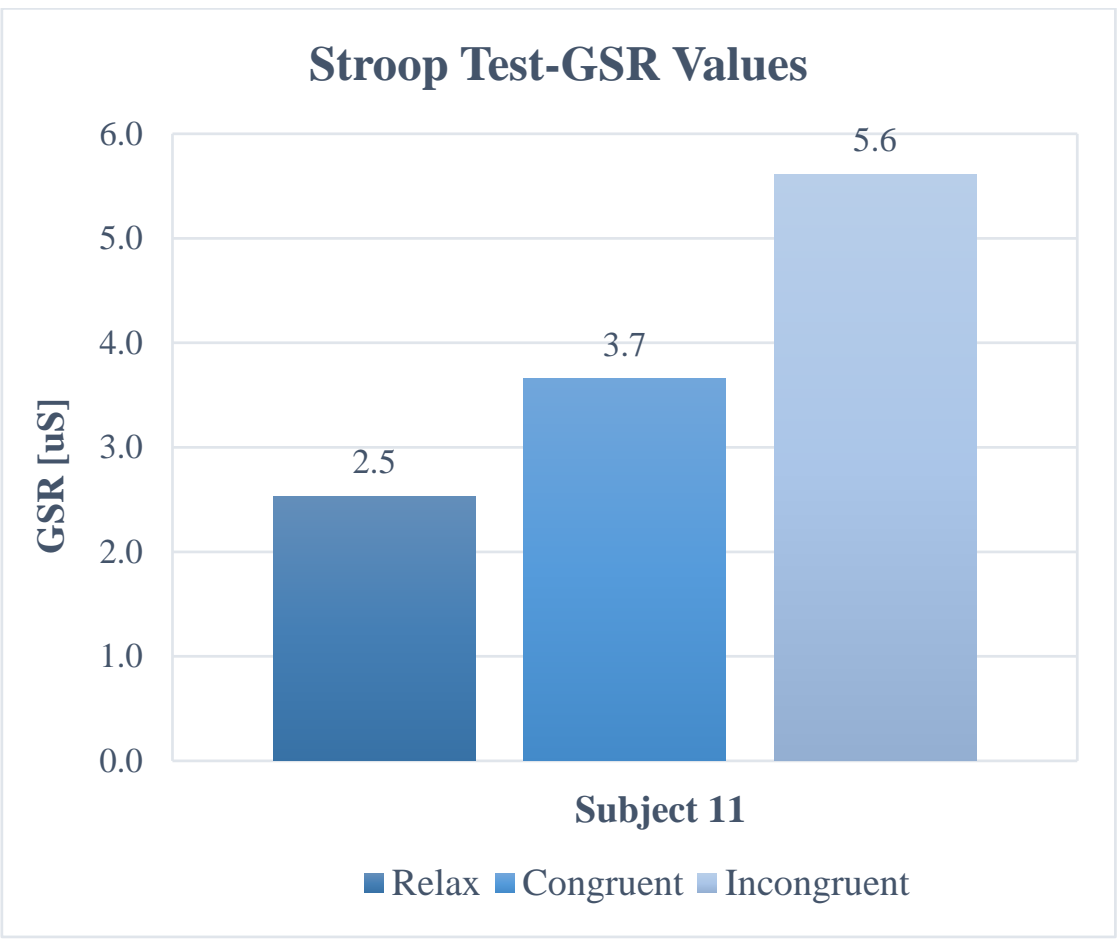

Figure 34: Mean GSR Values for Subject 11 


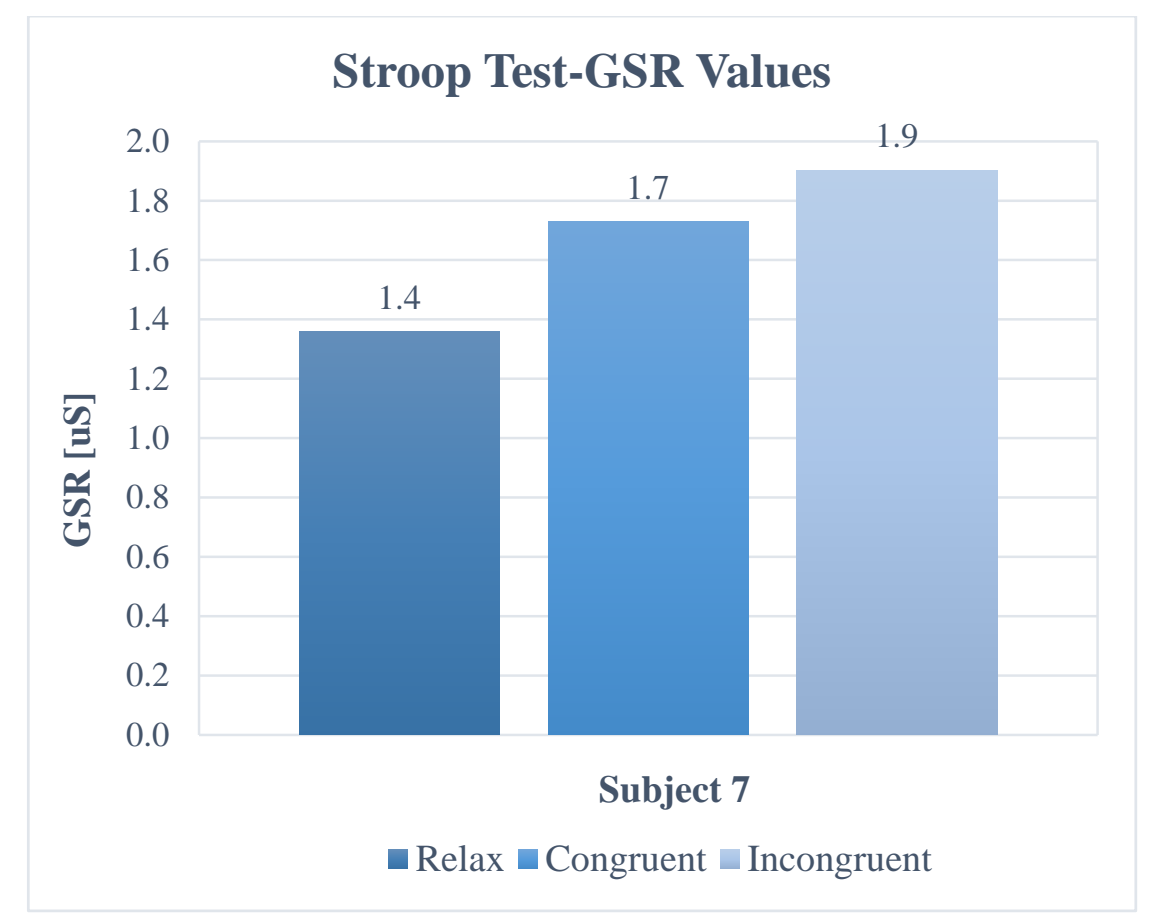

Figure 35: Mean GSR Values for Subject 7

The following outlier results are belong to the subjects become calm after getting used to with the task or the ones not feel stressed or excited with their task during the overall Stroop test process. These subjects are also the ones less interested, excited or tense during the experiment. Related Stroop test graphs belongs to subjects numbered as 3 and 5 can be seen in Figure 36 and Figure 37. 


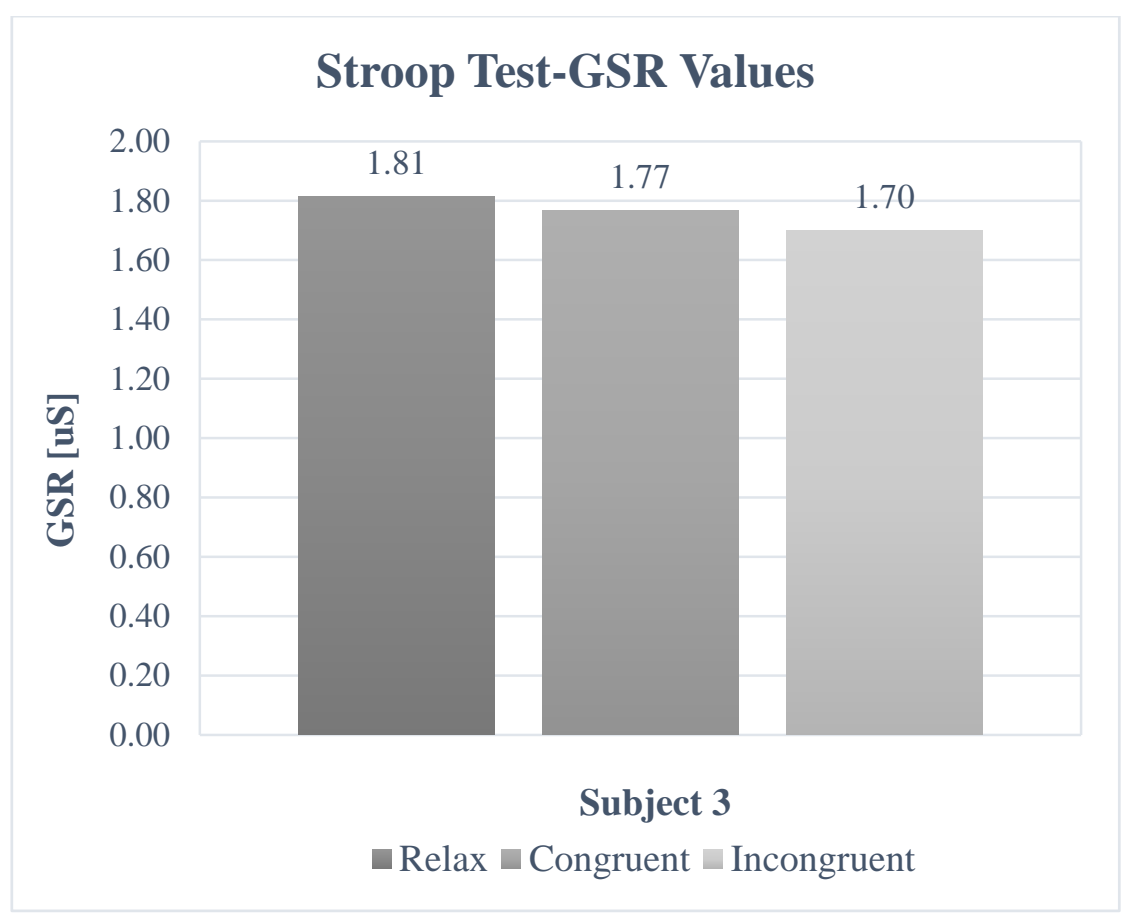

Figure 36: Mean GSR Values for Subject 3

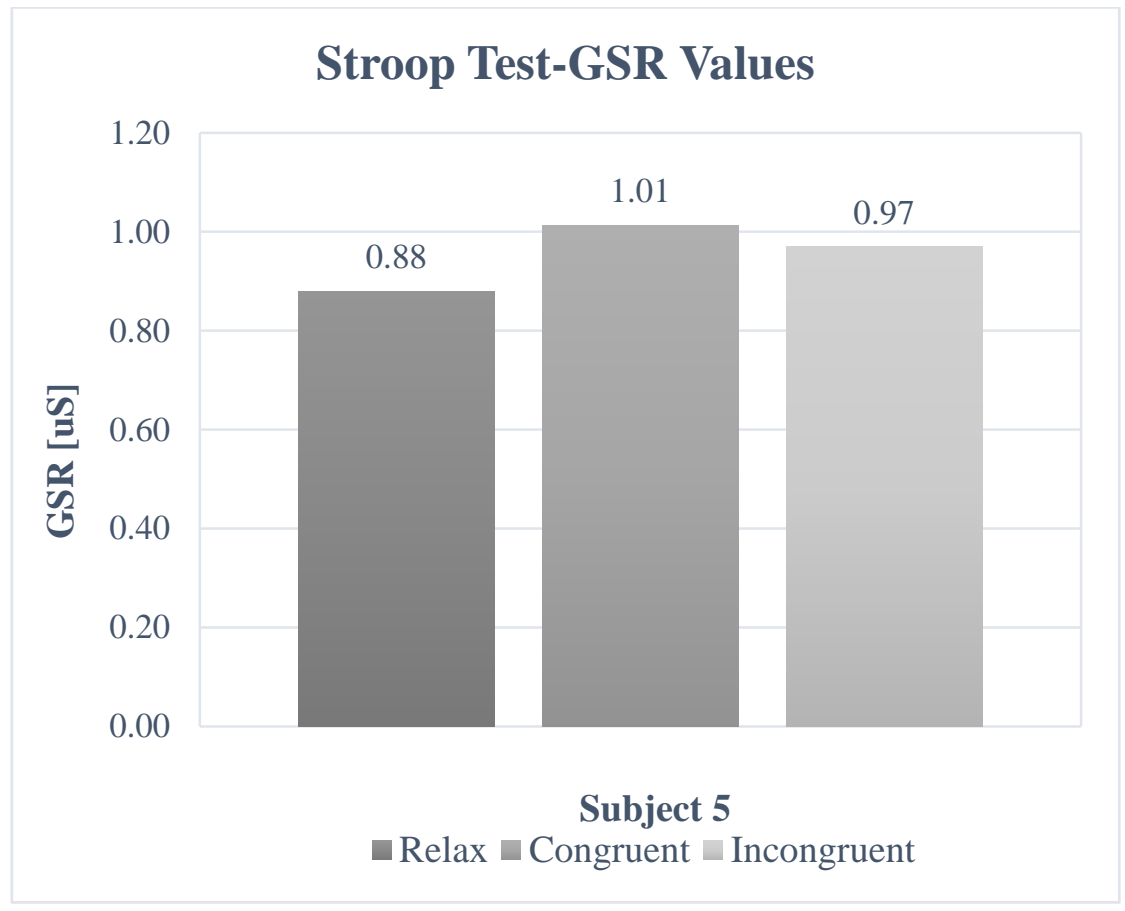

Figure 37: Mean GSR Values for Subject 5 
When mean value for congruent and incongruent Stroop test steps are compared, overall picture shows an increase as expected. As per Figure 38, mean GSR value increases from 0.621 to 0.994 .

\author{
Mean GSR Values for Stroop Test \\ घ Congruent Test $\quad$ Incongruent Test
}

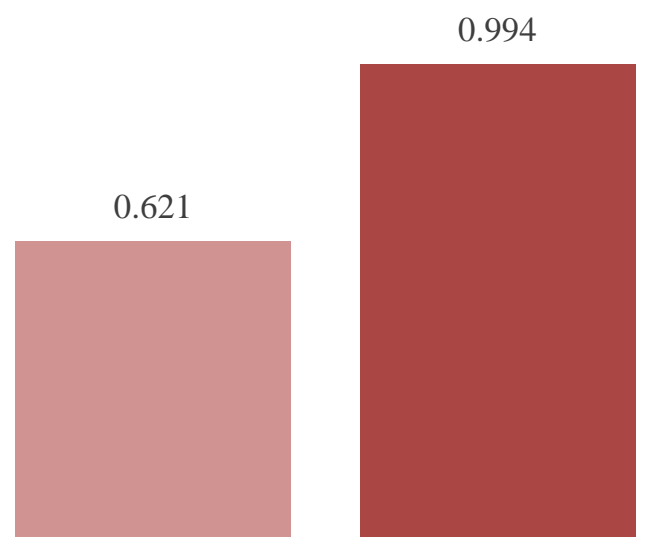

Figure 38: Mean GSR Values for Stroop Test

\title{
7.2 Scene
}

\subsubsection{Construction Site Simulation}

During real construction site simulation, animated with four major hazards, it is anticipated to observe subjects reactions during the stimuli implemented and the task assigned them to detect moving yellow workers. Most of the workers' result have the same overall graph with a negative correlation between times. Which means that while time passing their adaptation to the virtual environment increases and this bring about less stressed or excited results, besides that some of the subjects give reaction to the 
expected stimuli. Following graphs display these relations and reactions throughout construction simulation for all subjects can be examined with respect to Figure 39.

There is a negative correlation between time and GSR values for all of the subjects, the numerical results can be seen from the table and also the graph all results are gathered together shows a negative slope for all curves as an indicator for the GSR value decrease with respect to the time increase.

Table 7: Correlation between Time \& GSR Results

\begin{tabular}{|c|c|}
\hline Subject & Correlation \\
\hline $\mathbf{1}$ & -0.9935 \\
\hline $\mathbf{2}$ & -0.6412 \\
\hline $\mathbf{3}$ & -0.9887 \\
\hline $\mathbf{4}$ & -0.9627 \\
\hline $\mathbf{5}$ & -0.9983 \\
\hline $\mathbf{6}$ & -0.8810 \\
\hline $\mathbf{7}$ & -0.9621 \\
\hline $\mathbf{8}$ & -0.9376 \\
\hline $\mathbf{9}$ & -0.9373 \\
\hline $\mathbf{1 0}$ & -0.1981 \\
\hline $\mathbf{1 1}$ & -0.9928 \\
\hline $\mathbf{1 2}$ & -0.6208 \\
\hline
\end{tabular}




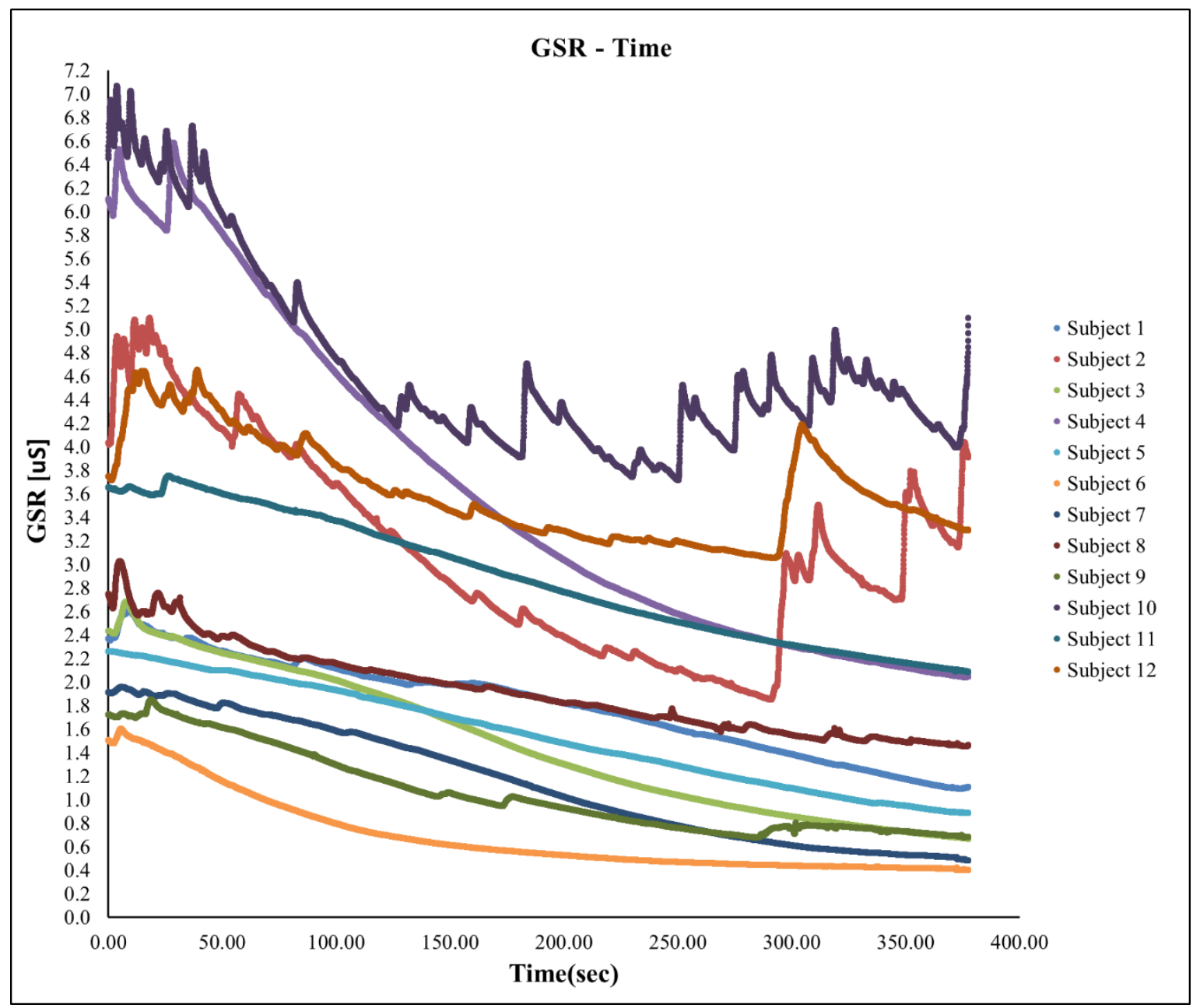

Figure 39: GSR Values for all Subjects

Subjects give less reaction for overall simulation also has less numerical change under intentional stimuli implemented. The ones with more reactive results are examined during specific stimuli as follows;

For the time between 15.00 and 45.00 sec reactions for Subject 4 and Subject 10 can be observed from the peak points on Figure 40, which means that these subjects were under an emotional change during that time. This time period belongs to the first yellow worker detection task that starts at $20.00 \mathrm{sec}$ and lasts until $40.00 \mathrm{sec}$. 


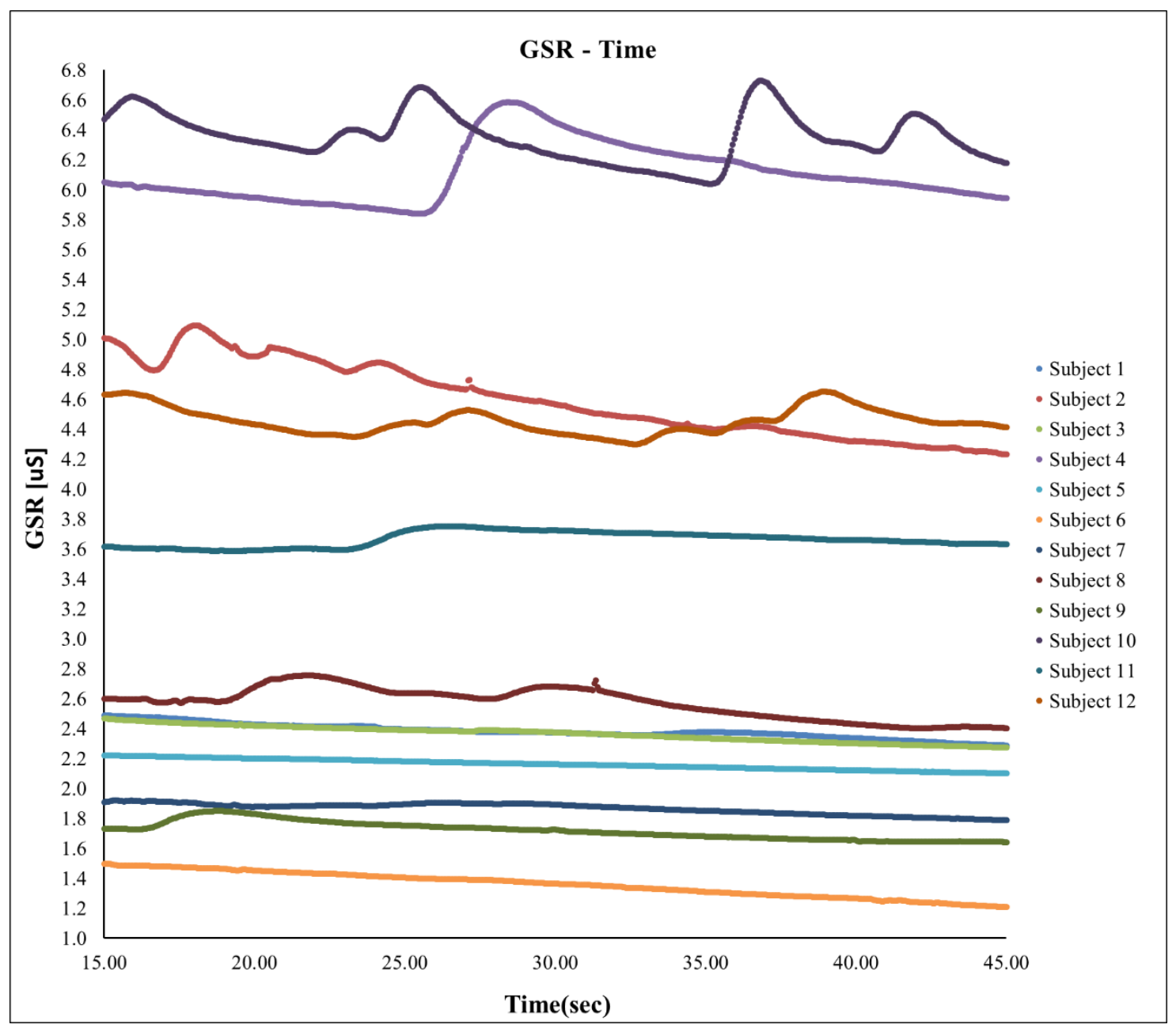

Figure 40: Detailed GSR Graph between Time 15.00 - 45.00 sec 


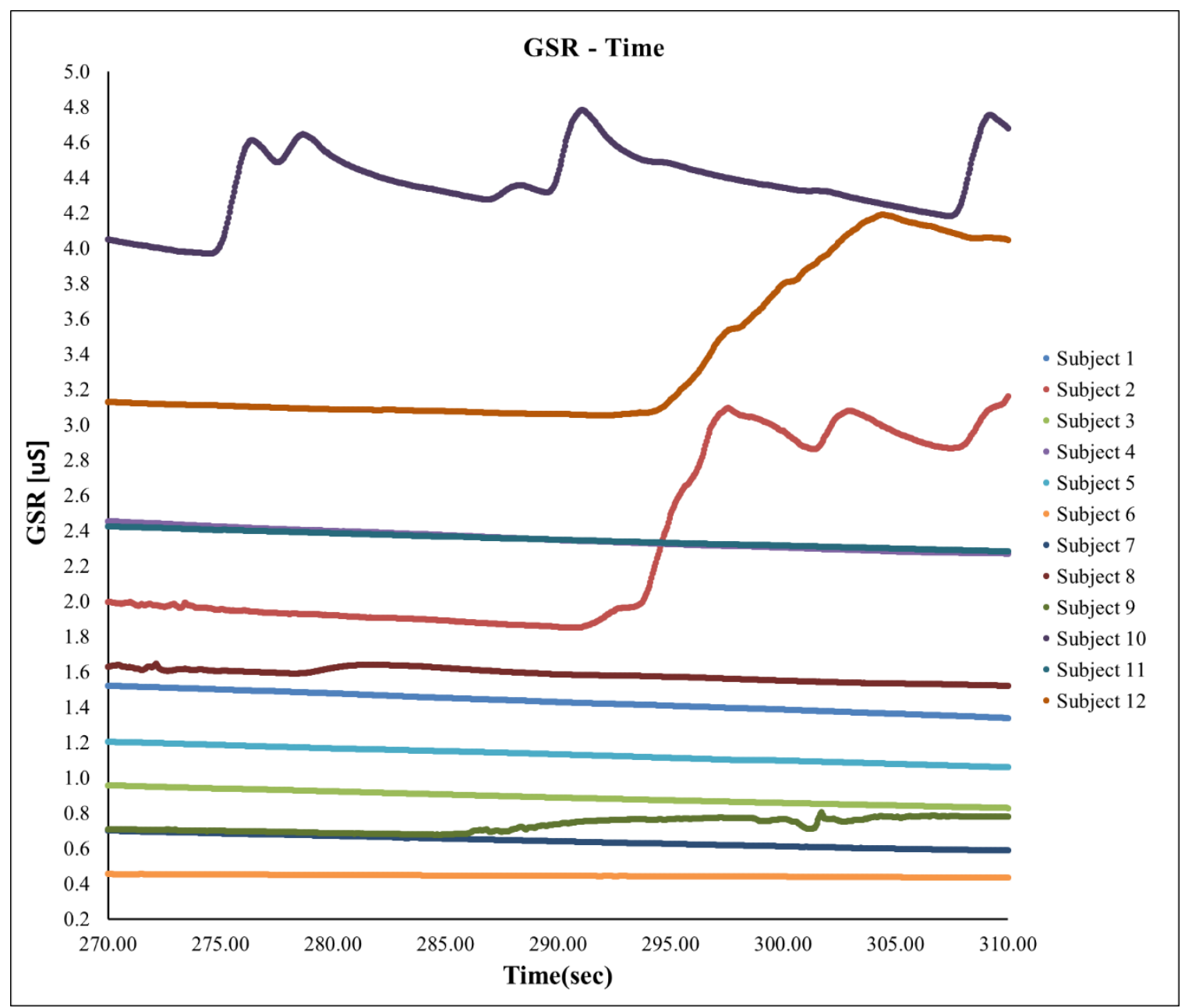

Figure 41: Detailed GSR Graph between Time 270.00-310.00 sec

From Figure 41, reaction for Subject 2, 10 and 12 can be observed in an increasing manner with distinct peak points in specific time. This duration is designed for 3 different yellow worker and fall from ladder hazard. When the subjects have more task demand adjacently combined with hazard scenarios their emotional change could be observed with the help of arising GSR value. The responses for the subjects with respect to specific stimuli is analyzed for the following graphs, to see the difference between reactive and nonreactive subjects. 
Subject 10 can be analyzed as the reactive subject as can be seen in Figure 42 under material fall hazard and Figure 43 for fall from ladder hazard implemented in the simulation.

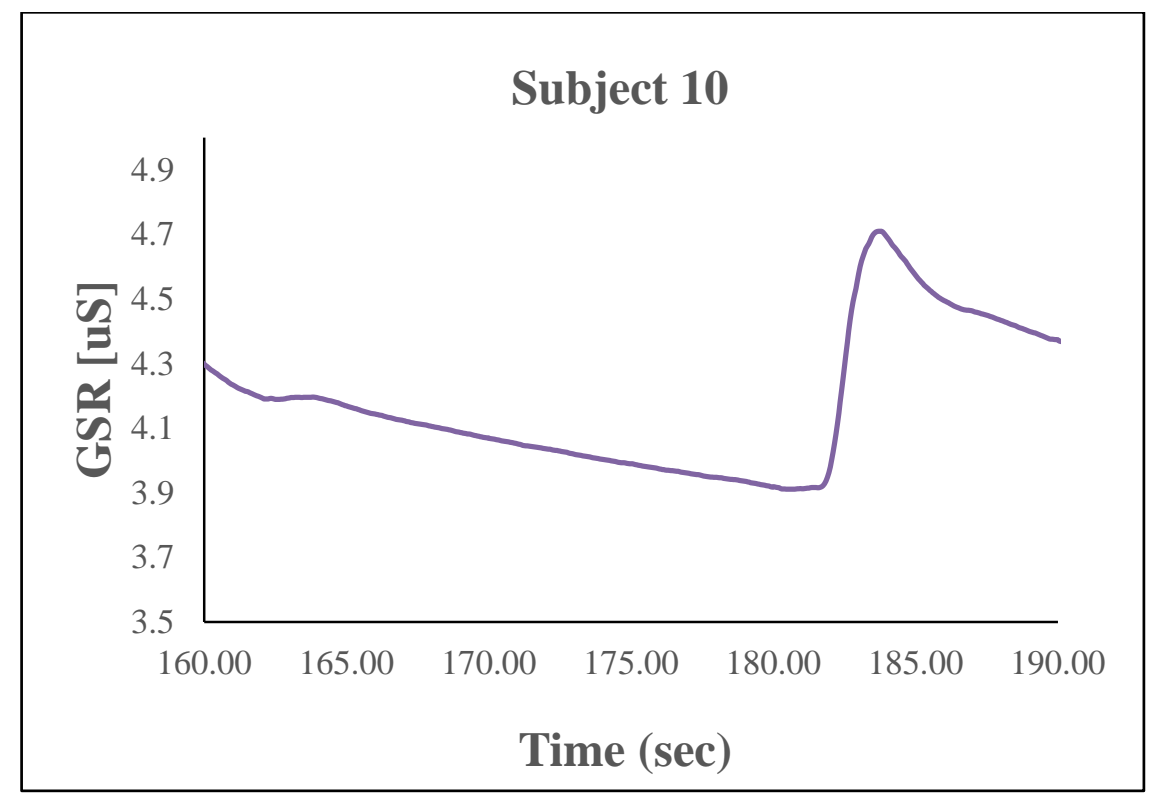

Figure 42: Subject 10 Material Fall Reaction

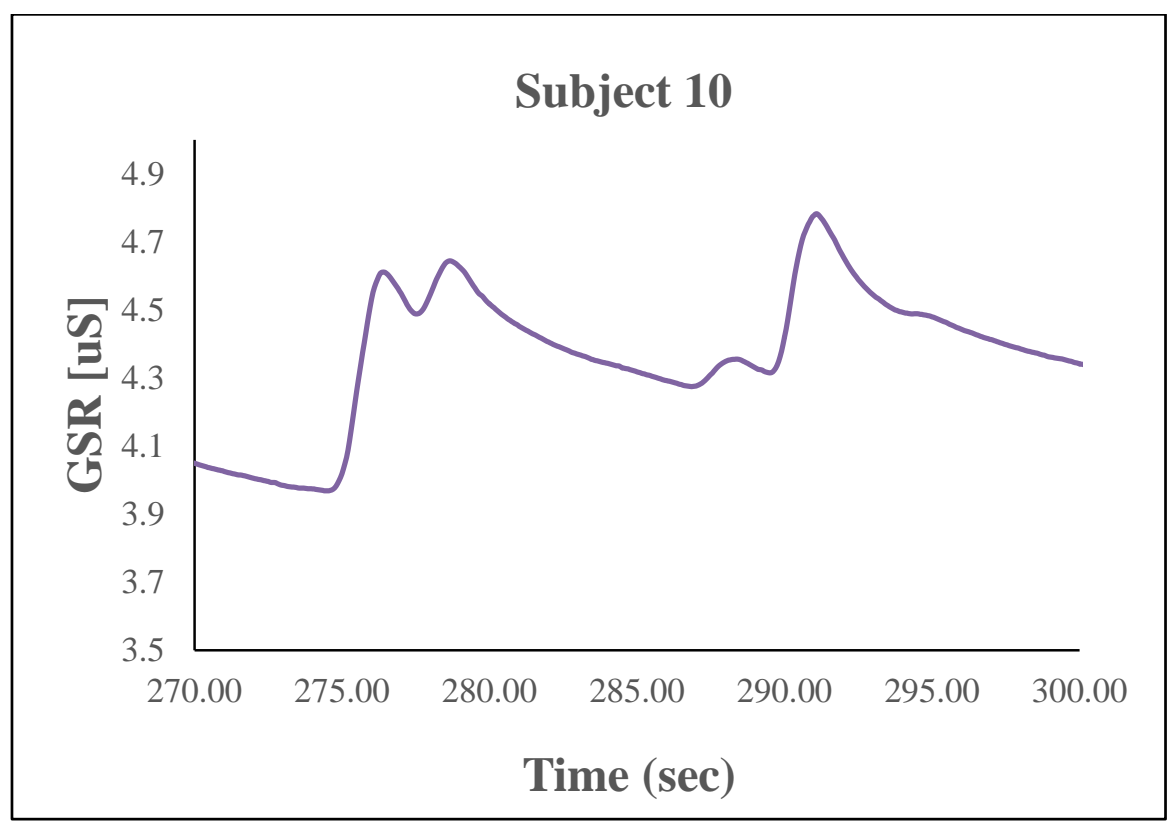

Figure 43: Subject 10 Fall from Ladder Reaction 
Subject 3 can be analyzed as the non-reactive subject as can be seen in Figure 44 under material fall hazard and Figure 45 for fall from ladder hazard developed for simulation.

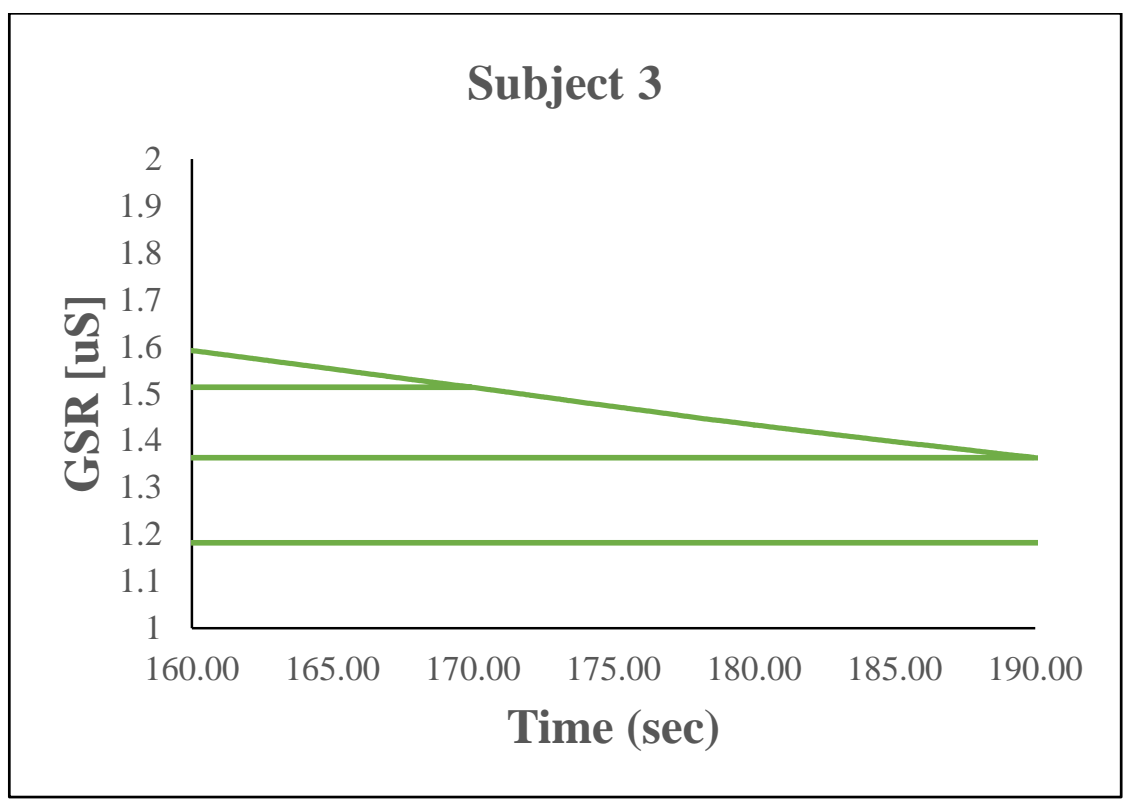

Figure 44: Subject 3 Material Fall Reaction

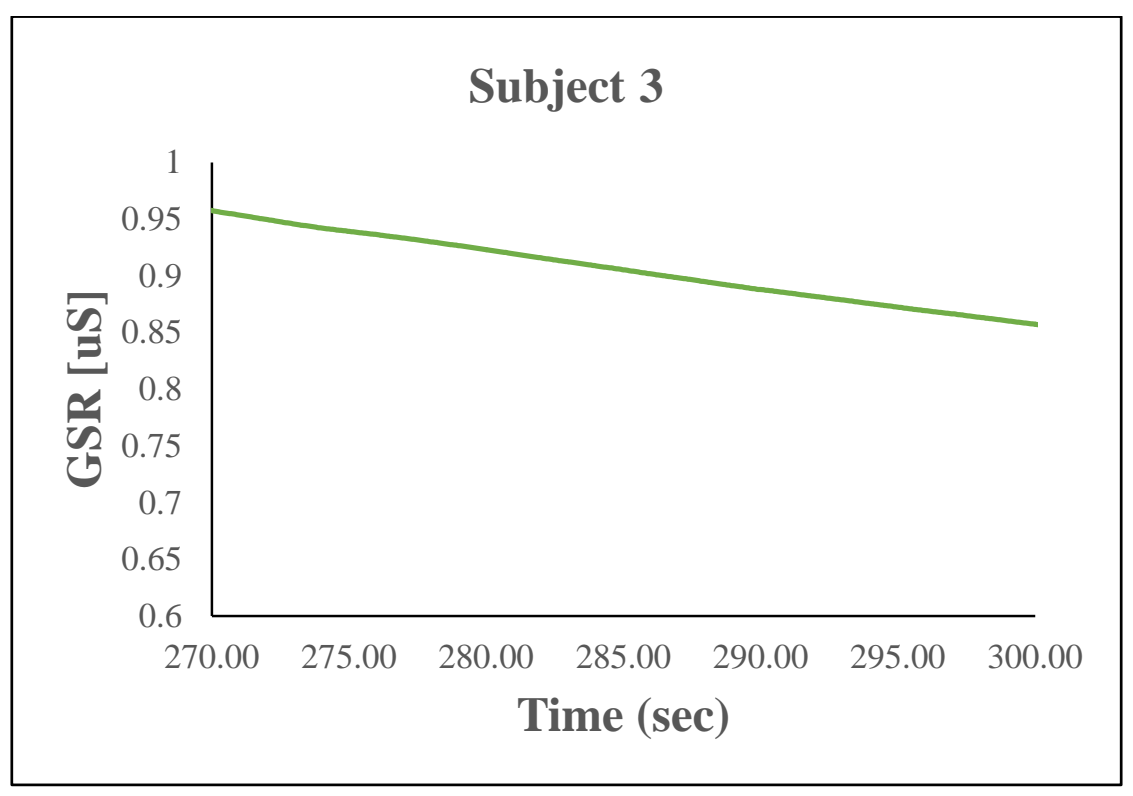

Figure 45: Subject 3 Fall from Ladder Reaction 


\subsubsection{Oculus Demo}

The purpose of performing this experiment phase is monitoring subjects' reactions for another virtual environment. Two different kind of demo scenes help to observe difference between a highly active virtual scene and the opposite one. The subjects without reaction during the construction simulation have more reactive GSR results during the "Helix" rollercoaster simulation. Following graph Figure 46 is belong to subject watched “Helix” demo;

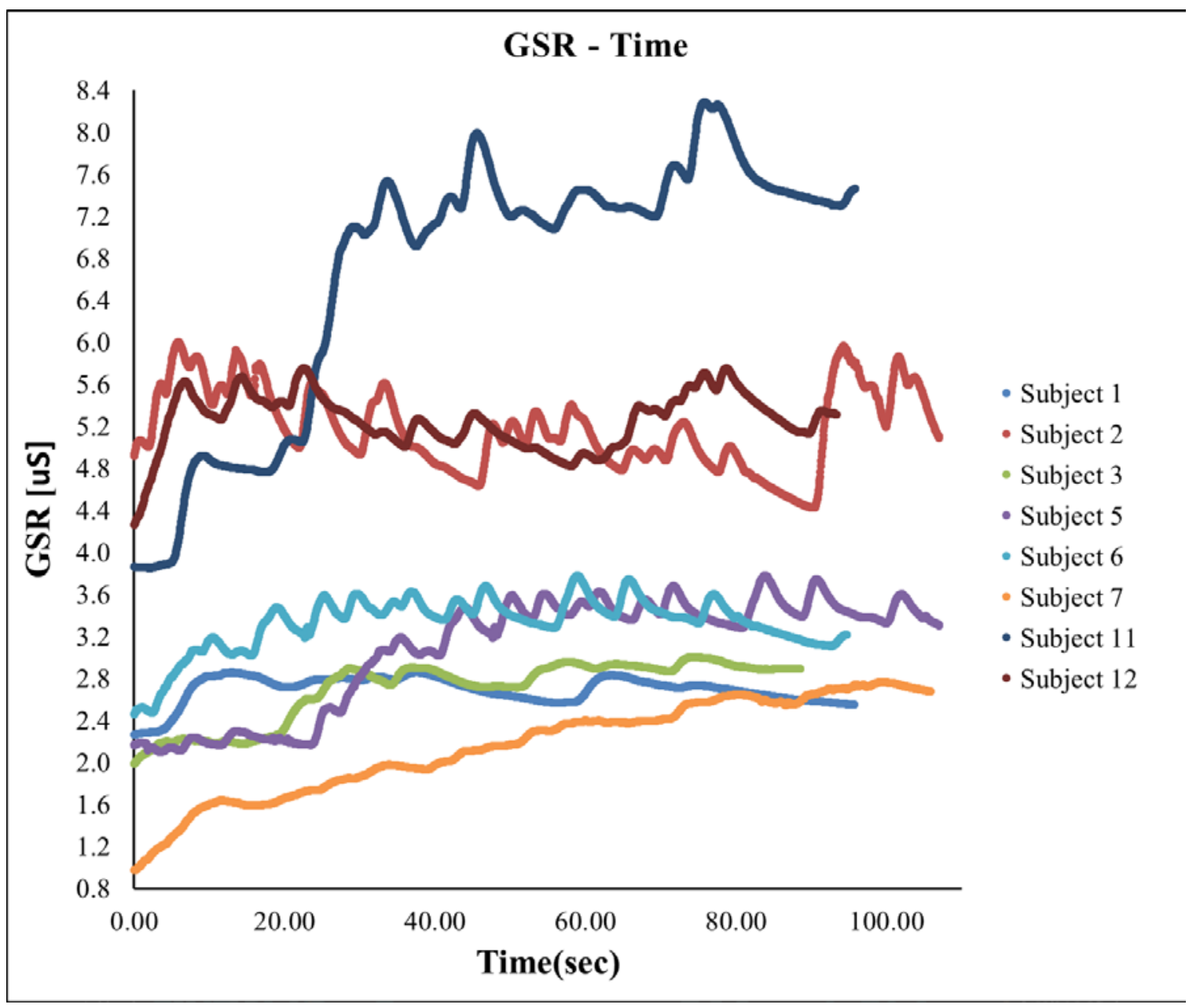

Figure 46: GSR values for "Helix" Demo 
When this graph is compared with the overall GSR values for construction simulation, the Subjects numbered as 1, 3, 5, 6, 7 and 11 have less reactive results for construction site but their "Helix" demo results reflect emotional change or excitement. This can be interpreted as realism of the virtual environment is a determinant for the response.

With purpose of deciding the factor of different virtual environment, a group of subject participates the "Tuscany" oculus demo that is less active than the rollercoaster one. During these virtual display, variety of GSR values are observed with respect to time as per Figure 47.

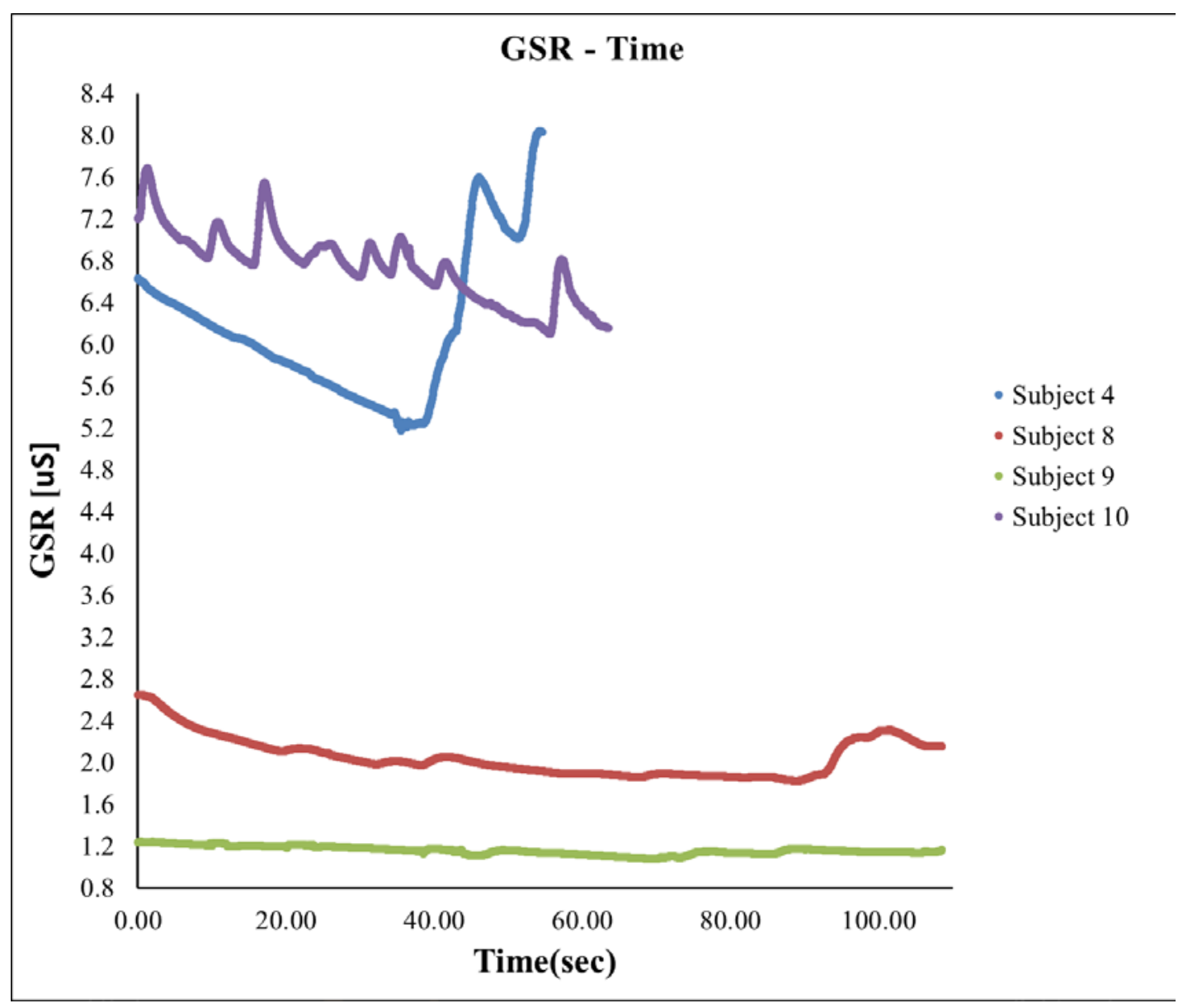

Figure 47: GSR Values for "Tuscany" Demo 
After conducting demo scenes construction simulation and demo results are compared to see the reaction manner of the same person to the different virtual environments. Although the subject is nonreactive to the construction site scene, he/she gives reaction the demo. This shows that improving virtual environment with realistic features create more emotional changes and reactions. Following graphs demonstrate this in a better way in Figure 48 and Figure 49 for Subject 5 and in Figure 50 and Figure 51 for Subject 6.

Subject 5

Construction Field Simulation vs. Rollercoaster Demo

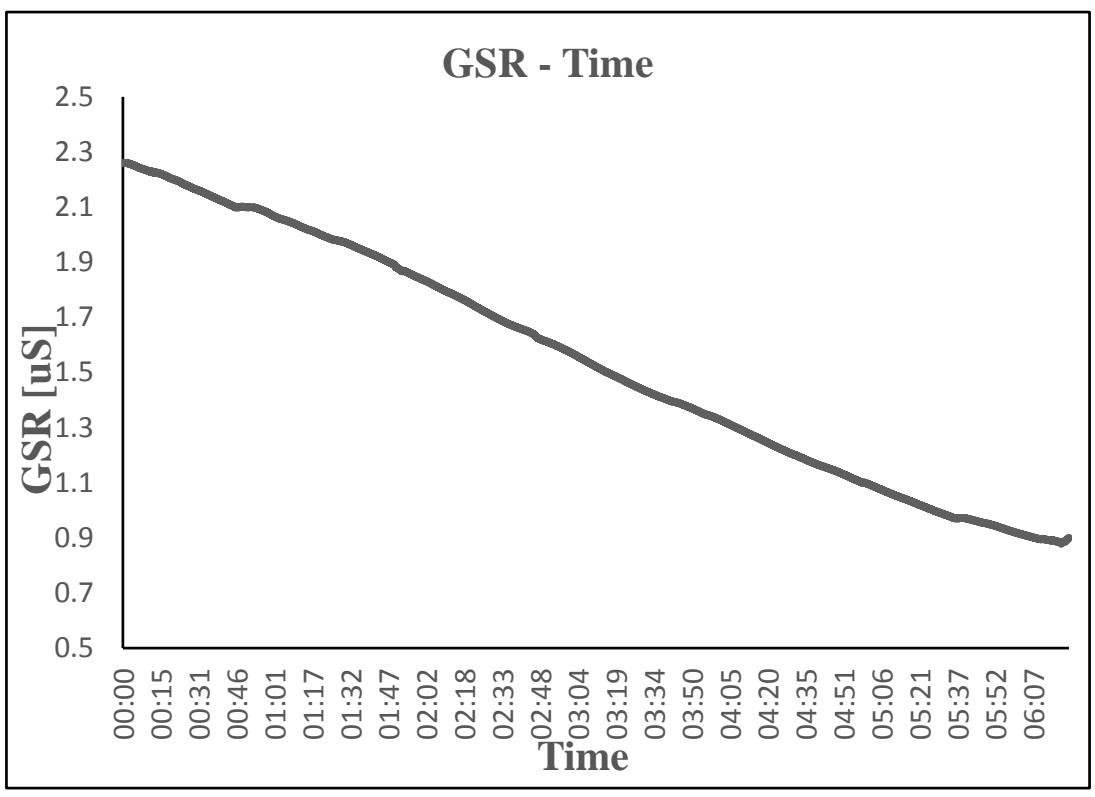

Figure 48: Subject 5 Construction Simulation GSR Results 


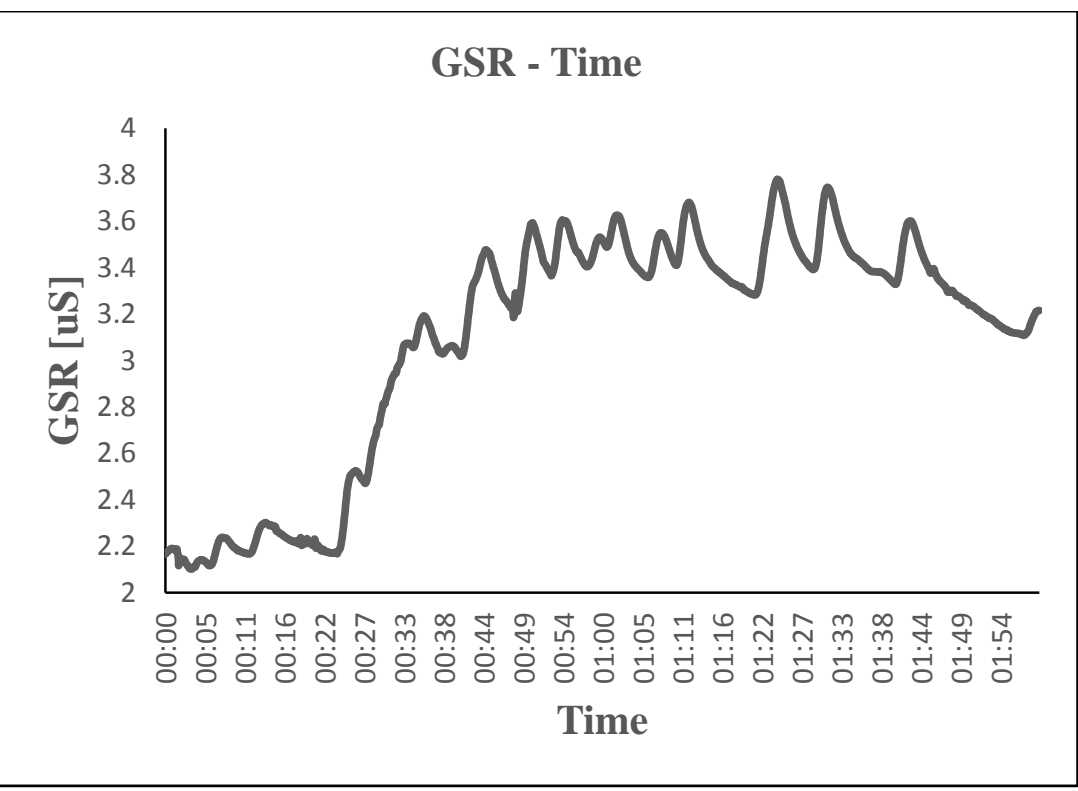

Figure 49: Subject 5 Rollercoaster Demo GSR Results

Subject 6

Construction Field Simulation vs. Rollercoaster Demo

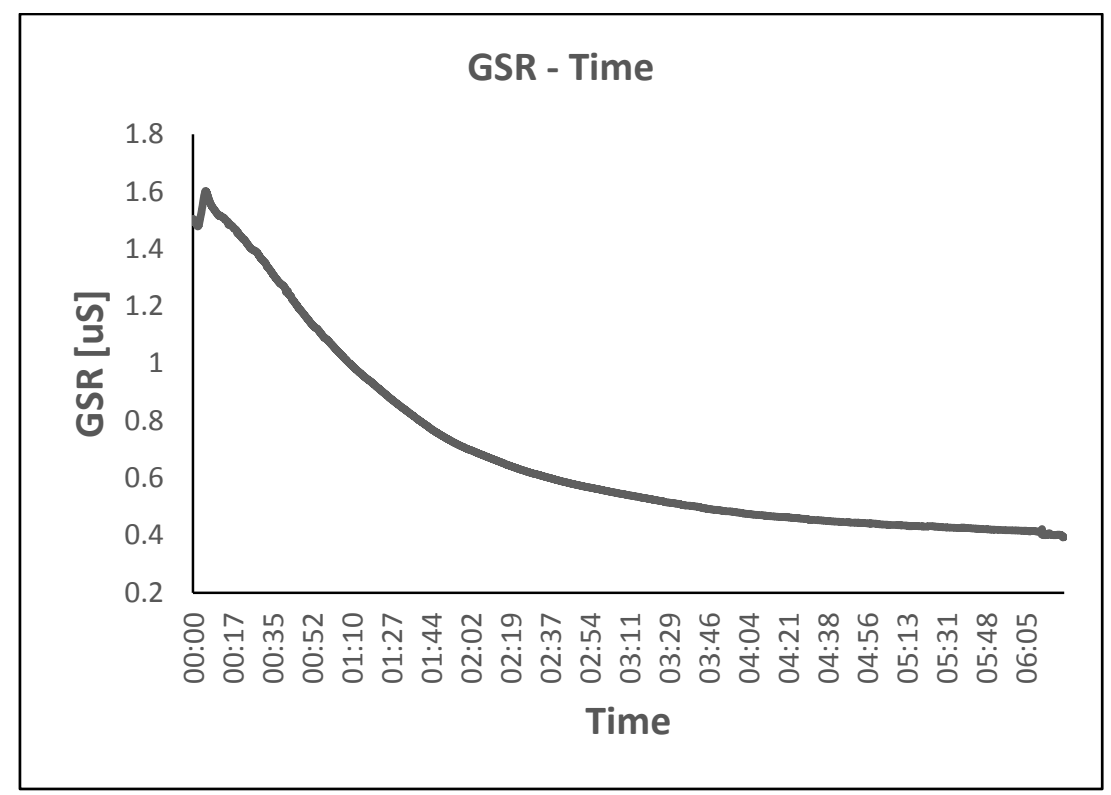

Figure 50: Subject 6 Construction Simulation GSR Results 


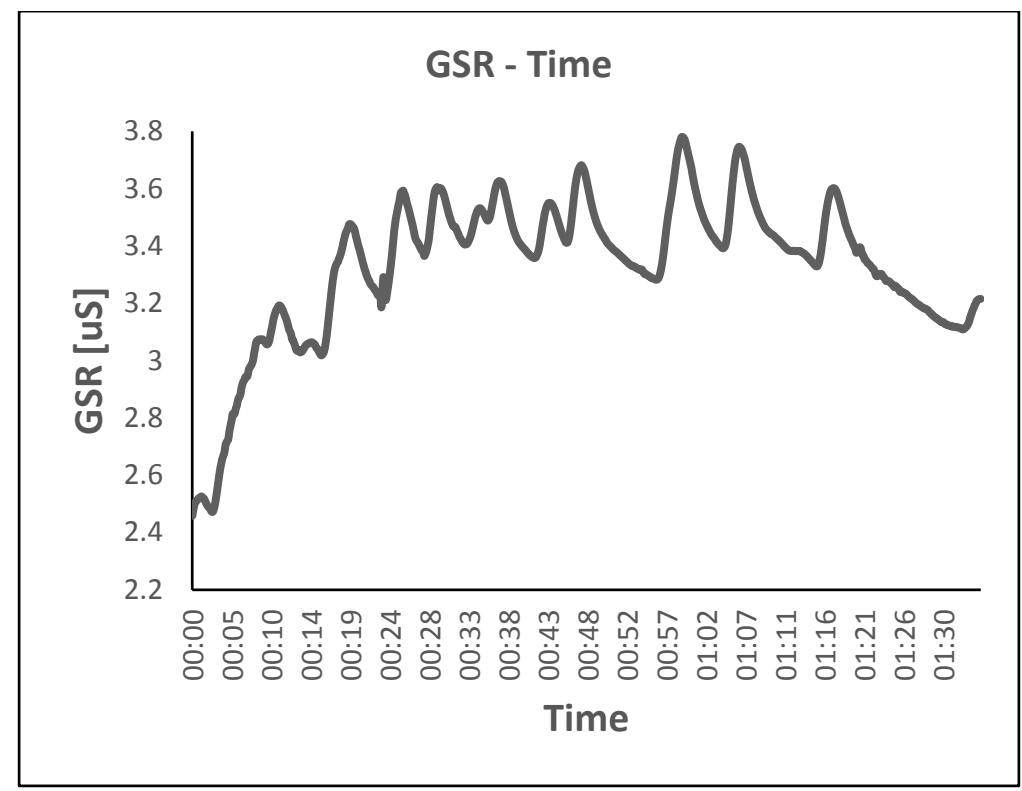

Figure 51: Subject 6 Rollercoaster Demo GSR Results

\subsection{Questionnaire}

A question part is prepared, since the experiment results may vary depending on the person, their background and personality, factors make them stressed or excited and their perception with respect to the challenging tasks. This section helps to understand potential reasons for decrease in GSR value during construction site simulation and the results do not match up with the expectations to observe less emotional change during the first half of the experiment rather than the second part. Accordingly answers collected from the subjects, reasons can be summarized under 5 different factor as follows:

Indifference: Since from the beginning of the experiment subjects are expecting a virtual environment, the most frequent reply is being aware of this is not real and nobody going to get injured or feel any kind of other danger. This makes subjects less reactive to virtual changes. In order to change this perception, virtual scene should be as possible as correlated with the reality and subjects should feel every stimuli by using more sense 
organs. The importance of realistic scene can be easily understood by observing the difference between the reactions for construction and oculus demo simulations. This can be interpreted as, increase in the reality of construction simulation may bring about more distinct reactions to specific stimuli.

Lack of control: During the simulation subjects are not allowed to control the truck path or any other intervention to surrounding activities. This makes them less responsible and also less tensed. Giving them control affects the trajectory of the simulation and make them to pay more attention. With respect to this general answer it can be construed that, control make subjects to feel more into the virtual environment.

Expectation: Answers to the questions direct us another result as the subjects are able to realize the overall picture for the simulation after short period from the beginning. Since there was not any drastic hazard in the simulation, this makes themselves to feel safe and less emotional change is observed.

Task: Subjects are asked to perform dual task as detecting yellow workers while they are moving and observing changes in construction site. Because of the fact that they need to provide input by using a stopwatch, they are more focused to their task rather than analyzing changes in surrounding environment. Because of this reason most of them missed some of the major hazards and without detecting it cannot be expected to have any reaction for that specific stimuli.

Proximity: Another common comment is the distance between the hazards during simulation. Staying away from the hazardous scene and observing from a distance in 
virtual environment makes them to feel safe and comfortable again, that can be monitored with stationary GSR values during time change.

Duration: Since the simulation takes long time, it is possible for subjects to lose their attention and interest after a while.

Magnitude: Although subjects realize the stimuli, depending on the amount of the reaction it might not be reflected to the results. Therefore, magnitude of the emotional change affects the outcome and it is not determinable.

When overall answers to the questions are evaluated, it is observed that construction simulation was good for subjects but they recommended to improve animations and graphics. Accordingly, scene should be improved with better graphics, worker movements closer to the physical world and with less lag in Oculus caused by head movements. GSR results are mostly indicating conformity for the person describe himself/herself as one can stay calm; but it was opposite for the ones describes themselves as a panic person. This can be explained by indifference, although subjects have a panic personality in daily life knowing experiment is a virtual environment made them less reactive than the expected. 


\section{CONCLUSION}

\subsection{Summary of Research}

The purpose of the research is having a feasibility study in order to see future possibilities for combining safety related topics and affective sensing technology. The statistical results for fatalities and injuries in construction industry demonstrates the importance of human life for which all regulations, restrictions, information and also training methods should be improved with respect to the technological progress.

The frame for the researches begins with a detailed literature review about safety statistics and accident causes in this industry. The four major construction hazards are analyzed in detail to have a proper simulation in virtual environment. Background improvement about the safety related topics is followed by stress area. Understanding how to response under stress and activity of human brain with dual task or cognitive load provides a better understanding about accidents and their root causes. Since investigating causes is not enough, physiological reactions during the emotional changes like; stress, excitement, fear or anger are also need to be analyzed. With all of these related aspects research is built on a huge frame.

Based upon these ideas a three step experiment is developed, in which stroop test, a real construction site simulation and immersive virtual demo display are performed. Experiment starts with Stroop Test in order to collect data during subjects' relax phase before the test and compare the difference between two major test phases; congruent and incongruent. Validating sensor devices with the help of Stroop Test is followed by site simulation involving four major hazards and variety of different distractions happen in a 
real construction field frequently. Finally, third phase is included to see the impacts of different virtual environments.

According to the data collected, strop test results can validate the sensors involved in experiment. Majority of the subject group has an increase in the GSR values with a following order from relax phase to congruent and incongruent tests. During the site simulation, although the participants were excited or nervous at the beginning of the second phase, indifference, lack of control, expectation, task and distance factors made them less awake and involved for the further stages of the simulation. Despite the negative correlation during the simulation, highly active third phase virtual environment shows the effect of virtual scene on human emotional changes. With a better understanding, improvement in virtual scene and arousing a realistic perception in subjects brings about a successful physiological reaction monitoring.

\subsection{Contributions}

Several problems in using virtual reality for monitoring construction workers' physiological reactions were identified as indifference, lack of control, expectation, task, proximity, duration and magnitude. It is observed that physiological response to stimuli through different types of sensors vary from subject to subject. Experiments with more types of sensors needed to assess the feasibility of using physiological sensors in construction context. Furthermore, incoherent responses indicate potential of further research after addressing the problems identified during this study. The path that the study shows has potential to be used in many other fields; likewise, driving simulation, different training methods, productivity enhancement trainings, etc. 


\subsection{Limitations}

Subjects were only students and workers could not be included. Since the target for the research is equipment operators testing with workers may bring about more relevant results within understanding perspective of workers' to real site conditions and existing safety precautions or regulations. Moreover, workers' opinions might have contributions by evaluating their lesson learned from experiences.

Secondly, it was not possible to practice the real values can be obtained from a real construction field. Since, it is unknown that what should be the reactions, values, expectations and perception under real conditions; there was not a concrete numerical results or graphs to compare.

Because of the fact that every subject has their own personal emotions, concerns or pleasure during the experiment, it was not possible to isolate emotions. Also, some timeframe in the construction simulation has multiple stimuli; subjects' overlapping reactions are observed. Congruently, subjects’ with different backgrounds cause the same type of limitations.

\subsection{Future Work \& Recommendations}

Virtual scene should be improved by animations, physics and graphics to give more realistic effect. In future it can be supported by additional senses to create 4D virtual environments.

Due to fact that subject might be nonreactive to the sensor, multiple number of sensors can be used and their accuracy can be analyzed separately to have better 
understanding which type of affective sensing device gives better result under this kind of experiment.

Also practicing the experiment in a real construction site gives an opportunity to compare results with a real case, in which effectiveness of virtual environment can be evaluated in a more concrete way.

\subsection{Implications}

Combining virtual reality, affective sensing and construction safety might bring about different kind of implications in industry with high benefits. First of all, virtual reality can be used for training, the major hazards for the specific construction sites can be implemented in virtual environment. With the help of this, both workers can be prepared before their tasks and also their confidence level can be measured by affective sensing. If an employee needs more training it can be detected and training duration might be extended under specific conditions. Also recruitment process can be arranged according to sensing results, if a worker is more panic under stress or vulnerable to hazardous conditions he/she can be preferred for safer work positions. 


\section{REFERENCES}

Abudayyeh, O., Fredericks, T. K., Butt, S. E., \& Shaar, A. (2006). An investigation of management's commitment to construction safety. International Journal of Project Management, 24(2), 167-174.

Arborsci [Internet]. 2015 [cited 2015 Sep 23]. Available from: http://www.arbors ci.com/neulog-gsr-sensor

Arteschnica [Internet]. 2015 [cited 2015 Sep 23]. Available from: $\quad$ http://arstechnica.com/gadgets/2014/03/oculus-rift-dev-kit-2-launches-with960x1080-resoluti on-lower-latency/

Barreto, A. (2008). Non-intrusive physiological monitoring for affective sensing of computer users. INTECH Open Access Publisher.

Bayouth, S. T., Keren, N., Franke, W. D., \& Godby, K. (2013). Examining Firefighter Decision-Making: How Experience Influences Speed in Process and Choice. International Fire Service Journal of Leadership and Management, 7, 51.

BUREAU OF LABOR STATISTICS, "Injuries, illnesses, and fatalities.” http://www.bls.gov/iif/, 2013. [Online, cited September 15, 2015]

BUREAU OF LABOR STATISTICS, "Injuries, illnesses, and fatalities.” http://www.bls.gov/iif/oshwc/cfoi/cfch0012.pdf, 2013. [Online, cited September 15,2015]

BUREAU OF LABOR STATISTICS, “Occupational Injury and Illness Classification Manual, Section 2”’ http://www.bls.gov , 2003. [Online, cited September 20, 2015]

Busing, S. A. (2014). Response to the performed story: tracking emotional response to a theatrical performance using galvanic skin response (Doctoral dissertation).

Cawley, J. C., \& Homce, G. T. (2006, September). Trends in Electrical Injury, 19922002. In Petroleum and Chemical Industry Conference, 2006. PCIC'06. Record of Conference Papers-IEEE Industry Applications Society 53rd Annual (pp. 1-14). IEEE.

Chantawit, D., Hadikusumo, B. H., Charoenngam, C., \& Rowlinson, S. (2005). 4DCADSafety: visualizing project scheduling and safety planning. Construction Innovation, 5(2), 99-114.

Chen, A., Golparvar-Fard, M., \& Kleiner, B. (2013). SAVES: A safety training augmented virtuality environment for construction hazard recognition and severity identification. CONVR 2013, 373-384.

Cheng, T., \& Teizer, J. (2013). Real-time resource location data collection and visualization technology for construction safety and activity monitoring applications. Automation in Construction, 34, 3-15. 
Chi, C. F., Chang, T. C., \& Ting, H. I. (2005). Accident patterns and prevention measures for fatal occupational falls in the construction industry. Applied ergonomics, 36(4), 391400.

Dharmawan, Z. (2007). Analysis of computer games player stress level using EEG data. Master of Science Thesis Report, Faculty of Electrical Engineering, Mathematics and Computer Science, Delft University of Technology, Netherlands.

Drury, C. G., \& Brill, M. (1983). Human factors in consumer product accident investigation. Human Factors: The Journal of the Human Factors and Ergonomics Society, 25(3), 329-342.

Grabowski, M., Ayyalasomayajula, P., Merrick, J., Harrald, J. R., \& Roberts, K. (2007). Leading indicators of safety in virtual organizations. Safety Science,45(10), 1013-1043.

Gutiérrez-Maldonado, J., Wiederhold, B. K., \& Riva, G. (2015). Future Directions: How Virtual Reality Can Further Improve the Assessment and Treatment of Eating Disorders and Obesity. Cyberpsychology, Behavior, and Social Networking.

Healey, J., \& Picard, R. W. (2005). Detecting stress during real-world driving tasks using physiological sensors. Intelligent Transportation Systems, IEEE Transactions on, 6(2), 156-166.

Hinze, J., \& Godfrey, R. (2003). An evaluation of safety performance measures for construction projects. Journal of Construction Research, 4(01), 5-15.

Hinze, J., Huang, X., \& Terry, L. (2005). The nature of struck-by accidents.Journal of Construction Engineering and Management, 131(2), 262-268.

Hinze, J., Pedersen, C., \& Fredley, J. (1998). Identifying root causes of construction injuries. Journal of Construction Engineering and Management, 124 (1), 67-71.

Hinze, J., Thurman, S., \& Wehle, A. (2013). Leading indicators of construction safety performance. Safety science, 51(1), 23-28.

Huang, X., \& Hinze, J. (2003). Analysis of construction worker fall accidents.Journal of Construction Engineering and Management, 129(3), 262-271.

Hugdahl, K. (1995). Psychophysiology: The mind-body perspective. Harvard University Press.

Keren, N., \& Franke, W. D. [Internet]. 2015 [cited 2015 Sep 23]. Decision Making under Stress in Emergency Response: Challenges and Opportunities (http://public.vrac.iastate.edu/ nir/decision-making/dmwp.pdf)

Klein, G. A. (1999). Sources of power: How people make decisions. MIT press.

Liao, W., Zhang, W., Zhu, Z., \& Ji, Q. (2005, June). A real-time human stress monitoring system using dynamic Bayesian network. In Computer Vision and Pattern RecognitionWorkshops, 2005. CVPR Workshops. IEEE Computer Society Conference on (pp. 70-70). IEEE. 
Lindsay, F. D. (1992). Successful health and safety management. The contribution of management audit. Safety Science, 15(4), 387-402.

Lu, L., Connell, M., \& Tullberg, O. (2001). The Use of Virtual Reality in Interactive Finite Element Analysis-State of the Art Report. Chalmers University of Technology.

Luciano, C., Banerjee, P., \& DeFanti, T. (2009). Haptics-based virtual reality periodontal training simulator. Virtual reality, 13(2), 69-85.

Lupien, S. J. HOW TO MEASURE STRESS IN HUMANS.

M. R. Jusoh. Prognosis of Stroke. Consensus Statement on the Management Of Ischaemic Stroke. Academy of Medicine of Malaysia, Kuala Lumpur, Malaysia, 2006.

Marks, E. (2014). Active Safety Leading Indicators for Human-Equipment Interaction on Construction Sites.

McGrath, J.E. (1976). Stress and behavior in organizations. In M.D. Dunnette (Ed.), Handbook of industrial and organizational psychology (pp. 1351-1395). Chicago: Rand McNally.

Miller, J. J., Fletcher, K., \& Kabat-Zinn, J. (1995). Three-year follow-up and clinical implications of a mindfulness meditation-based stress reduction intervention in the treatment of anxiety disorders. General hospital psychiatry,17(3), 192-200.

NATIONAL SAFETY COUNCIL, "Injury facts, 2008 edition.” https://www.usw12775.org/uploads/InjuryFacts08Ed.pdf, 2008. [Online, cited September 15, 2015].

Nguyen, L., Rosicki, S., Rowe, C., \& Schoenberger, H. (2015). The Effects of Cell Phone Distractions on Cognitive Flexibility.

Occupational Safety and Health Administration (OSHA), "Construction Focus Four: Electrocution Hazards" https://www.osha.gov/dte/outreach/construction/focus_four /caught/caught_iorb_ig.pdf, 2011. [Online, cited September 21, 2015]

Occupational Safety and Health Administration (OSHA), "Construction Focus Four: Electrocution Hazards" https://www.osha.gov/dte/outreach/construction/focus_four /electrocution/electr_ig.pdf, 2011. [Online, cited September 21, 2015]

Overseas Shipholding Ground, Inc., "Near miss reporting improvements, OSG newsletter.” http://www.osg.com/index.cfm?pageid=74\&itemid=32, 2009. [Online, cited Sep 10, 2015].

Pan, H. (2015, June). Research on Application of Computer Virtual Reality Technology in College Sports Training. In Measuring Technology and Mechatronics Automation (ICMTMA), 2015 Seventh International Conference on (pp. 842-845). IEEE.

Partala, T., \& Surakka, V. (2003). Pupil size variation as an indication of affective processing. International journal of human-computer studies, 59(1), 185-198. 
Pashler, H. (1994). Dual-task interference in simple tasks: data and theory. Psychological bulletin, 116(2), 220.

Pickering, T. G., Devereux, R. B., James, G. D., Gerin, W., Landsbergis, P., Schnall, P. L., \& Schwartz, J. E. (1996). Environmental influences on blood pressure and the role of job strain. Journal of hypertension. Supplement: official journal of the International Society of Hypertension, 14(5), S179-85.

Pradhananga, N. (2014). Construction site safety analysis for human-equipment interaction using spatio-temporal data.

Regard, M. (1984). Cognitive rigidity and flexibility: A neuropsychological study. In O. Spreen \& E. Strauss (Eds.), A compendium of neuropsychological tests. Oxford, Ma: Oxford University Press.

Sean Hollister and Sean Buckley. "Here's The Final Oculus Rift, Coming In Early 2016". Gizmodo. Gawker Media. Retrieved October 6, 2015.

Segerstrom, S. C., \& Miller, G. E. (2004). Psychological stress and the human immune system: a meta-analytic study of 30 years of inquiry. Psychological bulletin, 130(4), 601.

Selye, H. (1980). Selye's guide to stress research. Van Nostrand Reinhold.

Sen, S. L., Xiang, Y. B., Ming, E. S. L., Xiang, K. K., Fai, Y. C., \& Khan, Q. I. (2015, May). Enhancing effectiveness of virtual reality rehabilitation system: Durian Runtuh. In Control Conference (ASCC), 2015 10th Asian (pp. 1-6). IEEE.

Setareh, M., Bowman, D. A., \& Kalita, A. (2005). Development of a virtual reality structural analysis system. Journal of architectural engineering, 11(4), 156-164.

Seth, A., Vance, J. M., \& Oliver, J. H. (2011). Virtual reality for assembly methods prototyping: a review. Virtual reality, 15(1), 5-20.

Sharma, N. L. (2014). A computational model of observer stress.

Sharma, N., \& Gedeon, T. (2012). Objective measures, sensors and computational techniques for stress recognition and classification: A survey. Computer methods and programs in biomedicine, 108(3), 1287-1301.

Sharma, N., \& Gedeon, T. (2013, May). Modeling stress recognition in typical virtual environments. In Proceedings of the 7th International Conference on Pervasive Computing Technologies for Healthcare (pp. 17-24). ICST (Institute for Computer Sciences, Social-Informatics and Telecommunications Engineering).

Staal, M. A. (2004). Stress, cognition, and human performance: A literature review and conceptual framework. NaSA technical memorandum, 212824, 9.

Stinson, C., \& Bowman, D. (2014). Feasibility of training athletes for high-pressure situations using virtual reality. Visualization and Computer Graphics, IEEE Transactions on, 20(4), 606-615. 
Stokes, A.F., \& Kite, K. (2001). On grasping a nettle and becoming emotional. In P.A. Hancock, \& P.A. Desmond (Eds.), Stress, workload, and fatigue. Mahwah, NJ: L. Erlbaum.

Stroop, J. R. (1935). Studies of interference in serial verbal reactions. Journal of experimental psychology, 18(6), 643.

Telford, C. W. (1931). The refractory phase of voluntary and associative responses. Journal of Experimental Psychology, 14(1), 1.

Tóth, V. MEASUREMENT OF STRESS INTENSITY USING EEG.

Ulstein, I., Wyller, T. B., \& Engedal, K. (2007). High score on the Relative Stress Scale, a marker of possible psychiatric disorder in family carers of patients with dementia. International journal of geriatric psychiatry, 22(3), 195-202.

Van De Poll, M. N., Zajaczkowski, E. L., Taylor, G. J., Srinivasan, M. V., \& van Swinderen, B. (2015). Using an abstract geometry in virtual reality to explore choice behaviour: visual flicker preferences in honeybees. The Journal of experimental biology, jeb-125138.

Zhang, S., Teizer, J., Lee, J. K., Eastman, C. M., \& Venugopal, M. (2013). Building information modeling (BIM) and safety: Automatic safety checking of construction models and schedules. Automation in Construction, 29, 183-195.

Zhao, D., Thabet, W., McCoy, A., \& Kleiner, B. (2012). Managing electrocution hazards in the US construction industry using VR simulation and cloud technology. In eWork and eBusiness in Architecture, Engineering and Construction-Proceedings of the European Conference on Product and Process Modelling (pp. 759-764). 
APPENDICES 
FIU IRB Approval:

9/9/2015

FIU IRB Expiration:

9/9/2016

Appendix 1. Adult Consent From 


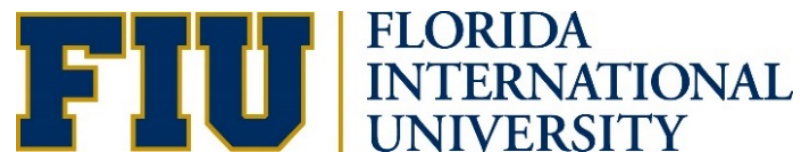

ADULT CONSENT TO PARTICIPATE IN A RESEARCH STUDY

Affective Sensing and Virtual Reality for Construction Safety

PURPOSE OF THE STUDY

You are being asked to be in a research study. The purpose of this study is measuring reactions of human body under stress and understanding the physiological changes.

\section{NUMBER OF STUDY PARTICIPANTS}

If you decide to be in this study, you will be one of approximately 30 people in this research study.

\section{DURATION OF THE STUDY}

Your participation today will require approximately one hour.

\section{PROCEDURES}

If you agree to be in the study, you should expect the following.

You will be invited to the Built Environment Informatics Lab (BEIL) at FIU and shown different construction field simulations which contain major safety risks with respect to literature studies. While watching virtual reality simulations, you will be asked to navigate scenarios and make some input. Additionally, you will fill a questionnaire related with your feelings and observations after the experiment.

We will use Galvanic Skin Response (GSR), Skin Temperature (ST) and Blood Volume Pulse (BVP) sensors to record your body's reaction while you are looking on the computer screen. In order to be involved virtual reality simulation, you are going to wear a 3D glass and your GSR values going to be tracked with the help of electrodes placed on the index and ring fingers on the hand, BVP will be tracked with the sensor placed on your fingertip and also ST will be observed by sensor at the same time.

\section{RISKS AND/OR DISCOMFORTS}

No anticipated risks or discomforts are associated with this study.

\section{BENEFITS}

Understanding reaction under stress on construction field can lead to develop more efficient training programs and over the long term less injuries and fatalities among construction workers.

\section{ALTERNATIVES}

There are no alternatives available to you other than not taking part in this study. 


\section{CONFIDENTIALITY}

FIU IRB Expiration: $\quad$ 9/9/2016

FIU IRB Number: IRB-15-0356

The records of this study will be kept private and will be protected to the fullest extend provided by law. In any sort of report we might publish, we will not include any information that will make it possible to identify a subject. Research records will be stored securely and only the researcher will have access to the records. However, your records may be reviewed for audit purposes by authorized University or other agents who will be bound by the same provision of confidentiality.

\section{COMPENSATION \& COSTS}

You will not receive any compensation for the study. You will not be responsible for any costs associated with this study.

\section{RIGHT TO DECLINE OR WITHDRAW}

Your participation in this study is voluntary. You are free to participate in the study or withdraw your consent at any time during the study. Your withdrawal or lack of participation will not affect any benefits to which you are otherwise entitled. In case you withdraw you will be compensated at the rate described previously and any data collected will be discarded and not used as part of the study. The investigator reserves the right to remove you without your consent at such time that they feel it is in the best interest.

\section{RESEARCHER CONTACT INFORMATION}

If you have any questions about the purpose, procedures, or any other issues relating to this research study you may contact Nipesh Pradhananga at Florida International University, OHL School of Construction, 305-348-0224, npradhan@fiu.edu

\section{IRB CONTACT INFORMATION}

If you would like to talk with someone about your rights of being a subject in this research study or about ethical issues with this research study, you may contact the FIU Office of Research Integrity by phone at 305-348-2494 or by email at ori@fiu.edu

\section{PARTICIPANT AGREEMENT}

I have read the information in this consent form and agree to participate in this study. I have had a chance to ask any questions I have about this study, and they have been answered for me. I understand that I am entitled to a copy of this form after it has been read and signed.

Signature Participant

Date

Printed Name of Participant 
